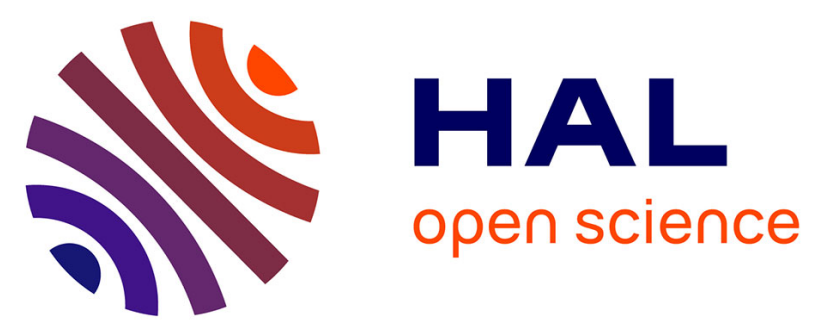

\title{
Halo-substituted benzenesulfonyls and benzenesulfinates convenient sources of arenes in metal-catalyzed C-C bond formation reactions for the straightforward access to halo-substituted arenes
}

Haoran Li, Arpan Sasmal, Xinzhe Shi, Jean-François Soulé, Henri Doucet

\section{To cite this version:}

Haoran Li, Arpan Sasmal, Xinzhe Shi, Jean-François Soulé, Henri Doucet. Halo-substituted benzenesulfonyls and benzenesulfinates convenient sources of arenes in metal-catalyzed C-C bond formation reactions for the straightforward access to halo-substituted arenes. Organic \& Biomolecular Chemistry, 2018, 16 (24), pp.4399-4423. 10.1039/c8ob00632f . hal-01807880

\section{HAL Id: hal-01807880}

https://hal-univ-rennes1.archives-ouvertes.fr/hal-01807880

Submitted on 3 Sep 2018

HAL is a multi-disciplinary open access archive for the deposit and dissemination of scientific research documents, whether they are published or not. The documents may come from teaching and research institutions in France or abroad, or from public or private research centers.
L'archive ouverte pluridisciplinaire HAL, est destinée au dépôt et à la diffusion de documents scientifiques de niveau recherche, publiés ou non, émanant des établissements d'enseignement et de recherche français ou étrangers, des laboratoires publics ou privés. 


\section{Halo-substituted benzenesulfonyls and benzenesulfinates:}

\section{Convenient sources of arenes in metal-catalyzed C-C bond formation reactions \\ for the straightforward access to halo-substituted arenes \\ Haoran Li, ${ }^{[\mathrm{a}]}$ Arpan Sasmal, ${ }^{[\mathrm{a}]}$ Xinzhe Shi, ${ }^{[\mathrm{a}]}$ Jean-François Soulé, ${ }^{[\mathrm{a}]_{*}}$ Henri Doucet $^{\left[\mathrm{a}{ }_{*}\right.}$}

[a] Mr. H. Li, Mr. A. Sasmal, Mrs. X. Shi, Dr. J.-F. Soulé, Dr. H. Doucet

aniv Rennes, Ecole Nationale Supérieure de Chimie de Rennes, CNRS, ISCR-UMR 6226, F-35000 Rennes, France.

Tel: $+(33) 0223236384$

E-mail: jean-francois.soule@univ-rennes1.fr, henri.doucet@univ-rennes1.fr

Abstract: Palladium-catalyzed reactions using aryl halides as one of the coupling partners represent a very popular method for generating carbon-carbon bonds. However, such couplings suffer of important limitations. As most palladium catalysts are very effective for the cleavage of C-halo bonds (Halo = Cl, Br or I), in many cases, the presence of several halide functional groups on arenes is not tolerated. Since two decades, and especially during the last few years, a new class of coupling partners: benzenesulfonyl and benzenesulfinate derivatives has emerged as a powerful alternative to aryl halides for the Pd-catalyzed C-C bond formation, as the reactions performed with these substrates generally tolerate C-halo bonds. With these substrates, after a metal-catalyzed desulfitative coupling, a variety of halo-substituted arenes such as biaryls, styrenes, phenylacetylenes, acetophenones, benzonitriles... has been synthetized with high chemoselectivities. The use of these aryl sources allowed the synthesis of molecules containing several halo-substituents including iodo-substituents in only a few steps, and provides a very simple access to a very wide variety of halo-substituted arenes useful to material chemists and also to biochemists. In this review, we will summarize the scope of the use of halo-substituted benzenesulfonyls and benzenesulfinates as coupling partners in metal-catalyzed C-C bond formation. 
The use of halo-substituted $\mathrm{ArSO}_{2} \mathrm{R}$ as aryl source in metal-catalyzed C-C bond formation reactions presents several advantages, as the reaction often proceeds without cleavage of the C-halo bonds, allowing the easy access to halo-substituted compounds.

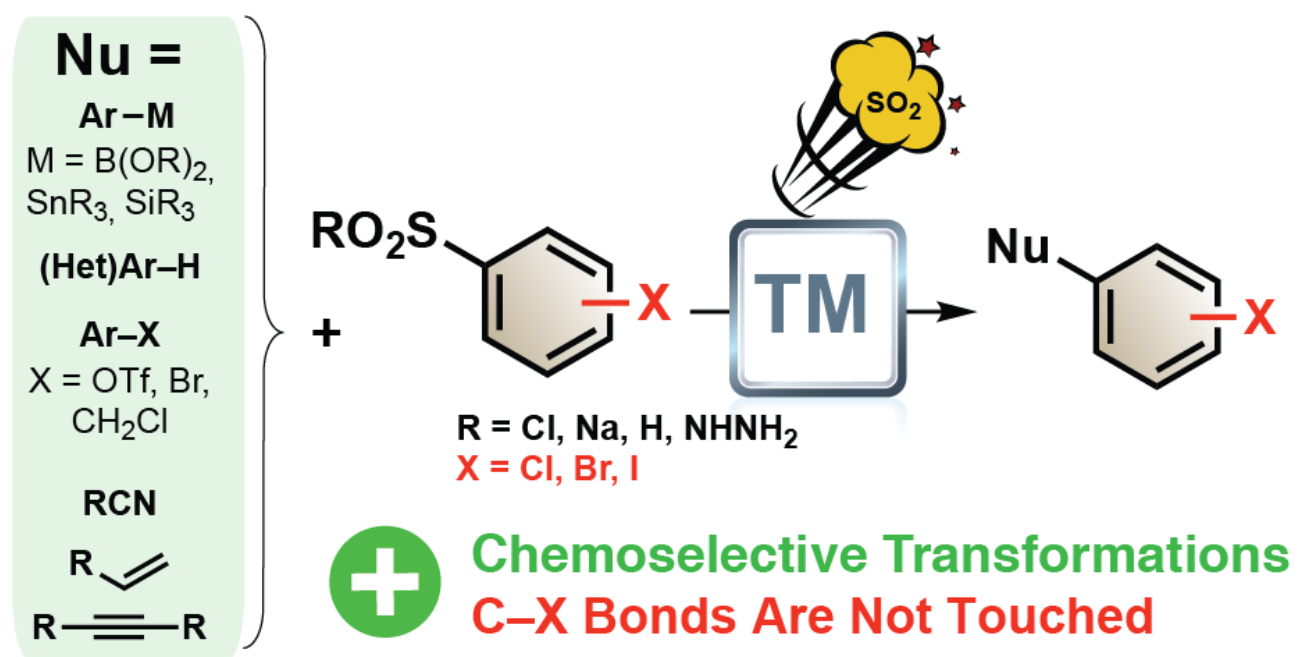

Key words: Carbon-Halo bonds / Benzenesulfonates / Benzenesulfinates / C-C bond formation / Catalysis / Desulfitative / Palladium

\section{Introduction}

2. Access to halo-substituted benzenesulfonate and benzenesulfinate derivatives

3. Stille coupling

4. Suzuki coupling

5. Hiyama coupling

6. Coupling with aryl triflates and aryl, benzyl or vinyl halides

7. Homocoupling

8. Direct desulfitative functionalization of $\mathrm{C}-\mathrm{H}$ bonds

8.1 Functionalization of six-membered ring arenes

8.2 Functionalization of five-membered ring heteroarenes containing one hetero-element

8.2.1 Pyrroles, indoles and indolizines

8.2.2 Thiophenes and benzothiophenes

8.2.3 Furans and benzofurans

8.2.4 Selenophenes

8.3 Functionalization of five-membered ring heteroarenes containing more than one heteroelement

8.3.1 Oxazoles and benzoxazoles

8.3.2 Benzothiazoles

8.3.3 Purines

8.3.4 Thiazolotriazoles

8.3.5 Triazoles 
9. Reaction with alkenes

9.1 Heck type reaction

9.2 Reductive Heck reaction

9.3 Ring-opening of oxabenzonorbornadienes

9.4 Synthesis of 4-aryl-1,2,3,4-tetrahydroquinolines

9.5 Heck-type alkylation/aryl migration/desulfonylation

10. Reaction with alkynes

10.1 Hydroarylation of alkynes

10.2 Sonogashira type cross-coupling

11. Reaction with nitriles

11.1 Carbonylation

11.2 Cyanation

11.3 Synthesis of 2-arylbenzofurans

12. Conclusions and perspectives

13. References 


\section{Introduction}

Chloro-, bromo- and also iodo-substituents on benzene derivatives are highly valuable as they can be very easily transformed into a huge number of other important functional groups via metalcatalyzed reactions or via more classical organic reactions. Moreover, halogen atoms may drastically modify the physical and biological properties of benzene derivatives. Therefore, the discovery of procedures allowing to prepare building blocks containing halo-substituents on benzenes currently represent a very important research area.

The arylation, vinylation, alkynylation, carbonylation or even cyanation of (hetero)aromatics via metal-catalyzed reactions provides a powerful access to a wide range of (hetero)aromatic derivatives. ${ }^{1}$ For such reactions, palladium catalysis certainly represents the most widely used method. ${ }^{2}$ However, it is well known that $\mathrm{C}-\mathrm{Cl}, \mathrm{C}-\mathrm{Br}$ and especially $\mathrm{C}-\mathrm{I}$ bonds are generally reactive in the presence of palladium complexes. ${ }^{3}$ As a consequence, for Pd-catalyzed transformations, it is often not possible to employ halo-substituted benzene derivatives without cleavage of these C-halo bonds. In recent years, a new class of coupling partners: benzenesulfonyls and benzenesulfinates has been successfully employed to prepare functionalized benzene derivatives via Pd-catalyzed reactions. ${ }^{4}$ A chief advantage of such coupling partners is that, the use of halo-substituted $\mathrm{ArSO}_{2} \mathrm{R}$ derivatives generally affords the functionalized benzene derivatives without cleavage of the Ar-Cl, Ar-Br or Ar-I bonds, allowing further transformations. Other advantages of these coupling partners is that many halo-substituted benzenesulfonyl chlorides are commercially available and that they are easy to handle. Moreover, $\mathrm{ArSO}_{2} \mathrm{Cl}$ derivatives can be easily prepared from sulfonic acids or sulfur substrates by chlorination; ${ }^{5}$ and benzenesulfinates ${ }^{6}$ or benzenesulfonyl hydrazides ${ }^{7}$ can be obtained by the reduction of the corresponding $\mathrm{ArSO}_{2} \mathrm{Cl}$. For these reasons, such aryl sources now provide new viable accesses to halo-containing benzene derivatives.

To the best of our knowledge, there is no review focusing on the metal-catalyzed functionalization of halo-substituted benzenesulfonyls and benzenesulfinates for access to halo-substituted arenes. ${ }^{8}$ 
In this review, we will summarize the scope of the use of halo-substituted benzenesulfonyls and benzenesulfinates as coupling partners in Pd- and Rh-catalyzed C-C bond formation (Scheme 1). In the first section, the most general methods for the preparation of halo-substituted benzenesulfonyl chlorides, sodium benzenesulfinates and benzenesulfonyl hydrazides will be briefly described. Then, in parts three to five, the Pd-catalyzed synthesis of halo-substituted biaryls via Stille, SuzukiMiyaura and Hiyama shall be reviewed. Parts six and seven deals with the Pd-catalyzed reactions with aryl triflates, aryl or vinyl bromides and benzyl chlorides. The reactivity of (hetero)arenes for Pd-catalyzed desulfitative arylations via a C-H bond activation shall be presented in part eight. Then, the reactions with alkenes and alkynes such as Heck and Sonogashira reactions will be described. Finally, the reactions of nitriles for carbonylation or cyanation of benzenes will be summarized. In the conclusion, the current challenges in the field will be evoked.

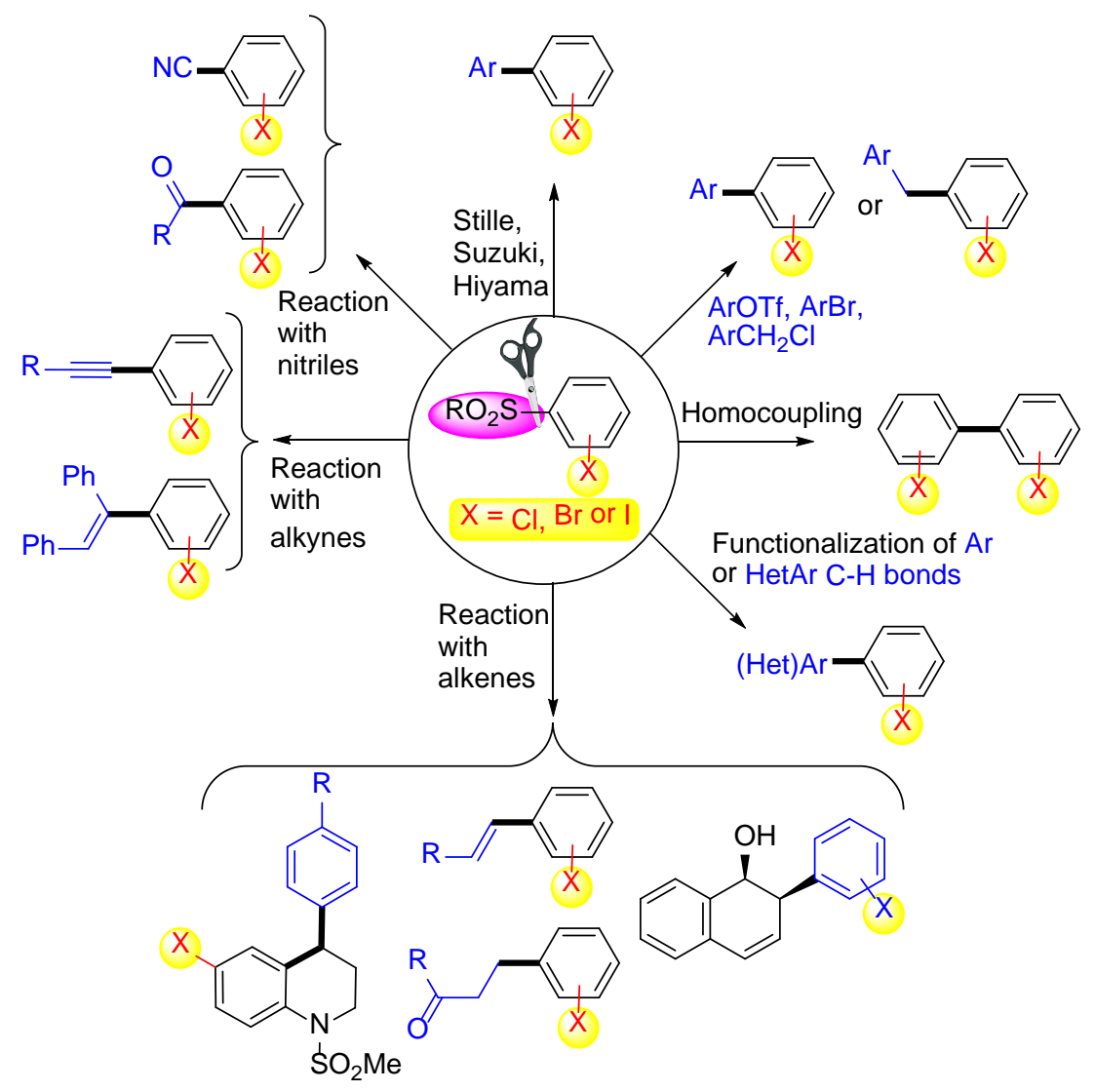

Scheme 1. 


\section{Access to halo-substituted benzenesulfonate and benzenesulfinate derivatives}

The three major sources of halo-substituted benzenesulfonyl and benzenesulfinate derivatives for Pd-catalyzed reaction are benzenesulfonyl chlorides, sodium benzenesulfinates and benzenesulfonyl hydrazides.

There are a few methods for the preparation of halo-substituted benzenesulfonyl chlorides. In most cases, they are prepared by reaction of halobenzenes with chlorosulfonic acid or from sulfur substrates by (oxy)chlorination. ${ }^{5}$ It should be mentioned that several halo-substituted benzenesulfonyl chloride derivatives, containing or not additional functional groups, are commercially available; and many of them can be purchased at an affordable cost (Figure 1). Even 2- and 4-iodobenzenesulfonyl chlorides are commercially available. Therefore, the use of halosubstituted benzenesulfonyl chlorides in cross-coupling reactions is very attractive.
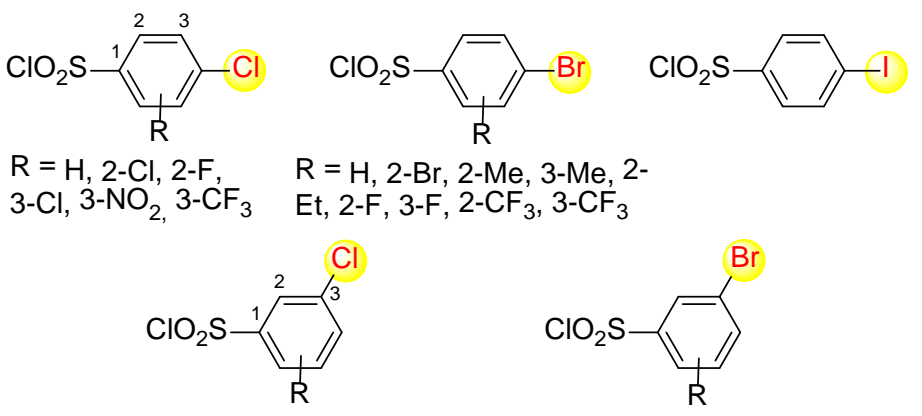

$\mathrm{R}=\mathrm{H}, 2-\mathrm{F}, 4-\mathrm{F}, 2-\mathrm{Me}, 4-\quad \mathrm{R}=\mathrm{H}, 6-\mathrm{Cl}, 6-\mathrm{F}, 4-\mathrm{MeO}, 6-\mathrm{MeO}$ $\mathrm{Me}, 2-\mathrm{Cl}, 5-\mathrm{Cl}, 6-\mathrm{Cl}, 6-\mathrm{Br}$

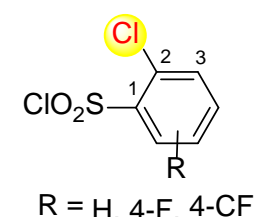

$\mathrm{R}=\mathrm{H}, 4-\mathrm{F}, 4-\mathrm{CF}_{3}$, $5-\mathrm{CF}_{3}, 5-\mathrm{Cl}, 6-\mathrm{Cl}^{3}$

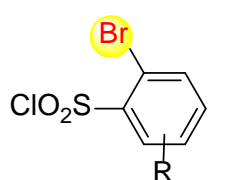

$\mathrm{R}=\mathrm{H}, 5-\mathrm{Br}, 4-$<smiles>O=S(=O)(O)c1ccccc1Cl</smiles><smiles>O=C(OSc1ccc(Br)s1)Sc1ccc(Cl)s1</smiles>

Figure 1. Selection of commercially available halo-substituted arenesulfonyl chlorides

Conversely, relatively few halo-substituted benzenesulfinates are commercially available, and sodium 4-chlorobenzenesulfinate is one of the rare ones available at an affordable cost. However, 
benzenesulfinates can be easily prepared by reaction of benzenesulfonyl chlorides with a mixture of $\mathrm{NaHCO}_{3}$ and $\mathrm{Na}_{2} \mathrm{SO}_{3}{ }^{6}$ Currently, there are no halo-substituted benzenesulfonyl hydrazides which are available at an affordable cost. These compounds are generally prepared by reaction of benzenesulfonyl chlorides with hydrazine (Scheme 2). ${ }^{7}$

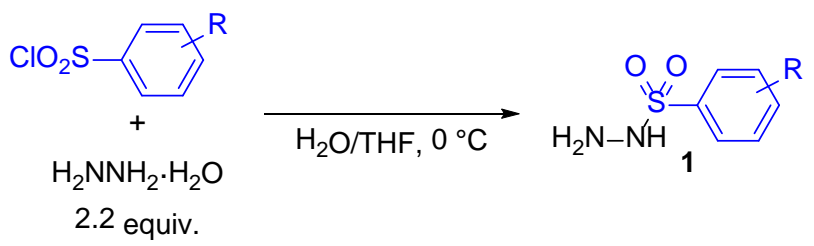

Scheme 2. Synthesis of benzenesulfonyl hydrazides

\section{Stille coupling}

The rare examples of Stille couplings using halo-substituted benzenesulfonyl chlorides, without cleavage of the C-halo bonds, were described by Vogel et al. in 2003. They reported that the Pdcatalyzed reactions of 4-chloro- and 4-bromo-benzenesulfonyl chlorides with tributyl(phenyl)stannane derivatives afforded the biaryl derivatives $\mathbf{2}$ in moderate yields, but without cleavage of the C-Cl and C-Br bonds (Scheme 3, a). For these reactions $\operatorname{Pd}_{2}\left(\mathrm{dba}_{3}\right.$ was associated to tri-2-furylphosphine as catalyst and 0.1 equiv. of $\mathrm{CuBr}$ were added to the reaction mixture. ${ }^{9}$ One year later, they applied their procedure to the coupling of a tingalactal derivative with 4-chlorobenzenesulfonyl chloride (Scheme 3, b). ${ }^{10}$ 
a)<smiles>[R]c1ccc([Sb]CCCC)cc1</smiles>

1.3 equiv.

$\mathrm{Pd}_{2}(\mathrm{dba}) 31.5 \mathrm{~mol} \%$, $\underset{\text { CuBi-2-furylphosphine } 5 \text { mol\% }}{\stackrel{\mathrm{Pd}_{2}(\mathrm{dba})_{3}}{\longrightarrow}}$

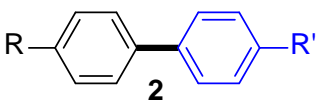

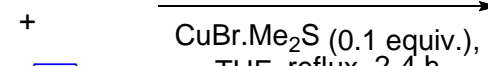

b) 1 equiv. THF, reflux, 2-4 $\mathrm{h}$

\section{$\mathrm{R} \quad \mathrm{R}^{\prime} \quad$ Yield (\%)}

$\begin{array}{llll}\mathrm{Me} & \mathrm{Cl} & \mathbf{2 a} & 66\end{array}$

$\begin{array}{llll}\mathrm{F} & \mathrm{Cl} & \mathbf{2 b} & 51\end{array}$

$\mathrm{F} \quad \mathrm{Br} \quad 2 \mathrm{c} 38$

F I 2d trace

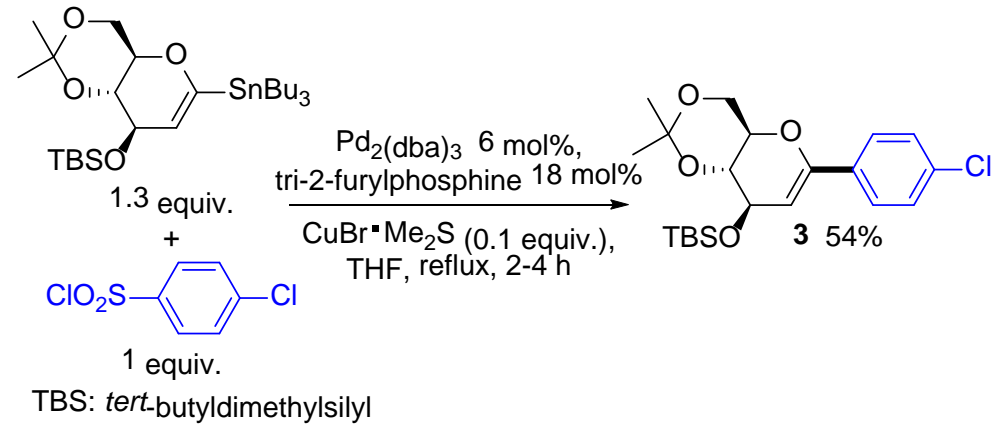

Scheme 3. Stille coupling using halo-substituted benzenesulfonyl chlorides

\section{Suzuki coupling}

Vogel et al. also reported the first examples of Suzuki couplings ${ }^{11}$ using halo-substituted benzenesulfonyl chlorides (Scheme 4). ${ }^{12}$ They employed 8-10 mol\% $\mathrm{Pd}\left(\mathrm{PPh}_{3}\right)_{4}$ as catalyst and $\mathrm{K}_{2} \mathrm{CO}_{3}$ as base. The coupling of nitro- or methyl-substituted arylboronic acids with 4chlorobenzenesulfonyl chloride gave the corresponding biaryls $\mathbf{4 a}$ and $\mathbf{4 b}$ in $62 \%$ and $65 \%$ yields, without C-Cl bond cleavage (Scheme 4, a). With 4-bromobenzenesulfonyl chloride, they performed successive Suzuki couplings. The first coupling reaction occurred with the sulfonyl chloride group and the second with the bromo substituent, affording terphenyl derivative $\mathbf{6}$ in $52 \%$ overall yield (Scheme 4, b). Conversely, the reaction of 4-iodobenzenesulfonyl chloride with 3 equiv. of p-tolylboronic acid directly afforded 4,4"-dimethylterphenyl derivative 7 in $52 \%$ yield as both iodo and sulfonyl chloride groups were reactive under these conditions (Scheme 4, c). 
a)

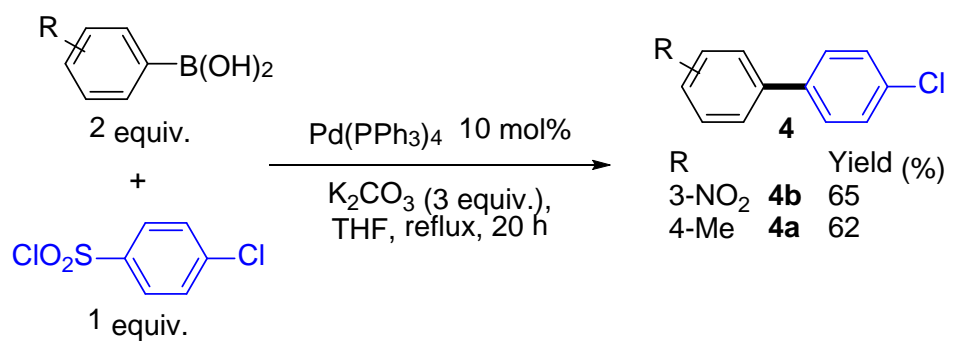

b)

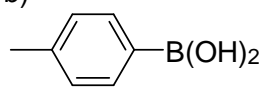

1 equiv.

Pd(PPh3) $48 \mathrm{~mol} \%$

$\mathrm{K}_{2} \mathrm{CO}_{3}$ (3 equiv.),

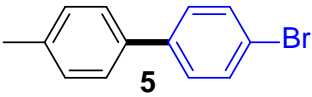

$\mathrm{ClO}_{2} \mathrm{~S}$

THF, reflux, $20 \mathrm{~h}$

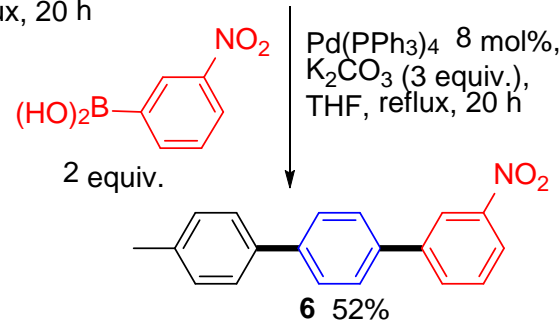

c) $\mathrm{B}(\mathrm{OH})_{2}$

$652 \%$
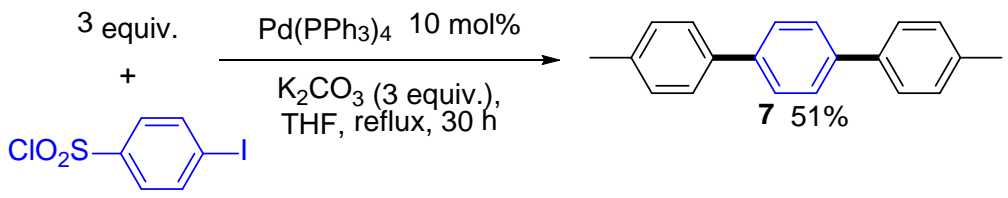

THF, reflux, 30 h

1 equiv.

Scheme 4. Suzuki couplings using halo-substituted benzenesulfonyl chlorides

In 2006, Luo et al. prepared a polymer-supported NHC-Pd complex from a polystyrene-supported bis-imidazole derivative and $\mathrm{Pd}(\mathrm{OAc})_{2} \cdot{ }^{13}$ They employed this complex in desulfitative Suzuki coupling. The reaction of with 4 equiv. of phenylboronic acid with chloro-substituted benzenesulfonyl chlorides in THF under reflux gave the corresponding biaryls 8 without cleavage of the C-Cl bonds (Scheme 5). Conversely, the reaction with 4-bromobenzenesulfonyl chloride, under the same reaction conditions, afforded terphenyl 9, as both $\mathrm{Br}$ and $\mathrm{SO}_{2} \mathrm{Cl}$ functional groups were reactive under these conditions. 


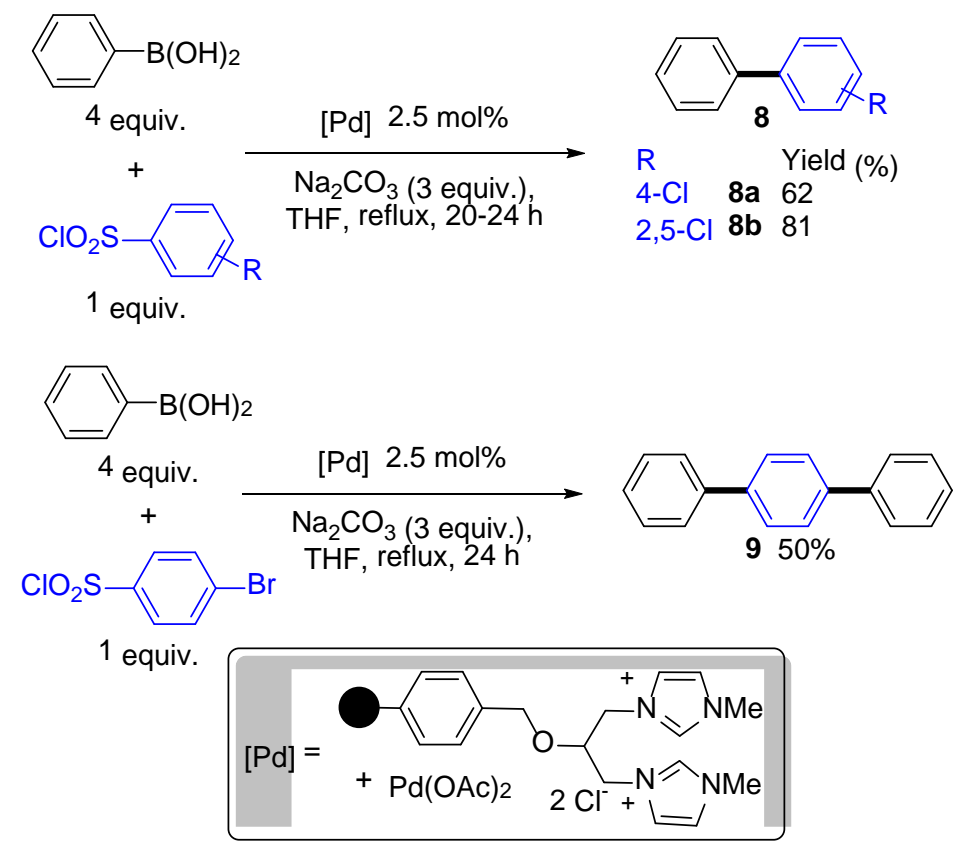

Scheme 5. Suzuki couplings with halo-substituted benzenesulfonyl chlorides using a polymersupported catalyst

The desulfitative Suzuki coupling is not limited to the use of benzenesulfonyl chlorides. The palladium-catalyzed desulfitative Suzuki reaction of sodium benzenesulfinates with a variety of arylboronic acids has been reported by Qi el al. in 2014 (Scheme 6). ${ }^{14}$ The reaction, which was conducted under simple aerobic conditions, was tolerant to several functional groups on both coupling partners including chloro- and bromo-substituents, affording the corresponding biaryls $\mathbf{1 0}$ in good to excellent yields. These reactions were accelerated by the addition of a catalytic amount of $\mathrm{Cu}(\mathrm{TFA})_{2}$ as co-catalyst.
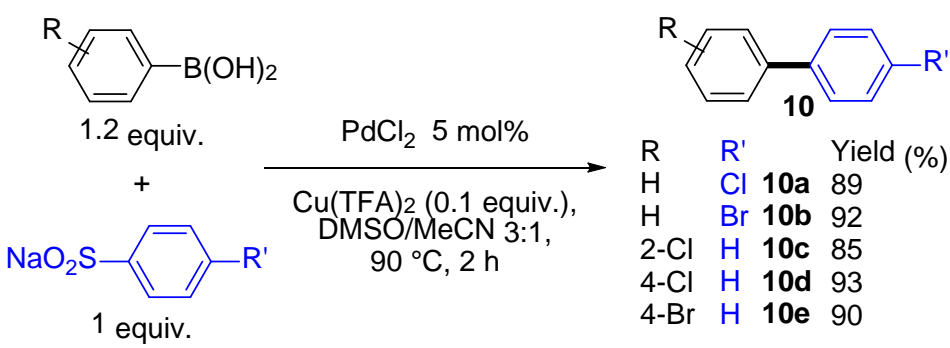

Scheme 6. Suzuki couplings using halo-substituted sodium benzenesulfinates 
The Pd-catalyzed desulfitative and denitrogenative Suzuki coupling using halo-substituted benzenesulfonyl hydrazides has been reported by Dou et al. in 2015 (Scheme 7). ${ }^{15}$ For these reactions, $\mathrm{Pd}(\mathrm{OAc})_{2} /$ Xantphos (Xantphos: 4,5-bis(diphenylphosphino)-9,9-dimethylxanthene) was employed as the catalyst in the presence of $\mathrm{K}_{2} \mathrm{CO}_{3}$. Again, chloro- and bromo-substituents were tolerated on both coupling partners. Even 4-iodobenzenesulfonyl hydrazide was successfully employed, affording 4-iodo-1,1'-biphenyl 11c in 84\% yield.
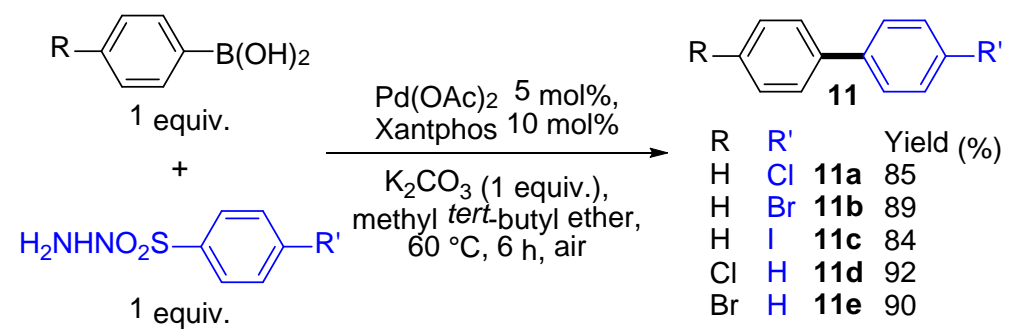

Scheme 7. Suzuki couplings using halo-substituted benzenesulfonyl hydrazides

Aryltrifluoroborates have also been employed in desulfitative Suzuki cross-couplings with benzenesulfonyl chlorides and benzenesulfinates. In 2016, Wei et al. reported a procedure which was tolerant to a 4-chloro-substituent on the benzenesulfonyl chloride and to 4-chloro-, 4-bromoand even 4-iodo-substituents on the aryltrifluoroborate (Scheme 8, a). ${ }^{16 a}$ In all cases, very high yields in the halo-substituted biaryls 12 were obtained. Two years later, Chang et al. extended the reaction to halo-substituted benzenesulfinates (Scheme $8, \mathrm{~b}) .{ }^{16 \mathrm{~b}}$ The reactions were performed in water using 2 mol\% of $\mathrm{Pd}(\mathrm{MeCN})_{4}\left(\mathrm{BF}_{4}\right)_{2}$ as catalyst, and afforded the coupling products 13 in similar yields than Wei’s procedure. 
a)

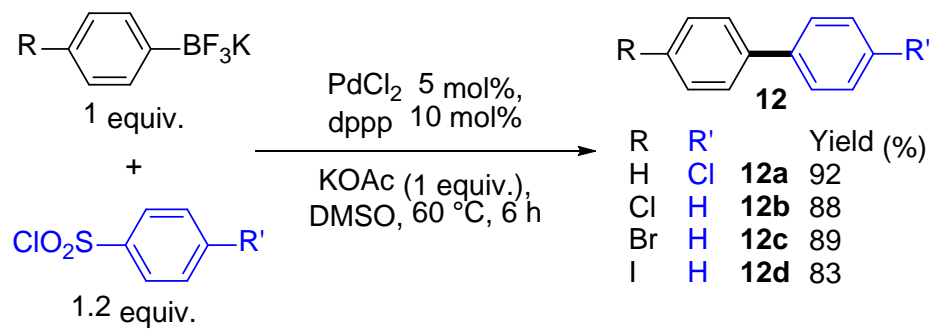

b)

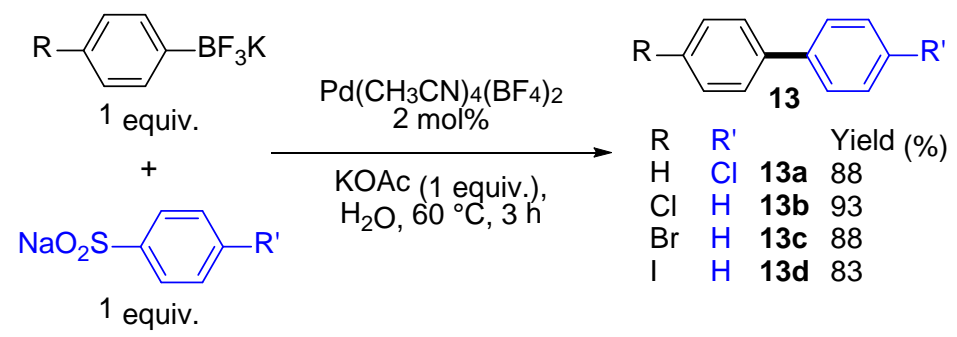

Scheme 8. Suzuki couplings using aryltrifluoroborates

In summary, a few efficient procedures are now available for the preparation of halo-substituted biaryls using Suzuki type reaction. Qi’s procedure in scheme 6 which is promoted by a phosphinefree catalyst and Wei's procedure (scheme 8, a) which employs an easily available catalyst and benzenesulfonyl chlorides as convenient aryl source are probably the most attractive.

\section{Hiyama coupling}

The first examples of Pd-catalyzed Hiyama-type cross-coupling ${ }^{17}$ reactions using halo-substituted benzenesulfinates for the preparation of biaryls $\mathbf{1 4}$ were reported by Qi et al. in 2013 (Scheme 9, a). ${ }^{18}$ The coupling of 2- or 4-chloro- and also 4-bromo-benzenesulfinates with phenyltriethoxysilane was achieved in good yields using $5 \mathrm{~mol} \% \mathrm{PdCl}_{2}$ catalyst under aerobic conditions at $70{ }^{\circ} \mathrm{C}$. The presence of fluoride in the reaction mixture was found to be essential, and tetrabutylammonium fluoride (TBAF) was shown to be the most efficient fluoride source for these cross-coupling reactions. One year later, Zhao et al. extended this reaction to 4-halo-substituted benzenesulfonyl chlorides (Scheme 9, b). ${ }^{19}$ Again, TBAF was used as additive. Good yields in 15 
were obtained from benzenesulfonyl chlorides and aryltri(methoxy)silanes bearing bromo- or chloro-substituents.

a)

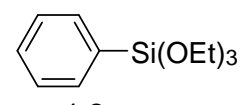

1.2 equiv.

$\mathrm{PdCl}_{2} 5 \mathrm{~mol} \%$

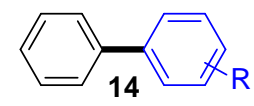<smiles>[R]c1ccc(S(N)(=O)=O)cc1</smiles>

$\mathrm{Bu}_{4} \mathrm{NF}(1 \mathrm{M}$ in THF)

R 2 -Cl $14 \mathrm{a}$ Yield (\%)

$70^{\circ} \mathrm{C}, 3 \mathrm{~h}$, air $\quad 4-\mathrm{Cl} 14 \mathrm{~b} 84$

$\begin{array}{lll}4-\mathrm{Cl} & 14 \mathrm{~b} & 84 \\ 4-\mathrm{Br} & 14 \mathrm{c} & 86\end{array}$

b)

$$
1 \text { equiv. }
$$

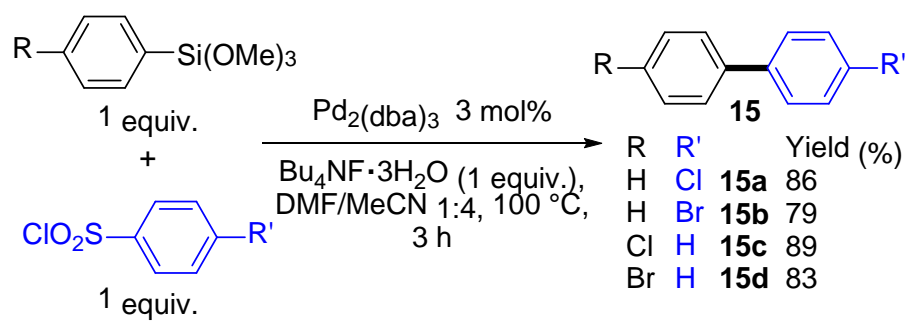

Scheme 9. Hiyama-type cross-coupling reactions

The Pd-catalyzed Hiyama coupling reaction using benzenesulfonyl hydrazides as coupling partners was reported by Zhou et al. in 2015 (Scheme 10, c). ${ }^{20}$ They performed this reaction with Pd(TFA) ${ }_{2}$ as catalyst, 1,3-dimethyl-2-imidazolidinone as solvent and tetrabutylammoniumdifluorotriphenylsilicate (TBAT) as additive under oxygen. This reaction tolerated 4-chloro-, 4-bromo- and even 4-iodo-substituents on the benzenesulfonyl hydrazide. Again, high yields in the desired halo-substituted biphenyls $\mathbf{1 6}$ were obtained. However due to the high molecular mass and cost of TBAT, this procedure appears to be less attractive than the Qi's procedure (Scheme 9, a).

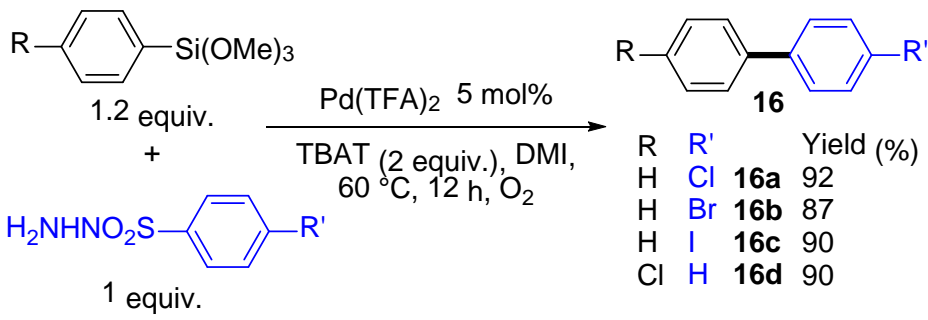

DMI: 1,3-dimethyl-2-imidazolidinone

TBAT: tetrabutylammoniumdifluorotriphenylsilicate 
Scheme 10. Hiyama-type cross-coupling reactions with benzenesulfonyl hydrazides

\section{Coupling with aryl triflates and aryl, benzyl or vinyl halides}

Aryl triflates and aryl, benzyl or vinyl halides can also be employed as coupling partners in Pdcatalyzed desulfitative cross-couplings. In 2012, Li, Duan et al. reported a procedure for the coupling of aryl triflates with sodium benzenesulfinates containing 4-chloro- or 4-bromosubstituents (Scheme 11, a). ${ }^{21}$ For these reactions, a mixture of $\mathrm{Pd}(\mathrm{OAc})_{2}$ and Xphos (Xphos: 2dicyclohexylphosphino-2',4',6'-triisopropylbiphenyl) was used as catalyst and toluene as solvent. It should be mentioned that no base or additives were required for such couplings, and the reaction was performed under nitrogen. However, a poor yield in $\mathbf{1 7 b}$ was obtained for the reaction with sodium 4-bromobenzenesulfinate. One year later, they extended their procedure to the coupling of 2-bromobenzonitrile with sodium 4-chlorobenzenesulfinate. Again, the reaction was performed without base and additive, to afford the chloro-substituted biaryl derivative 17a in $80 \%$ yield (Scheme 11, a). ${ }^{22}$ The same year, Forgione and Ortigies reported the coupling of the electron deficient aryl bromide, 4-bromobenzonitrile with sodium 4-chlorobenzenesulfinate (Scheme 11, b). ${ }^{23}$ The corresponding 4-chlorobiaryl derivative 18 was isolated in $45 \%$ yield. For this reaction 1.5 equiv. of $\mathrm{Cs}_{2} \mathrm{CO}_{3}$ was added to the reaction mixture. In 2013 again, Deng et al. reported the Pdcatalyzed desulfitative cross-coupling of sodium benzenesulfinates with benzyl chlorides (Scheme 11, c). ${ }^{24}$ Chloro-substituents were tolerated on both coupling partners affording 1-chloro-4-(4methylbenzyl)benzene 19 in 66\% yield. 
a)<smiles>[R]C1=CC=CCC1[O-]</smiles><smiles>C/C=C\[GeH2]C(C)=O</smiles>

1.2 equiv.

*: From 2-bromobenzonitrile, $40 \mathrm{~h}$

b)<smiles>N#Cc1ccc(Br)cc1</smiles>
**: GC yield
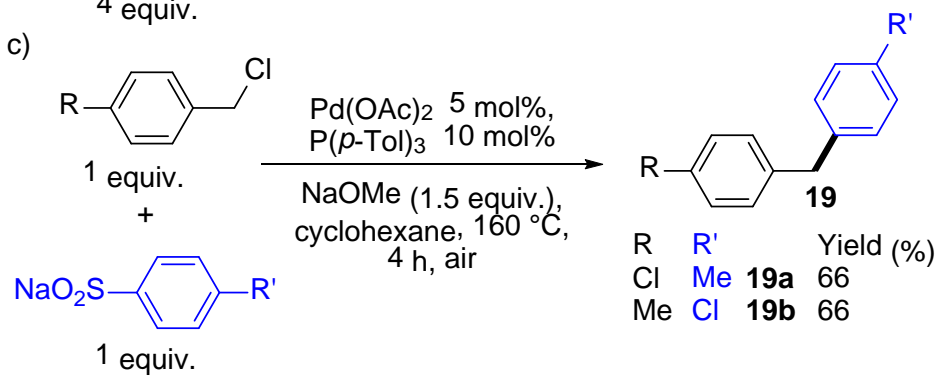

Scheme 11. Desulfitative cross-couplings with aryl triflates and aryl or benzyl halides

In 2015, Wang et al. also employed sodium benzenesulfinates in the Pd-catalyzed desulfitative arylation of 5-alkoxy-3,4-dibromo-2(5H)-furanone (Scheme 12$){ }^{25}$ The reaction occurred regioselectively at the 4-position of the 3,4-dibromofuranone derivative; whereas the $\mathrm{C}$ - $\mathrm{Br}$ bond at 3-position remained untouched. Sodium benzenesulfinates bearing ortho- and para-chloro substituents were tolerated, and the desired products 20 were obtained in $63-72 \%$ yields.

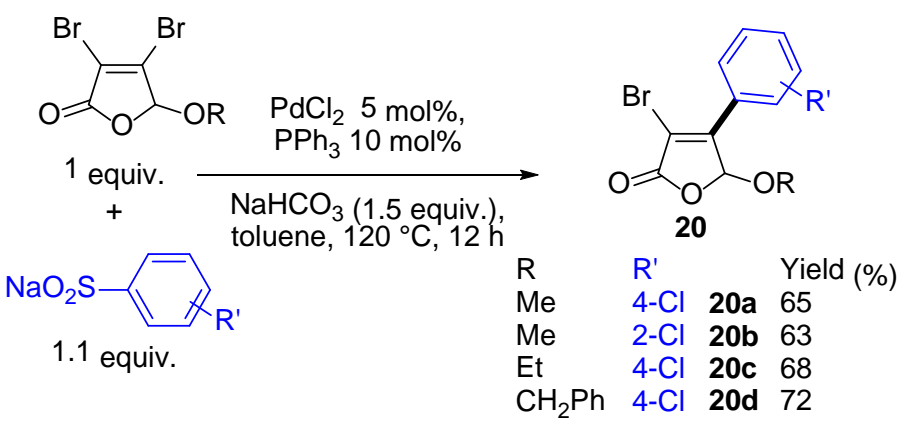

Scheme 12. Desulfitative cross-couplings with furanones 
Meng, Wang et al. described in 2013 the tandem elimination-cyclization-desulfitative arylation of 2-(gem-dibromovinyl)phenols with sodium benzenesulfinates (Scheme 13). ${ }^{26}$ In the presence of 10 mol\% $\mathrm{PdCl}_{2}, \mathrm{Bu}_{4} \mathrm{NF}, \mathrm{NEt}_{3}$ using $\mathrm{Cu}(\mathrm{OAc})_{2}$ as oxidant at $110{ }^{\circ} \mathrm{C}$, good yields in 2-arylbenzofurans 21 were obtained. A chloro-substituted 2-(gem-dibromovinyl)thiophenol was also successfully employed affording a 2-arylbenzothiophene 22 in 71\% yield.

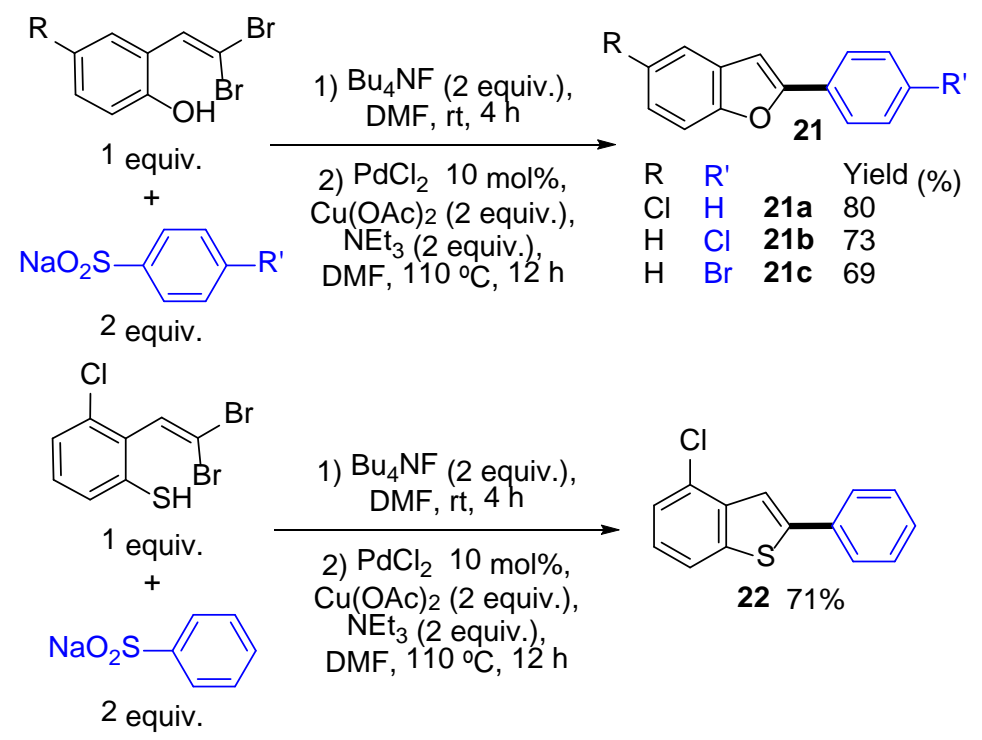

Scheme 13. Tandem elimination-cyclization-desulfitative arylation

The exact mechanism of this reaction was not elucidated; however, the authors assumed that firstly, an elimination of $\mathrm{HBr}$ from 2-(gem-dibromovinyl)phenol promoted by $\mathrm{Bu}_{4} \mathrm{NF}$ followed by an intramolecular nucleophilic addition affords the 2-bromobenzofuran derivative $\mathbf{A}$ (Figure 2). Then, the oxidative addition of the 2-bromobenzofuran to $\mathrm{Pd}(0)$ gave the benzofuran- $\mathrm{Pd}(\mathrm{II})-\mathrm{Br}$ intermediate B. Sodium benzenesulfinate would react with Pd(II) through a ligand exchange to form the $\mathrm{Pd}(\mathrm{II})$-sulfinate intermediate, which affords an aryl-Pd(II)-X intermediate $\mathbf{C}$ after desulfitation. A transmetallation of the two Pd(II) species followed by reductive elimination would provide the 2-arylbenzofurans $\mathbf{E}$. 


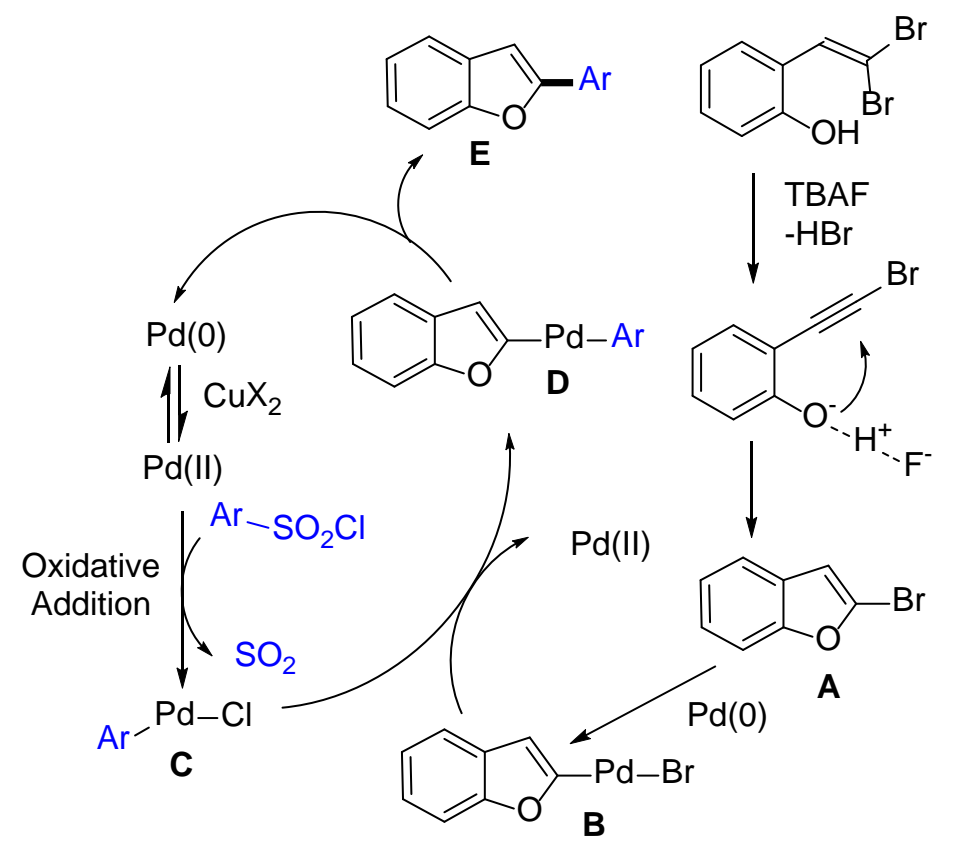

Figure 2. Proposed catalytic cycle

\section{Homocoupling}

The first examples of Pd-catalyzed homo-couplings of halo-substituted benzenesulfonyl chlorides were described by Miura et al. in 1990 (Scheme 14, a). ${ }^{27}$ The best yields in 23 were obtained with $2.5 \mathrm{~mol} \% \mathrm{PdCl}_{2}(\mathrm{PhCN})_{2}$ catalyst, but good yields were also obtained with $\mathrm{Pd}(\mathrm{OAc})_{2}$. The reaction required the use of $\mathrm{Ti}(\mathrm{i}-\mathrm{PrO})_{4}$ as oxidant (2 equiv.), and tolerated chloro- and bromo-substituents on the benzenesulfonyl chloride. In 2005, Kashiwabara and Tanaka reported that the heating of benzenesulfonyl chlorides in the presence of $3 \mathrm{~mol} \% \operatorname{Pd}_{2}(\mathrm{dba})_{3}$ as the precatalyst and hexamethyldisilane also promoted desulfonylative homo-coupling (Scheme 14, b). ${ }^{28}$ Under these conditions, from 4-bromobenzenesulfonyl chloride, 4,4'-dibromo-1,1'-biphenyl 24 was obtained in 74\% yield. In 2015, Wu, Wang et al. reported the homo-coupling of halo-substituted benzenesulfonyl chlorides using a mixture of $\mathrm{Pd}(\mathrm{OAc})_{2}$ and $\mathrm{PPh}_{3}$ as catalyst (Scheme $\left.14, \mathrm{c}\right){ }^{29}$ They performed the reaction with $\mathrm{CuI}, \mathrm{NaHCO}_{3}, \mathrm{Ag}_{2} \mathrm{CO}_{3}$ or $\mathrm{Ag}_{2} \mathrm{O}$ as oxidants and additives. With this procedure, para- meta- and also ortho-bromo-substituted benzenesulfonyl chlorides were 
successfully coupled affording products $\mathbf{2 5}$ in 65-96\% yields. All the procedures reported in the scheme 14 required the presence of stoichiometric amounts of additives $\left(\mathrm{Ti}(\mathrm{i}-\mathrm{PrO})_{4}\right.$, hexamethyldisilane or $\left.\mathrm{CuI} / \mathrm{Ag}_{2} \mathrm{CO}_{3}\right)$. As Miura's procedure employs quite inexpensive $\mathrm{Ti}(\mathrm{i}-\mathrm{PrO})_{4}$ as additive and a phosphine-free catalyst, it appears to be the most convenient procedure for large scale synthesis of such biaryls from benzenesulfonyl chlorides.

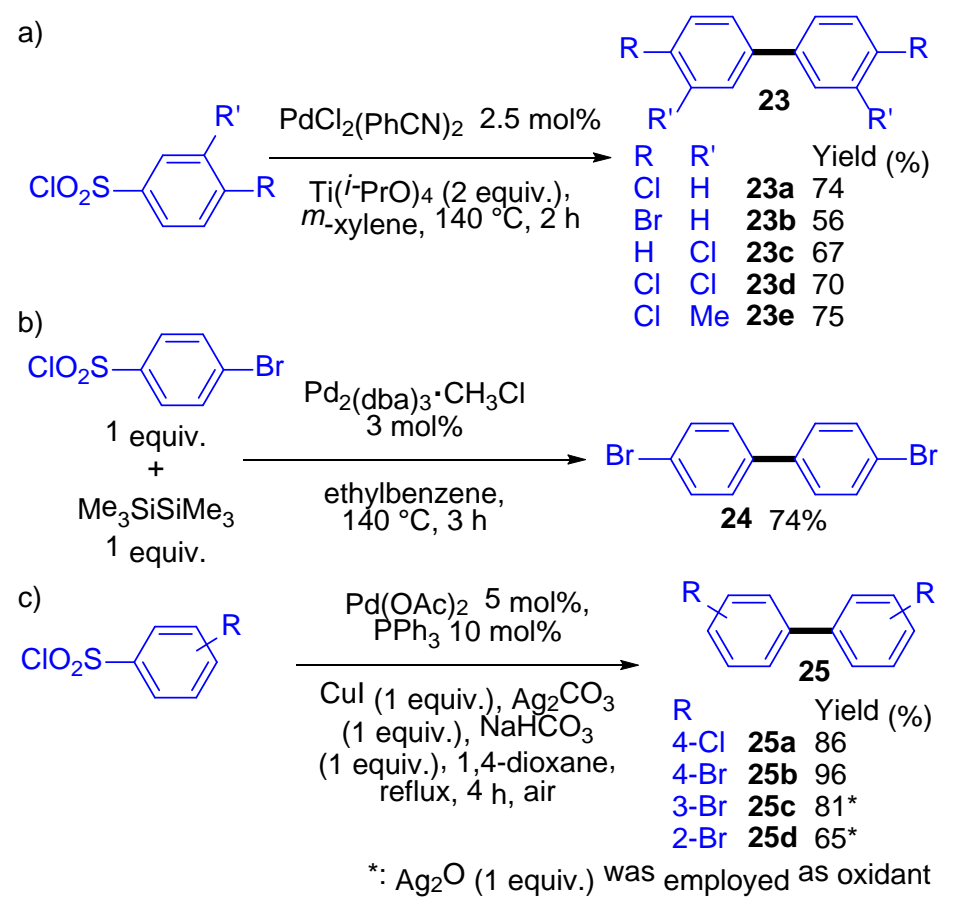

Scheme 14. Pd-catalyzed homo-couplings of halo-substituted benzenesulfonyl chlorides

Then, in 2012, Luo et al. reported a more environment-friendly procedure which employs sodium benzenesulfinates as aryl source, water as the solvent, and a catalytic amount of $\mathrm{Cu}_{2} \mathrm{O}$ and molecular oxygen as clean terminal oxidant (Scheme 15, a). ${ }^{30}$ The reaction tolerated 4-chloro- and 4-bromo-subtituents on the benzenesulfinate affording products 26 in good yields. Di-tertbutylperoxide can also be employed as oxidant for this reaction (Scheme 15, b). ${ }^{31}$ Finally, halosubstituted benzenesulfonyl hydrazides have been homo-coupled by Zhao et al. affording biaryls $\mathbf{2 8}$ using $\mathrm{Pd}(\mathrm{OAc})_{2}$ as the catalyst, DMA and THF as mixed solvent and $\mathrm{Cu}(\mathrm{OAc})_{2}$ as oxidant (Scheme 15, c). Even 4-iodobenzenesulfonyl hydrazide has been employed, affording 28c in 84\% yield without C-I bond cleavage. ${ }^{32}$ 

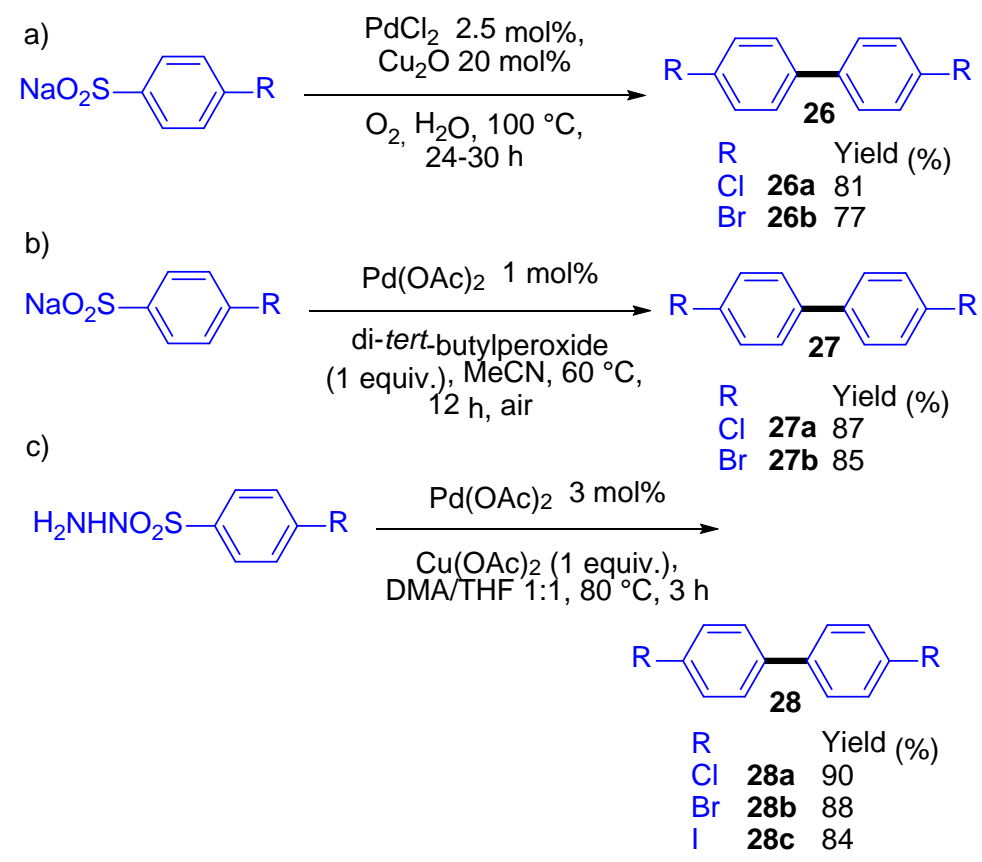

Scheme 15. Pd-catalyzed homo-couplings of sodium benzenesulfinates and benzenesulfonyl hydrazides

\section{Direct desulfitative functionalization of $\mathrm{C}-\mathrm{H}$ bonds}

Transition metal-catalyzed direct arylations of (hetero)arenes through a $\mathrm{C}-\mathrm{H}$ bond activation are certainly one of the most eco-friendly pathway to date for the preparation of (hetero)arylated arenes. For such reactions, aryl halides were generally employed as aryl sources. ${ }^{33}$ In recent years, benzenesulfonyl chlorides and sodium benzenesulfinates emerged as alternative aryl sources for Pdcatalyzed desulfitative couplings reactions with (hetero)arenes. In several cases, halo-substituted benzenesulfonyl chlorides and sodium benzenesulfinates have been successfully employed, especially for the arylation of 5-membered ring heteroaromatics. A few examples of couplings with benzene derivatives have also been reported.

\subsection{Functionalization of six-membered ring arenes}


Wang et al. reported in 2014 the direct desulfitative arylation of electron-deficient polyfluoroarenes using sodium benzenesulfinates as coupling partners (Scheme 16, a). ${ }^{34 a}$ The best reaction conditions were $7 \mathrm{~mol} \% \mathrm{PdCl}_{2}$ as catalyst in the presence of $\mathrm{Ag}_{2} \mathrm{CO}_{3}$ as oxidant and $\mathrm{Na}_{3} \mathrm{PO}_{4} \bullet \mathrm{H}_{2} \mathrm{O}$ as base in wet DMSO. The reaction was found to tolerate both 4-bromo and 4-choro-substituents on the sodium benzenesulfinate affording products $\mathbf{2 9}$ in $75-82 \%$ yields. The same reaction, using 4-chloro-substituted sodium benzenesulfinate as aryl source, was reported by Weng and co-workers (Scheme 16, b). ${ }^{34 \mathrm{~b}}$ They employed $20 \mathrm{~mol} \%$ [PdCl(allyl) $]_{2}$ associated to $20 \mathrm{~mol} \%$ of Xphos (Xphos: 2-dicyclohexylphosphino-2,4,6-triisopropylbiphenyl) in the presence of 2 equiv. of $\operatorname{Ag}_{2} \mathrm{O}$ as additive in wet DMF at $110^{\circ} \mathrm{C}$ as catalytic system. However, the arylated polyfluorobenzenes 30 were isolated in lower yields than under the Wang's conditions (Scheme 16, a). Moreover, this procedure requires the use of a large amount of the expensive phosphine ligand Xphos.

a)<smiles>[R]c1c(F)c(F)cc(F)c1F</smiles>

$+$
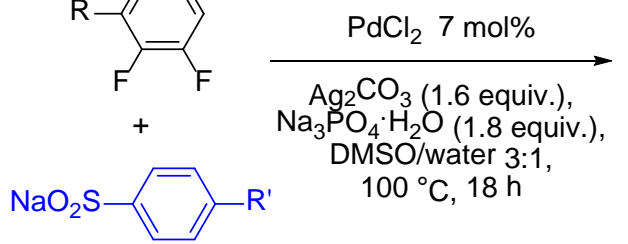

1.6 equiv. $100^{\circ} \mathrm{C}, 18 \mathrm{~h}$

b)<smiles>[R]c1c(F)c(F)cc(F)c1F</smiles>

2 equiv.<smiles>O=[N+]([O-])c1ccc(Cl)cc1</smiles>

[PdCl(allyl) $]_{2} 20$ mol\%, Xphos 20 mol\%

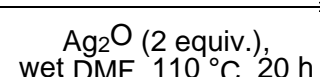

wet DMF, $110^{\circ} \mathrm{C}, 20 \mathrm{~h}$

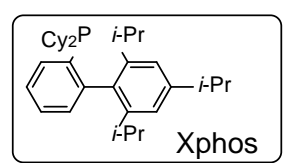

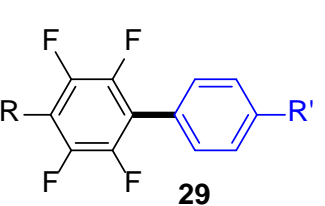

$\begin{array}{llll}\mathrm{R} & \mathrm{R} & & \text { Yield (\%) } \\ \mathrm{F} & \mathrm{Br} & \mathbf{2 9 a} & 75 \\ \mathrm{~F} & \mathrm{Cl} & \mathbf{2 9 b} & 82 \\ \text { OMe } & \mathrm{Cl} & \mathbf{2 9 c} & 75\end{array}$

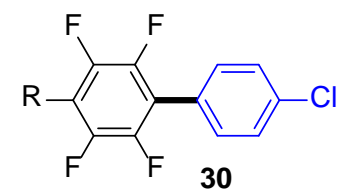

$\begin{array}{lll}\mathrm{R} & \text { Yield (\%) } \\ \mathrm{F} & \mathbf{3 0 a} 50\end{array}$

OMe 30b 27

Scheme 16. Desulfitative arylations of polyfluoroarenes

Very recently, Kianmehr and Tanbakouchian described the Pd-catalyzed regioselective arylation of anilides using benzenesulfonyl chlorides as arylating agents and $\mathrm{PdCl}_{2}$ as catalyst. (Scheme 17). ${ }^{35}$ Their procedure provided regioselectively and in high yields the 2-aminobiaryl derivatives 31 containing chloro- or bromo-substituents. 


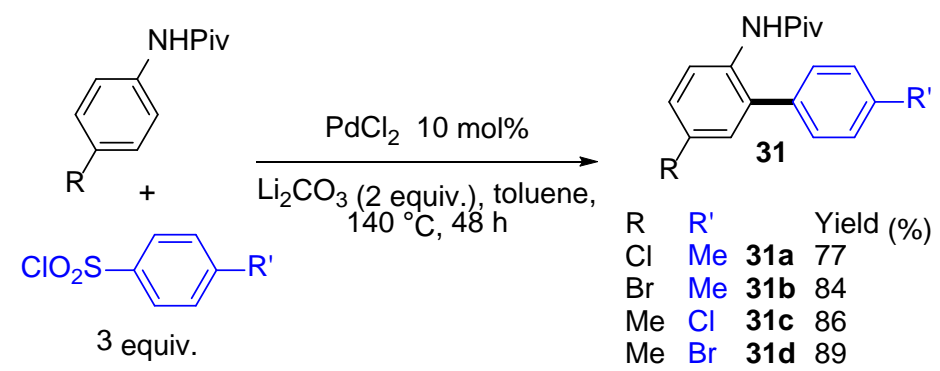

Scheme 17. Desulfitative arylations of anilides

\subsection{Functionalization of five-membered ring heteroarenes containing one hetero-element}

One of the advantages of the use of heteroarenes instead of arenes in metal-catalyzed $\mathrm{C}-\mathrm{H}$ bond functionalizations is the strong electronic effect of the presence of the heteroelement on the ring, which allows to control more easily the regioselectivity. This part is divided in four points depending on the nature of the heteroatom on the ring (i.e., $N$ with pyrroles, indoles and indolizines, $S$ with (benzo)thiophenes, $O$ with (benzo)furans, Se with selenophene).

\subsubsection{Pyrroles, indoles and indolizines}

The first Pd-catalyzed direct desulfitative arylation of indoles using a halo-substituted sodium benzenesulfinate was reported by Deng, Luo et al. in 2013 (Scheme 18). ${ }^{36}$ This coupling reaction was performed with sodium 4-bromobenzenesulfinate as the coupling partner and a palladium(II) catalyst in the presence of 2 equiv. of $\mathrm{CuCl}_{2}$ as oxidant in toluene/dioxane as solvent. With this coupling partner, the indole derivative was arylated exclusively at the C2-position providing products 32 in good yields.

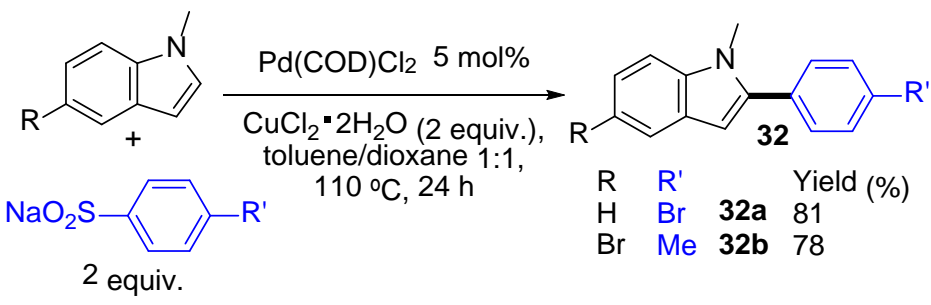


Scheme 18. Desulfitative arylations of indoles with sodium benzenesulfinates

Free $(\mathrm{NH})$-indoles were arylated with benzenesulfinic acids by Wang et al., via a Pd-catalyzed desulfitative coupling reaction, in the presence of AgOAc as oxidant and sulfuric acid as additive using microwave heating affording 33 in 56-80\% yields (Scheme 19). ${ }^{37}$ The use of $\mathrm{H}_{2} \mathrm{SO}_{4}$ as additive might minimize the decomposition of indoles and favor the regioselective functionalization at indole C2-position. The benzenesulfinic acids scope included 2-chloro-, 4-chloro- and also 4bromo-substituents. In addition, the reaction tolerated bromo-substituents on the indole.

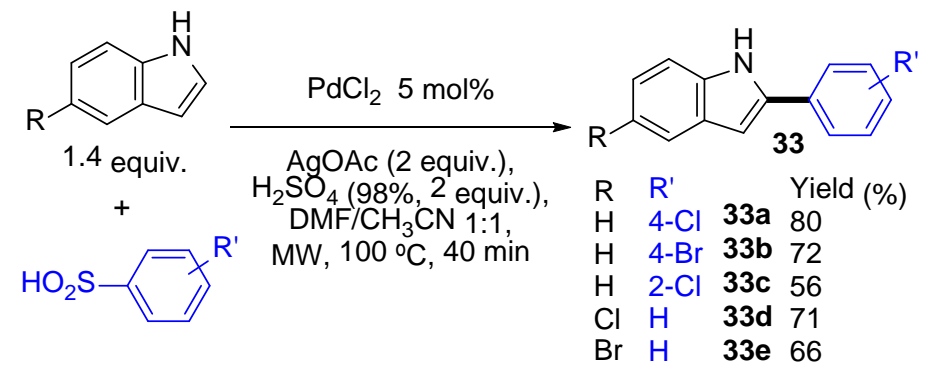

Scheme 19. Desulfitative arylations of indoles with benzenesulfinic acids

In 2014, our group reported the arylation of pyrrole derivatives using halo-substituted benzenesulfonyl chlorides as coupling partners (Scheme 20). ${ }^{38}$ The optimized conditions (i.e., 5 mol\% of $\mathrm{PdCl}_{2}\left(\mathrm{CH}_{3} \mathrm{CN}\right)_{2}$ in the presence of lithium carbonate in 1,4-dioxane at $140{ }^{\circ} \mathrm{C}$ ) allowed the formation of the C2-arylated pyrroles 34 in high yields and high regioselectivities. The reaction tolerated 4-chloro-, 2-, 3- or 4-bromo- and even 4-iodo-substituents on the benzenesulfonyl chloride and also halo-substituted thienylsulfonyl chlorides. ${ }^{39}$ Poly(bromo)benzenesulfonyl chlorides were also successfully employed. ${ }^{40}$ Two $N$-benzylpyrroles bearing bromo-substituents on the benzyl moiety were arylated at pyrrolyl C2-position by 3,5-dichlorobenzenesulfonylchloride to give 34u and $\mathbf{3 4 v}$ in high yields, without the cleavage of the $\mathrm{C}-\mathrm{Br}$ and $\mathrm{C}-\mathrm{Cl}$ bonds. ${ }^{41}$ It should be mentioned that the coupling of 4-bromobenzenesulfonyl chloride with 1-methylpyrrole also proceeded in the “greener” solvents DEC and CPME or using neat conditions. ${ }^{42}$ 


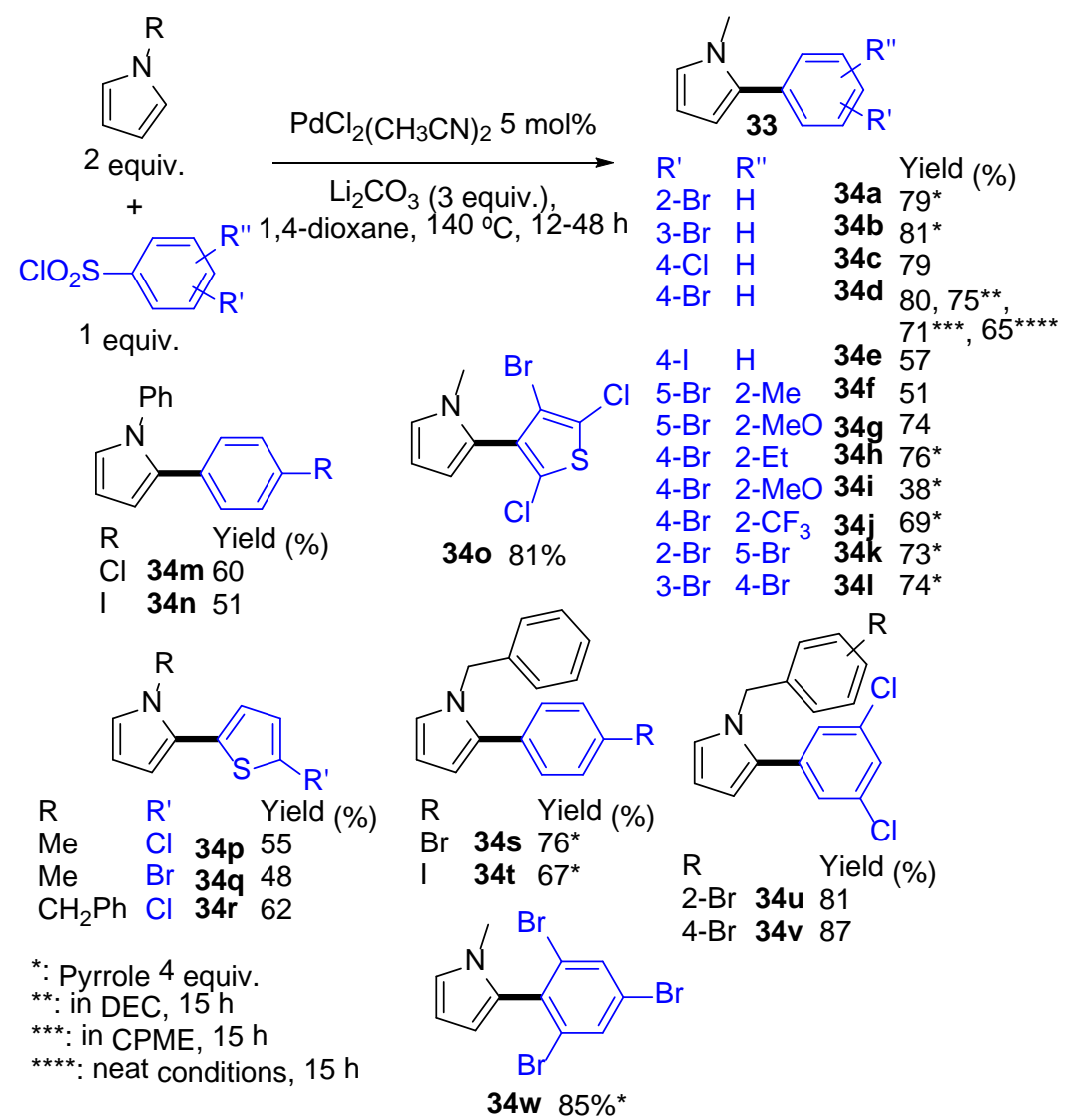

Scheme 20. Desulfitative arylations of pyrroles

Our group also reported that a 2-aryl-substituted $N$-benzylpyrrole in the presence of 2bromobenzenesulfonyl chloride led to the 2,5-diarylated pyrrole 35 in 52\% yield (Scheme 21, a). ${ }^{41}$ Moreover, from 2 equiv. of $N$-phenylpyrrole and 2-bromobenzenesulfonyl chloride, these desulfitative direct arylation conditions also allowed the formation of 2-(2-bromophenyl)-1phenylpyrrole, which was not purified. After a simple filtration over silica gel, the crude mixture was heated in the presence of $\operatorname{PdCl}\left(\mathrm{C}_{3} \mathrm{H}_{5}\right)(\mathrm{dppb})$ catalyst and PivOK to give a pyrrolo[1,2f]phenanthridine 36 in 62\% yield over two steps (Scheme 21, b). Moreover, from $N$-arylpyrroles and 2.5 equiv. of 2-bromobenzenesulfonyl chloride, the desulfitative direct 2,5-diarylation allowed the formation of 2,5-bis(2-bromophenyl)-1-arylpyrroles 37a and $\mathbf{3 7 b}$ in $73 \%$ and $79 \%$ yields (Scheme 21, c). The tetrabromo-substituted 2,5-diarylpyrrole 38 was also prepared by this method. $^{40}$ 
a)

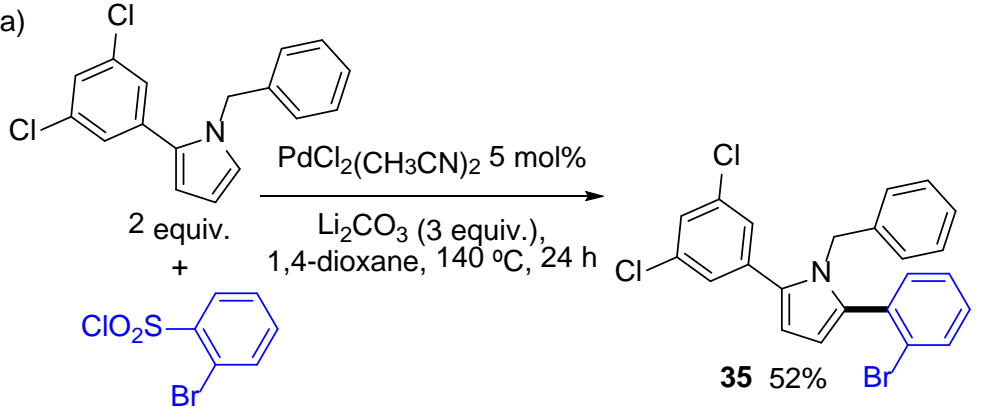

1.25 equiv.

b)

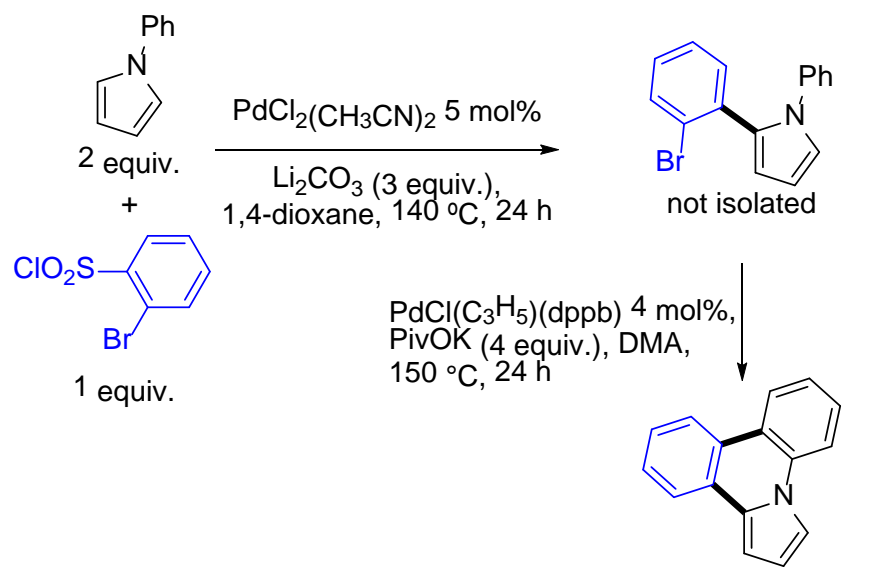

36 62\% over 2 steps

c)

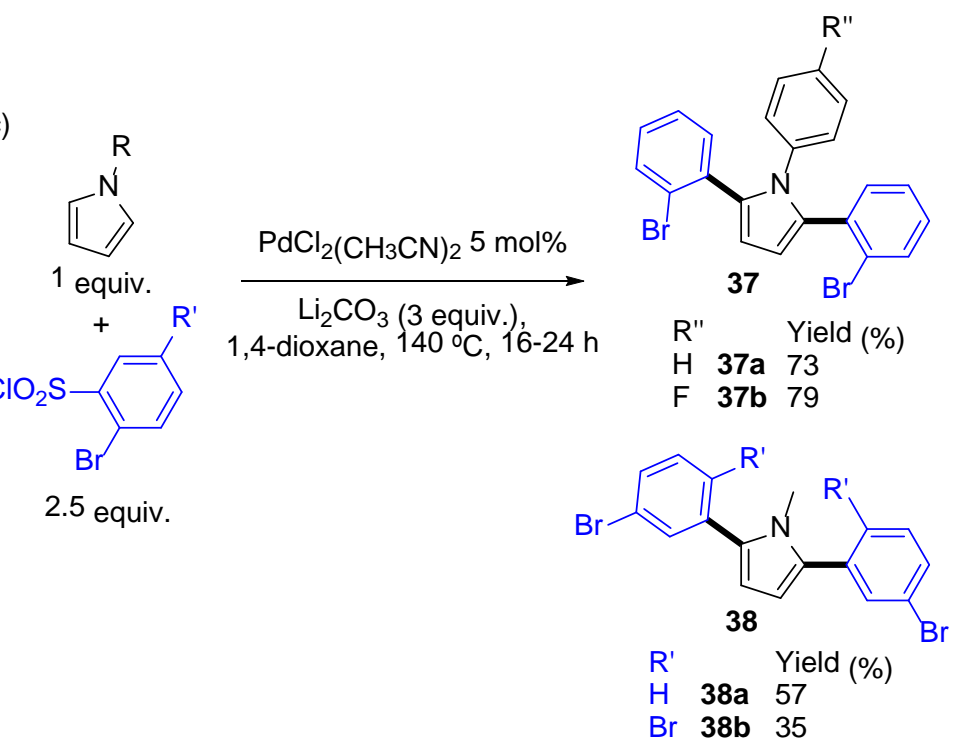

Scheme 21. Desulfitative arylations of pyrroles

The Pd-catalyzed desulfitative arylation using halo-substituted benzenesulfonyl chlorides also proceed nicely with indolizines (Scheme 22). ${ }^{43}$ In 2015, Zhao et al. described the coupling reaction of methyl indolizine-1-carboxylate with 4-chloro- and 4-bromo-benzenesulfonyl chlorides. Under their optimized reaction conditions, $5 \mathrm{~mol} \% \mathrm{Pd}\left(\mathrm{PPh}_{3}\right)_{4}$ catalyst in the presence of $\mathrm{NaHCO}_{3}$ in $\mathrm{DMF}$ 
under nitrogen, the desulfitative arylation occurred with high regioselectivity at C3-position and high yields, without dehalogenation affording products 39 in high yields.

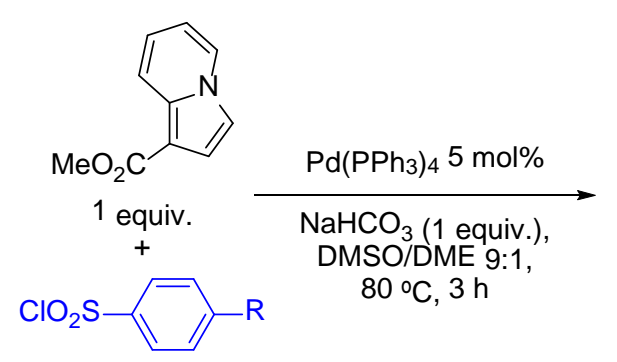

1.2 equiv.

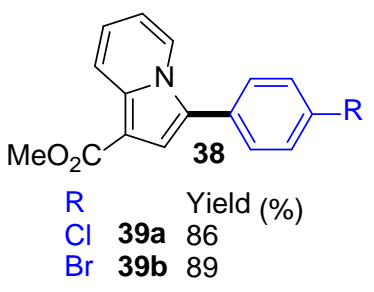

$\begin{array}{lll}\mathrm{Cl} & 39 a & 86 \\ \mathrm{Br} & 39 \mathrm{~b} & 89\end{array}$

Scheme 22. Desulfitative arylations of indolizines with benzenesulfonyl chlorides

Then, in 2016, Zhao group extended the arylation of indolizines to halo-substituted sodium benzenesulfinates and benzenesulfonyl hydrazides (Scheme 23). ${ }^{44}$ For the couplings of indolizines with sodium benzenesulfinates, tert-butylperoxyacetate was used as oxidant and $\mathrm{Pd}(\mathrm{OAc})_{2}$ was associated to 2,2'-bipyridine as catalyst; whereas, for the reaction with benzenesulfonyl hydrazides, $\mathrm{CuCl}_{2}$ was employed as oxidant and $\mathrm{Pd}(\mathrm{TFA})_{2}$ as catalyst. Both catalytic systems afforded the C3arylated indolizines $\mathbf{4 0}$ and $\mathbf{4 1}$ in high yields. Moreover, the reaction tolerated bromo- and chlorosubstituents on the indolizine unit. However, as the sodium benzenesulfinates and benzenesulfonyl hydrazides have to be prepared, and as an oxidant is required for these two procedures, they are probably less attractive than the procedure of scheme 22 . 


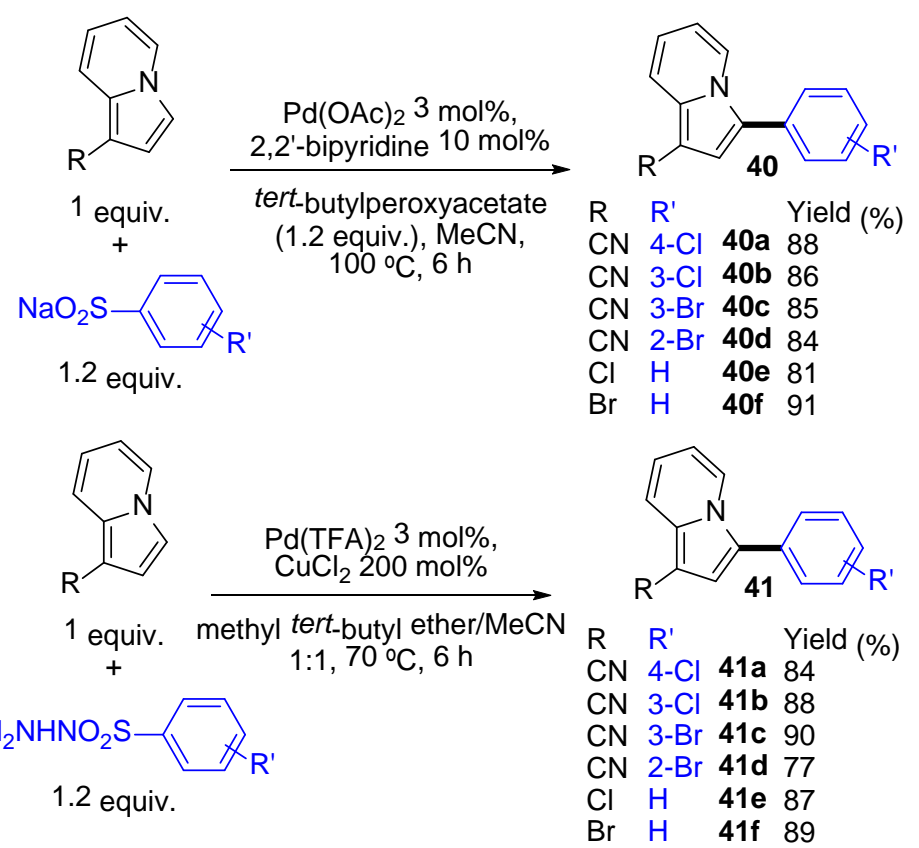

Scheme 23. Desulfitative arylations of indolizines with sodium benzenesulfinates and benzenesulfonyl hydrazides

Our group also studied the desulfitative arylation of $\mathrm{N}$-methylindole using 5 mol\% $\mathrm{PdCl}_{2}\left(\mathrm{CH}_{3} \mathrm{CN}\right)_{2}$ and $\mathrm{Li}_{2} \mathrm{CO}_{3}$ in 1,4-dioxane at $140{ }^{\circ} \mathrm{C}$ as reaction conditions. ${ }^{45}$ The coupling reaction with 4bromobenzenesulfonyl chloride was not regioselective, and a mixture of C2- and C3-arylated products 42 and 43 in 30:41 ratio was formed (Scheme 24, a). However, we demonstrated that an iodo-substituent at the indolyl C3-position act as temporary blocking group allowing the formation of halo-substituted 2-arylindoles $\mathbf{4 4}$ through direct desulfitative C2-arylation, followed by in situ deiodination (Scheme 24, b). ${ }^{46}$ On the contrary, from 3-bromoindole derivatives, the 2-aryl-3bromoindoles 45 and 46 were obtained without debromination (Scheme 24, c). 
a)

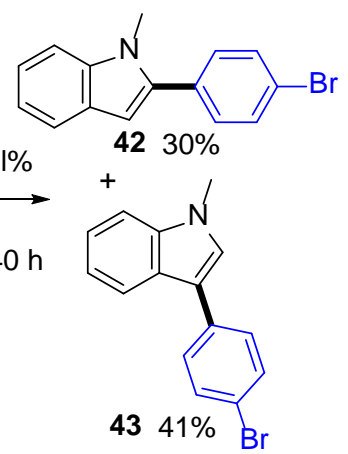

b)<smiles>Cn1ccc2ccccc21</smiles>
$\mathrm{PdCl}_{2}\left(\mathrm{CH}_{3} \mathrm{CN}\right)_{2} 5 \mathrm{~mol} \%$ $\mathrm{Li}_{2} \mathrm{CO}_{3}$ (3 equiv.),<smiles>O=[SH]c1ccc(Br)cc1</smiles>

1.5 equiv.<smiles>CCOC(=O)OCc1cn(Cc2ccccc2)c2ccccc12</smiles><smiles>[R]c1ccc(S(=O)(=O)Cl)cc1</smiles>
1,4-dioxane $1400^{\circ} \mathrm{C}$

1.25 equiv.<smiles>[R]c1ccc(-c2cc3ccccc3n2Cc2ccccc2)cc1</smiles>

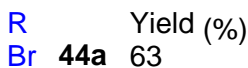

$\begin{array}{lll}\mathrm{Br} & 44 \mathrm{a} & 63 \\ \mathrm{I} & \mathbf{4 4 b} & 54\end{array}$

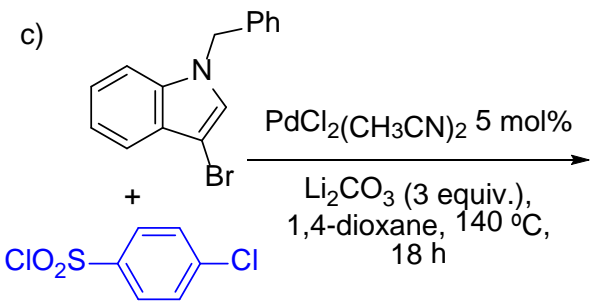

1.25 equiv.<smiles>[R6]c1c(-c2ccc(Cl)cc2)n(Cc2ccccc2)c2ccccc12</smiles>

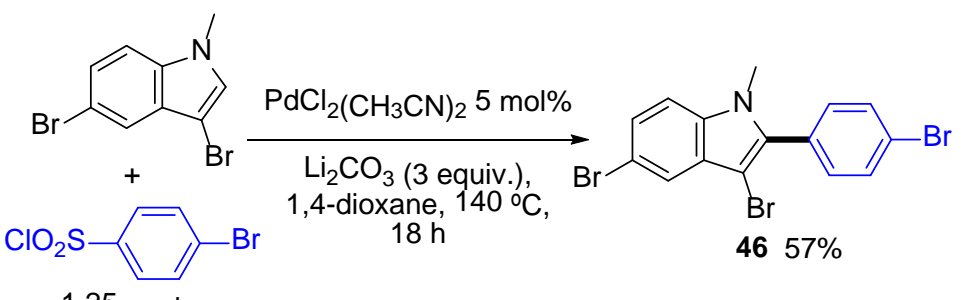

1.25 equiv.

Scheme 24. Desulfitative arylations of indoles

Conversely, Liu et al. obtained regioselectively the C2-arylated indoles by reaction of free ( $\mathrm{NH})$ indole with benzenesulfonyl hydrazides (Scheme 25). ${ }^{47}$ The reaction was conducted under oxygen atmosphere using $\mathrm{Pd}(\mathrm{OAc})_{2}$ catalyst and 1.2 equiv. of trifluoromethanesulfonic acid as additive. Halo-substituents were tolerated on both coupling partners.

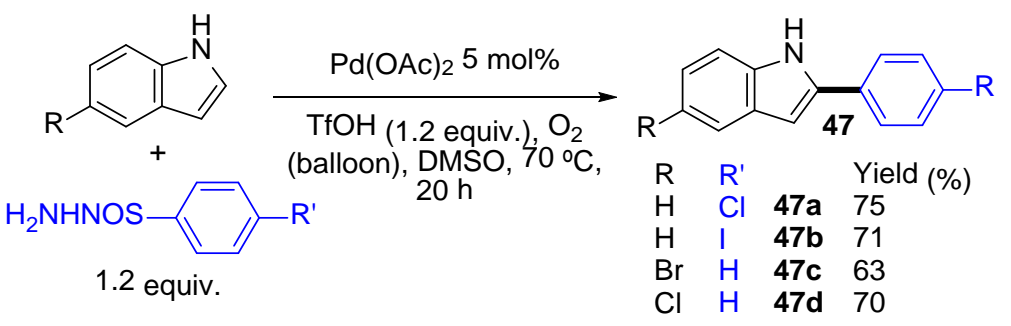


Scheme 25. Desulfitative arylations of indoles

\subsubsection{Thiophenes and benzothiophenes}

In 2014, our group reported the first Pd-catalyzed direct desulfitative arylations of thiophenes with benzenesulfonyl chlorides as coupling partners (Scheme 26). ${ }^{40,48}$ Interestingly, the arylation took place exclusively at the thienyl C4-position. ${ }^{108-116}$ 4-Chloro-, 4-bromo-, and even 4-iodobenzenesulfonyl chlorides in the presence of $5 \mathrm{~mol} \% \mathrm{PdCl}_{2}\left(\mathrm{CH}_{3} \mathrm{CN}\right)_{2}$ and of 3 equiv. of lithium carbonate as base gave the C4-arylated thiophenes $\mathbf{4 8}$ in high yields. The reaction tolerated alkylor bromo-substituents at C2-position on thiophene and could be performed in 1,4-dioxane or CPME. $^{42}$ Reaction with 2-chloro-4-fluorobenzenesulfonyl chloride was also successful, affording the coupling product $\mathbf{4 8 w}$ in $78 \%$ yield. $^{49}$ Later, our group extended the reaction to 2 - and 3 bromobenzenesulfonyl chlorides. ${ }^{39 a, 50}$ Using the same reaction conditions, 2-methylthiophene was coupled with 2-bromobenzenesulfonyl chloride to afford the C4-arylated thiophene 48f, without CBr bond cleavage, in 76\% yield. Thiophenes substituted at C2-position by pentyl, cyanomethyl or 4-methoxyphenyl groups in the presence of 2-bromobenzenesulfonyl chloride also gave the desired C4-arylated thiophenes $\mathbf{4 8 g}$, $\mathbf{4 8 h}$ and $\mathbf{4 8 r}$ in 73-43\% yields. 4-Trifluoromethyl-, 4-fluoro-, or 4,6difluoro-substituents on 2-bromobenzenesulfonyl chlorides were also tolerated. We also described a palladium-catalyzed one-pot “cascade” intermolecular C5-arylation using aryl bromides of some of these thiophene derivatives substituted at the C4-position by an aryl group containing an orthobromo substituent, followed by intramolecular arylation, which gives access to the corresponding phenanthro[9,10-b]thiophenes in a single operation. 


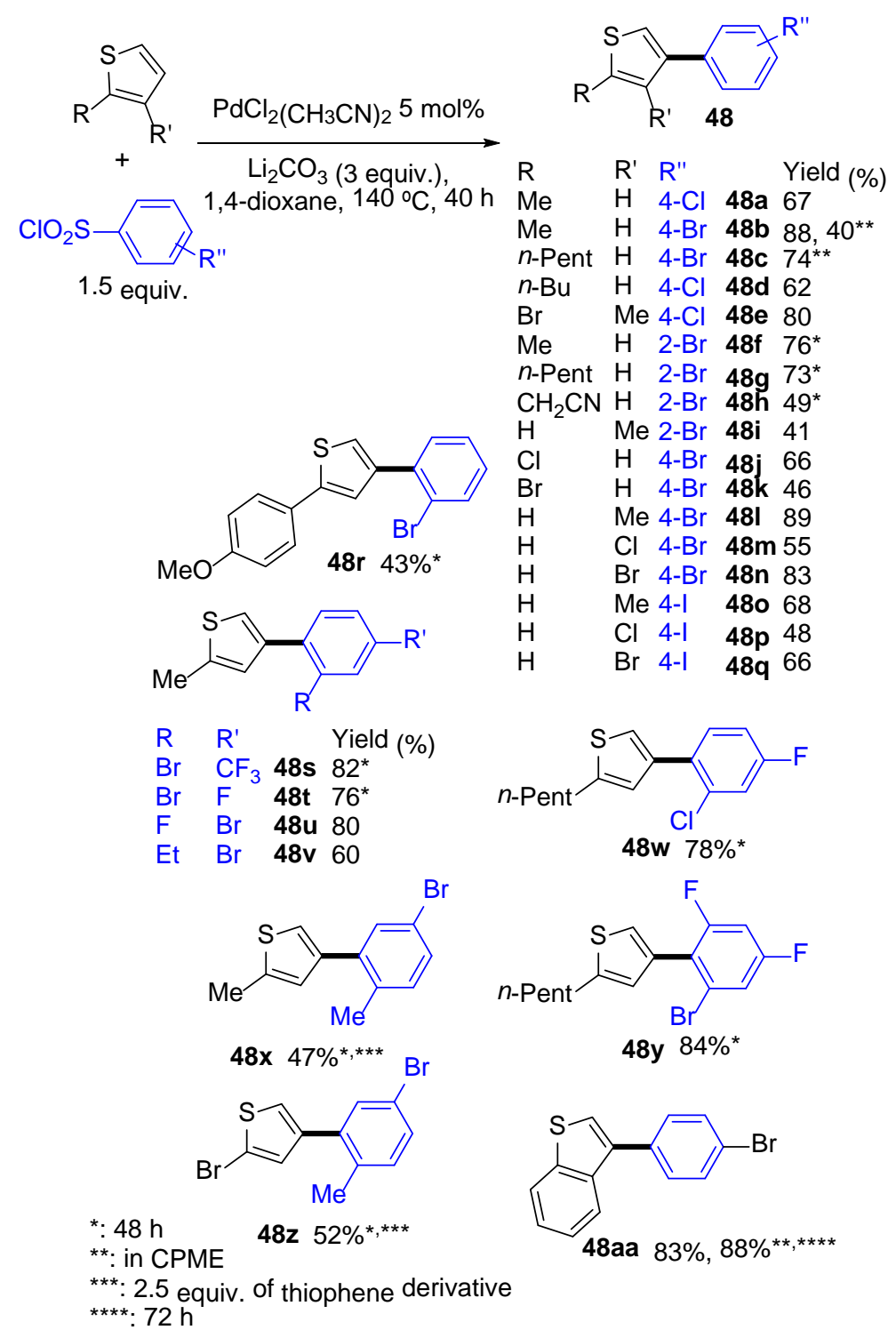

Scheme 26. Desulfitative arylations of thiophenes

\subsubsection{Furans and benzofurans}

From 2014, we applied our reaction conditions (see scheme 26$)^{48}$ to the synthesis of halosubstituted (benzo)furan derivatives 49 (Scheme 27). ${ }^{40,51} n$-Butylfuran or menthofuran were reacted with 4-chloro-, 4-bromo- and 4-iodo-benzenesulfonyl chlorides in the presence of 5 mol \% $\mathrm{PdCl}_{2}\left(\mathrm{CH}_{3} \mathrm{CN}\right)_{2}$ catalyst to afford the desired C2-arylated products $49 \mathrm{a}-\mathbf{4 9 c}$, $49 \mathrm{~g}$ and $\mathbf{4 9 h}$ in 50 76\% yields. A similar yield in 49i was obtained for the coupling of 2-chloro-4fluorobenzenesulfonyl chloride with menthofuran. ${ }^{49}$ Using the same reaction conditions, we also 
successfully arylated benzofuran at C2-position using 4-chloro-, 4-bromo- and also 3,5-dichlorobenzenesulfonyl chlorides as aryl sources. ${ }^{39,52}$ It should be mentioned that the reaction was completely regioselective, while reactions using aryl bromides as coupling partners, generally afforded mixtures of C2- and C3-arylated benzofuran derivatives. ${ }^{53}$ Several arylations of (benzo)furans using the greener solvents DEC, CMPE or under neat conditions instead of 1,4dioxane have also been described. ${ }^{42}$

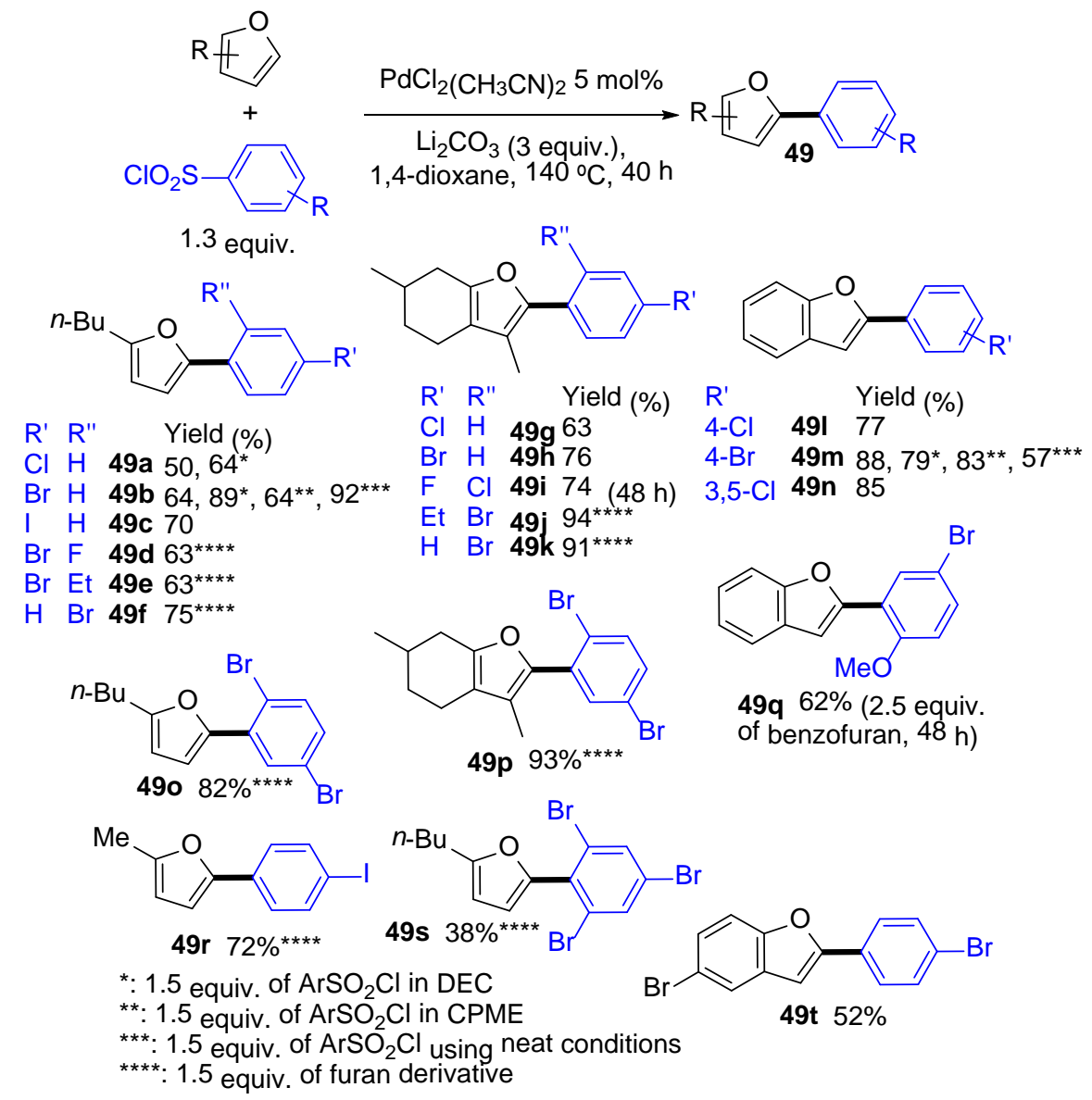

Scheme 27. Desulfitative arylations of (benzo)furans

\subsubsection{Selenophenes}

The first examples of Pd-catalyzed desulfitative arylations of selenophene have been reported by our group in 2017. ${ }^{54}$ We examined the behavior of several (poly)halobenzenesulfonyl chlorides for coupling with this heteroarene using $10 \mathrm{~mol} \% \mathrm{Pd}(\mathrm{OAc})_{2}$ catalyst and 3 equiv. of $\mathrm{Li}_{2} \mathrm{CO}_{3}$ as the base 
in 1,4-dioxane. In all cases, the C3-arylated selenophenes $\mathbf{5 0}$ were regiospecifically produced (Scheme 28). Satisfactory yields in 50a-50e were obtained in the presence of benzenesulfonyl chlorides containing 2-, 3-, or 4-chloro-substituents and also 2- or 4-bromo-substituents. An additional ortho-ethyl-substituent on 4-bromobenzenesulfonyl chloride exhibited a minor influence, as a high yield of $74 \%$ in the target product $\mathbf{5 0 0}$ was obtained. 2-Bromobenzenesulfonyl chlorides bearing fluoro- or trifluoromethyl-substituents also afforded to the C3-arylated selenophenes $\mathbf{5 0 j}$ and $\mathbf{5 0 1}$ in high yields. The reactivity of two dibromobenzenesulfonyl chlorides was also examined. In both cases, the target products $\mathbf{5 0 k}$ and 50p were obtained in good yields, without cleavage of both $\mathrm{C}-\mathrm{Br}$ bonds. A bromo-substituent at C2-position on selenophene was also tolerated, affording the desired 4-aryl-2-bromoselenophenes, without cleavage of the selenophenyl $\mathrm{C}-\mathrm{Br}$ bond. Moreover, in the presence of 3,4-dibromobenzenesulfonyl chloride, the expected C4-arylated 2bromoselenophene derivative $\mathbf{5 0 q}$ was obtained without cleavage of the $\mathrm{C}-\mathrm{Br}$ bonds on both coupling partners. Finally, we examined the reactivity of 4-iodobenzenesulfonyl chloride in the presence of selenophene and 2-bromoselenophene. The reaction afforded the $\beta$-arylated selenophenes $\mathbf{5 0 f}$ and $\mathbf{5 0 g}$ in low yields, but without cleavage of the C-I bond.

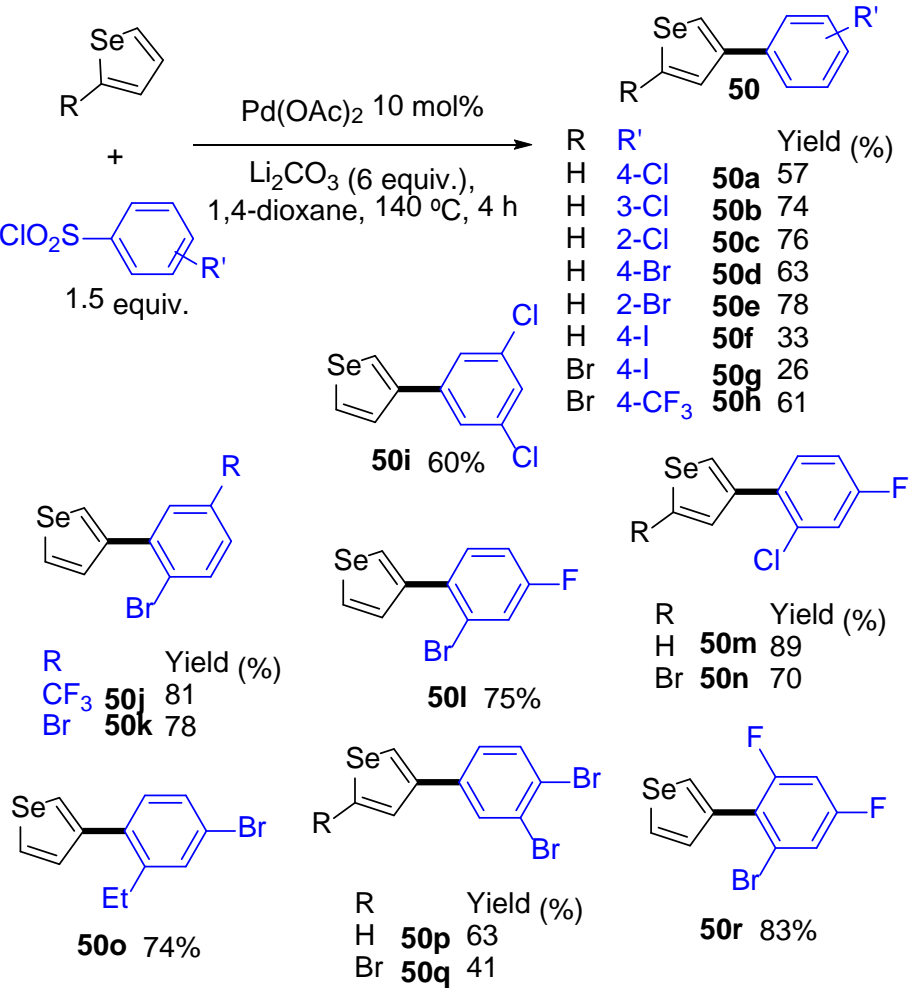


Scheme 28. Desulfitative arylations of selenophenes

\subsection{Functionalization of five-membered ring heteroarenes containing more than one hetero- element}

Five-membered ring heteroarenes containing more than one hetero-element such as benzoxazoles, benzothiazoles and purines are important building blocks in pharmaceutical chemistry. Their modifications through Pd-catalyzed desulfitative direct arylations has also been reported in recent years. These arylations generally proceeded at their most acidic position, which is the $\mathrm{C}-\mathrm{H}$ bond flanked by two hetero-elements. The C5-arylation of oxazole and triazole derivatives has also been described. Again benzenesulfonyl chlorides, benzenesulfinates, and benzenesulfonyl hydrazides were employed as the coupling partners, including those bearing halo-substituents, with high degrees of chemoselectivity.

\subsubsection{Oxazoles and benzoxazoles}

In 2011, Cheng et al. reported the first Pd-catalyzed desulfitative direct arylation of benzoxazole using halo-substituted benzenesulfonyl chlorides as coupling partners (Scheme 29, a). ${ }^{55}$ For this reaction they employed $10 \mathrm{~mol} \% \mathrm{Pd}(\mathrm{OAc})_{2}$ catalyst associated to 1 equiv. of CuI. The reaction displayed a broad substrate scope including 4-chloro- and 4-bromobenzenesulfonyl chlorides. The addition of a copper salt to the reaction mixture was found to be critical for the reactivity. It might promote the formation of a cuprate derivative through an electrophilic attack of CuI on the benzoxazole $\mathrm{C}-\mathrm{H}$ bond. The coupling of 3-bromobenzenesulfonyl chlorides with benzoxazole, under quite similar reaction conditions to provide products $\mathbf{5 3}$ had been reported by our group in 2015 (Scheme 29, b). ${ }^{39 a}$ 
a)

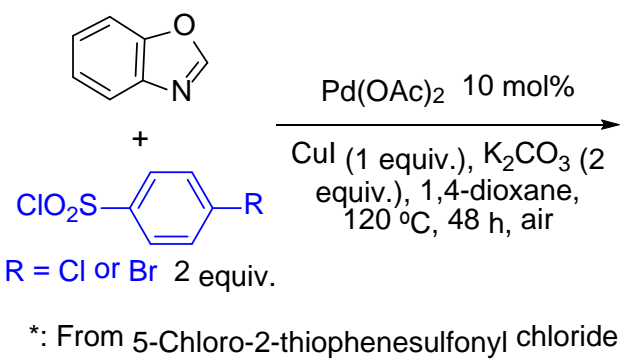

b)<smiles>c1ccc2ocnc2c1</smiles><smiles>[R]c1ccc(Br)c(S(=O)(=O)O[Na])c1</smiles>

$\mathrm{PdCl}_{2}\left(\mathrm{CH}_{3} \mathrm{CN}\right)_{2} 5 \mathrm{~mol} \%$

Cul (1 equiv.), $\mathrm{Li}_{2} \mathrm{CO}_{3}(3$ equiv.), 1,4-dioxane, $140{ }^{\circ} \mathrm{C}, 48 \mathrm{~h}$

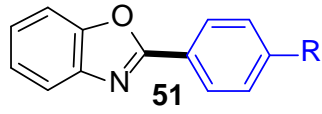

$\mathrm{R} \quad$ Yield (\%)

Cl 51a 55

$\mathrm{Br} \mathbf{5 1 b} 45$
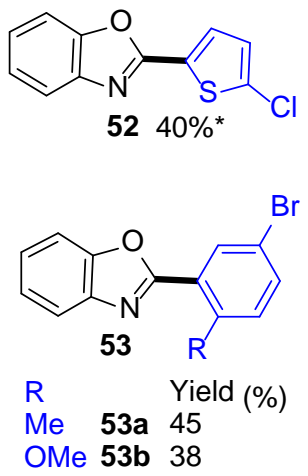

Scheme 29. Desulfitative arylations of oxazoles and benzoxazoles

Wang et al. also described a protocol for the direct desulfitative arylation of benzoxazole, but they employed a 4-bromo-substituted sodium benzenesulfinate as aryl source. ${ }^{56 a}$ In contrast to the examples of scheme 29, which required basic conditions, trifluoroacetic acid was used as additive (Scheme 30, a). Later, Liu, Chen et al. reported the C5-arylation of 2-phenyloxazole-4-carboxylate with sodium benzenesulfinates using Pd(OAc) 2 /DPEphos (DPEphos: bis[(2diphenylphosphino)phenyl] ether) as catalyst, $\mathrm{K}_{2} \mathrm{CO}_{3}$ as base under an oxygen atmosphere (Scheme 30, b). ${ }^{56 \mathrm{~b}}$ The reaction tolerated both chloro- and bromo-substituents on the benzenesulfinate and on the oxazole unit, affording products 55 in 64-85\% yields. These two procedures provided higher yields of 2-arylbenzoxazoles than the reactions using benzenesulfonyl chlorides as aryl sources described in the scheme 29. 
a)
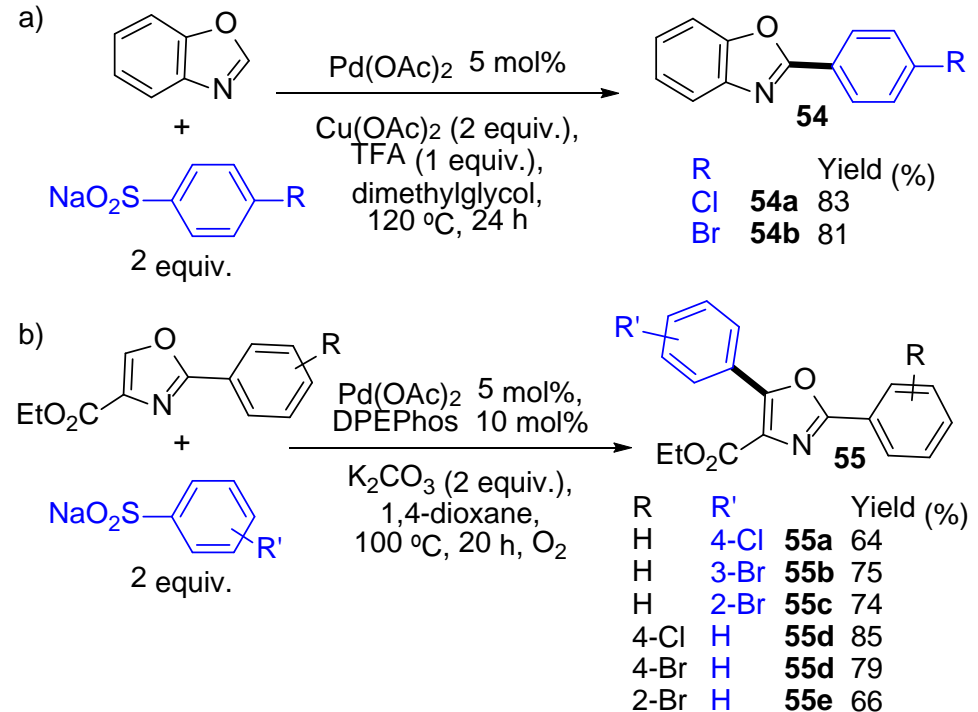

Scheme 30. Desulfitative arylations of oxazoles and benzoxazoles

In 2012, Wan et al. demonstrated that 4-bromobenzenesulfonyl hydrazide could also be used as aryl source in Pd-catalyzed desulfitative arylations of benzoxazole to provide products 56 (Scheme 31, a). ${ }^{57}$ The reaction was performed using $\mathrm{PdCl}_{2}\left(\mathrm{CH}_{3} \mathrm{CN}\right)_{2}$ associated to 1,10-phenantroline as catalyst in the presence of $\mathrm{Na}_{2} \mathrm{CO}_{3}$ as base, with $\mathrm{Cu}(\mathrm{OAc})_{2}$ and tetra- $n$-butylammonium bromide as additives in a mixture of dioxane/DMSO. The same year, Kwong et al. also described this transformation using a simpler catalytic system, namely, $\mathrm{Pd}(\mathrm{OAc})_{2}$ associated to triphenylphosphine, in the presence of only $\mathrm{Cu}(\mathrm{OAc})_{2}$ (2 equiv.) as additive, in dioxane under air atmosphere (Scheme 31, b). ${ }^{58}$ They obtained slightly lower yields in $\mathbf{5 7}$ than Wan et al.

a)<smiles>c1ccc2ocnc2c1</smiles><smiles>[R]c1ccc(S(=O)(=O)NN)cc1</smiles>
1.5 equiv.

b)<smiles>c1ccc2ocnc2c1</smiles>

$+$<smiles>[R]c1ccc(S(=O)(=O)NN)cc1</smiles>
1.5 equiv.

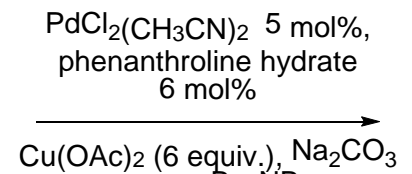

(1.5 equiv $) \mathrm{Bu}_{4} \mathrm{NBr}$ equiv.), 1,4-dioxane/DMSO $9: 1,100{ }^{\circ} \mathrm{C}, 4.5 \mathrm{~h}$

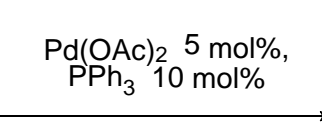

$\mathrm{Cu}(\mathrm{OAc}) 2$ (2 equiv.), 1,4-dioxane, $120^{\circ} \mathrm{C}$, air $18 \mathrm{~h}$

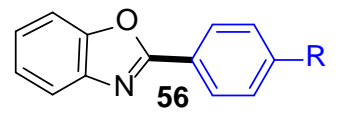

R Yield (\%)

Cl 56a 83

$\mathrm{Br}$ 56b 65

Scheme 31. Desulfitative arylations of benzoxazoles 


\subsubsection{Benzothiazoles}

In 2011, Deng et al. reported the Pd-catalyzed direct desulfitative C2-arylation of benzothiazole using a 4-chloro- and 4-bromo-substituted sodium benzenesulfinates as aryl sources (Scheme 32). ${ }^{59}$ Again, a copper salt, which promotes the oxidation of $\mathrm{Pd}(0)$ into $\mathrm{Pd}(\mathrm{II})$, was added to the reaction mixture.

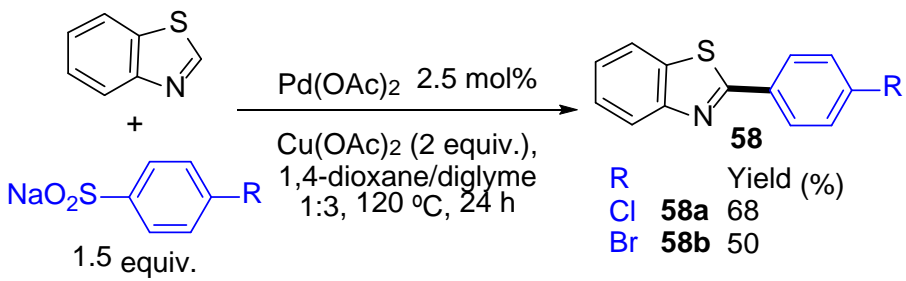

Scheme 32. Desulfitative arylations of benzothiazole

\subsubsection{Purines}

You et al. employed sodium 4-chloro- and 4-bromo-benzenesulfinates for the Pd-catalyzed direct desulfitative arylations of a purine derivative (Scheme 33, a). ${ }^{60}$ High yields in the desired products 59 were obtained using $2 \mathrm{~mol} \% \mathrm{PdCl}_{2}(\mathrm{PhCN})_{2}$ as the catalyst and a mixture of DMSO and 1,4dioxane as the solvent. Based on their previous work, ${ }^{60}$ You et al. also performed the direct desulfitative arylation of 1,3,7-trimethyl-3,7-dihydropurine-2,6-dione, but using 4-chloro- and 4bromo-benzenesulfonyl hydrazides as aryl sources (Scheme 33, b). ${ }^{61}$ The desired arylated purines 60 were also isolated in high yields. Both reaction conditions required the presence of 2 equiv. of $\mathrm{Cu}(\mathrm{OAc})_{2}$. 
a)

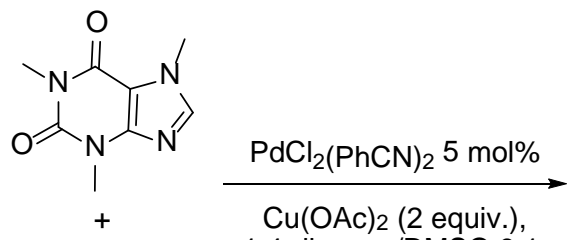<smiles>[R]c1ccc(-c2nc3c(c(=O)n(C)c(=O)n3C)n2C)cc1</smiles><smiles>[R]c1ccc(S(=O)(=O)O[Na])cc1</smiles>

R Yield (\%)

Cl 59a 95

$\mathrm{Br}$ 59b 91

2 equiv.<smiles>Cn1c(=O)c2c(ncn2C)n([12F])c1=O</smiles><smiles>[R]c1ccc(S(=O)(=O)NN)cc1</smiles>

1.2 equiv.

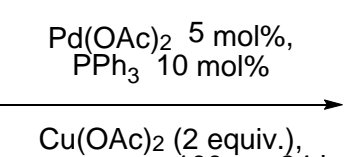<smiles>[R]c1ccc(-c2nc3c(c(=O)n(C)c(=O)n3C)n2C)cc1</smiles>

$R \quad$ Yield (\%)

$\mathrm{Cl} 60 \mathrm{a} 90$

$\mathrm{Br}$ 60b 89

Scheme 33. Desulfitative arylations of purines

\subsubsection{Thiazolotriazoles}

In 2014, Liu et al. reported the Pd-catalyzed direct arylation of thiazolo[3,2-b]-1,2,4-triazoles with sodium 3-chloro-, 4-chloro- and 4-bromo-benzenesulfinates (Scheme 34). ${ }^{62}$ The desired desulfitative arylation products $\mathbf{6 1}$ were isolated in $79-81 \%$ yields using 5 mol\% $\mathrm{Pd}(\mathrm{OAc})_{2}$ as catalyst, and two equiv. of $\mathrm{Cu}(\mathrm{OAc})_{2}$ as oxidant in dioxane/diglyme at $120{ }^{\circ} \mathrm{C}$. It should be mentioned that the reaction occurred only at the C5-position of the thiazolyl unit.

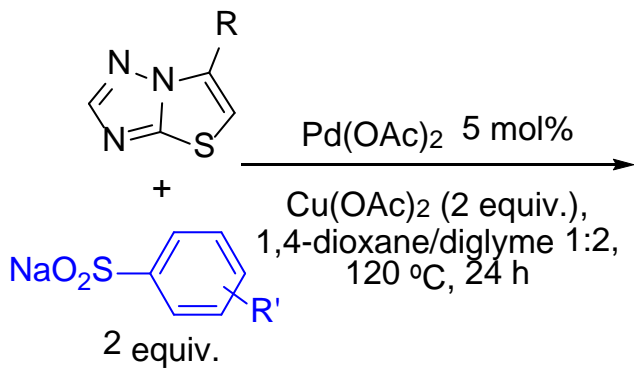

2 equiv.

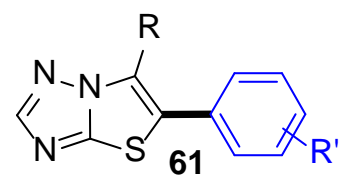

R R' Yield (\%)

Me 3-Cl 61a 77

$\mathrm{Me} 4-\mathrm{Cl}$ 61b 81

Me 4-Br 61c 79

$\mathrm{Ph}$ 3-Cl 61d 79

$\mathrm{Ph}$ 4- $\mathrm{Cl}$ 61e 80

$\mathrm{Ph}$ 4- $\mathrm{Br}$ 61f 81

Scheme 34. Desulfitative arylation of a thiazolotriazole 
For this coupling, a $\mathrm{Pd}(0) / \mathrm{Pd}(\mathrm{II})$ mechanism was proposed (Figure 3), where $\mathrm{Pd}(\mathrm{II})$ species A catalyzes the C-H bond activation process, followed by desulfitation to afford $\mathbf{D}$ and reductive elimination to afford the arylated product and $\operatorname{Pd}(0)$ species $\mathbf{E}$, which was reoxidized into Pd(II) $\mathbf{A}$ by the copper salt.

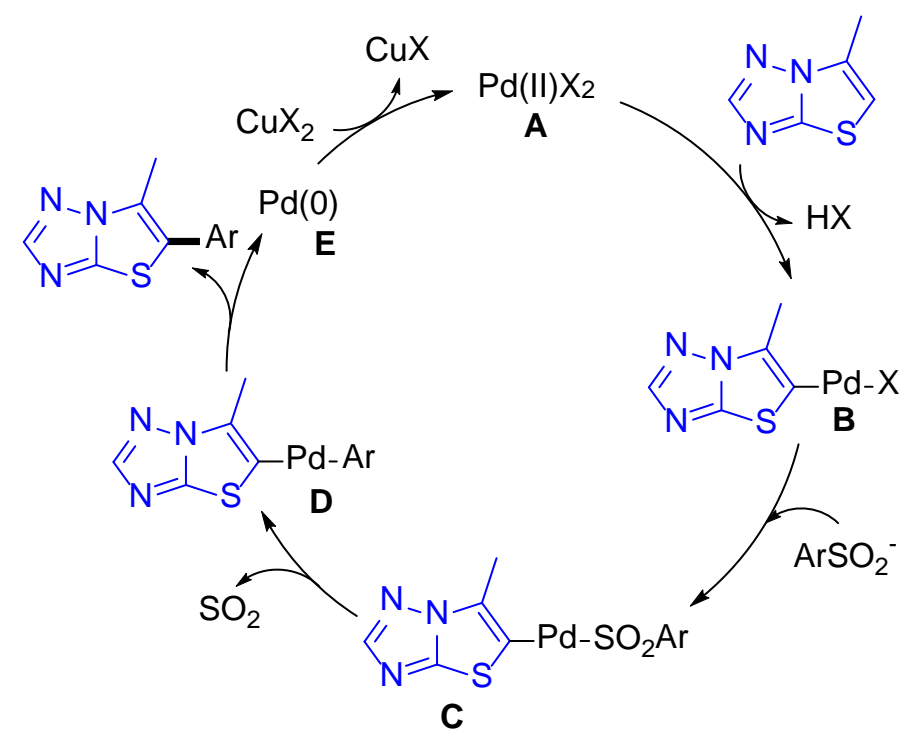

Figure 3. Proposed mechanism

\subsubsection{Triazoles}

In 2015, Huang, Lui et al. described the regioselective Pd-catalyzed direct C5-arylation of 1,2,3triazole $N$-oxides by sodium benzenesulfinates to produce 2,5-diaryl-1,2,3-triazole $N$-oxides 62 in good yields (Scheme 35). ${ }^{63}$ This coupling reaction was performed in the presence of $\mathrm{Ag}_{2} \mathrm{CO}_{3}$ and $\mathrm{K}_{3} \mathrm{PO}_{4}$ in DME/DMF as solvents. This protocol allowed the use of 4-bromobenzenesulfinate, and of a 3-chlorobenzene-substituted 1,2,3-triazole $N$-oxide. 


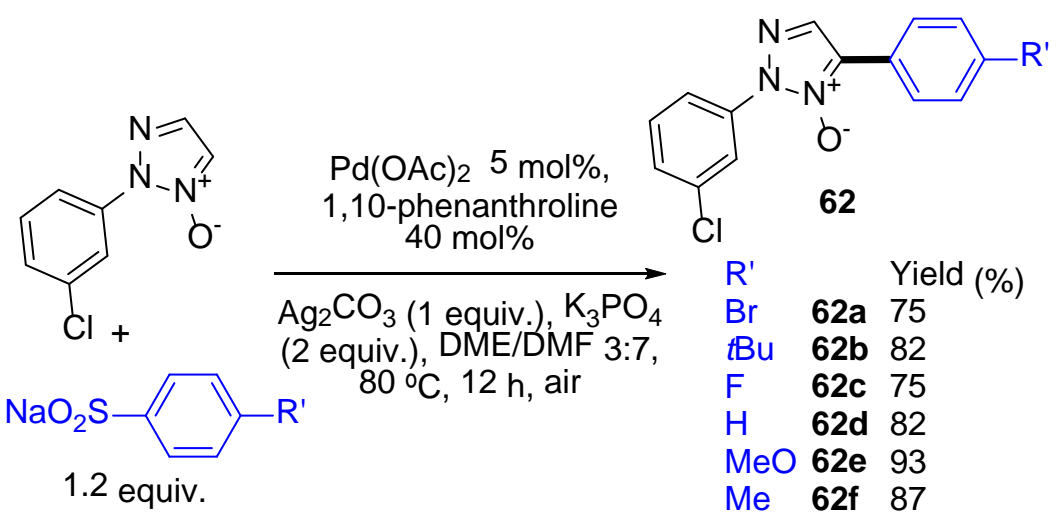

Scheme 35. Desulfitative arylations of a triazole $N$-oxide

\section{Reaction with alkenes}

Several examples of desulfitative Heck type reactions ${ }^{64}$ have been reported since the seminal work reported by Miura et al. in $1989 .{ }^{65}$ However, the desulfitative Pd-catalyzed reactions with alkenes are not limited to Heck reactions. Reductive Heck type reactions, ring-opening of oxabenzonorbornadienes, alkylations followed by aryl migrations and desulfonylation for the synthesis of quaternary centers, and also the synthesis of 4-aryl-1,2,3,4-tetrahydroquinolines via multi steps reactions have also been reported.

\subsection{Heck type reaction}

The first example of Pd-catalyzed desulfitative Heck type reaction ${ }^{64}$ using a halo-substituted benzenesulfonyl chloride was reported in 1989 by Miura et al. (Scheme 36). ${ }^{65}$ They discovered that the reaction of 4-chlorobenzenesulfonyl chloride with $n$-butyl acrylate in the presence of 2.5 mol\% $\mathrm{PdCl}_{2}(\mathrm{PhCN})_{2}$ under phase transfer conditions affords the corresponding (E)-3-(4chlorophenyl)acrylate in $89 \%$ yield, without $\mathrm{C}-\mathrm{Cl}$ bond cleavage. One year later, they extended the reaction to 3-chlorobenzenesulfonyl chloride, 4-bromobenzenesulfonyl chloride and also to 4- 
chloronaphthalene-1-sulfonyl chloride. ${ }^{66}$ A lower yield of $44 \%$ in $63 \mathrm{c}$ was obtained from the 4bromo-substituted benzenesulfonyl chloride.

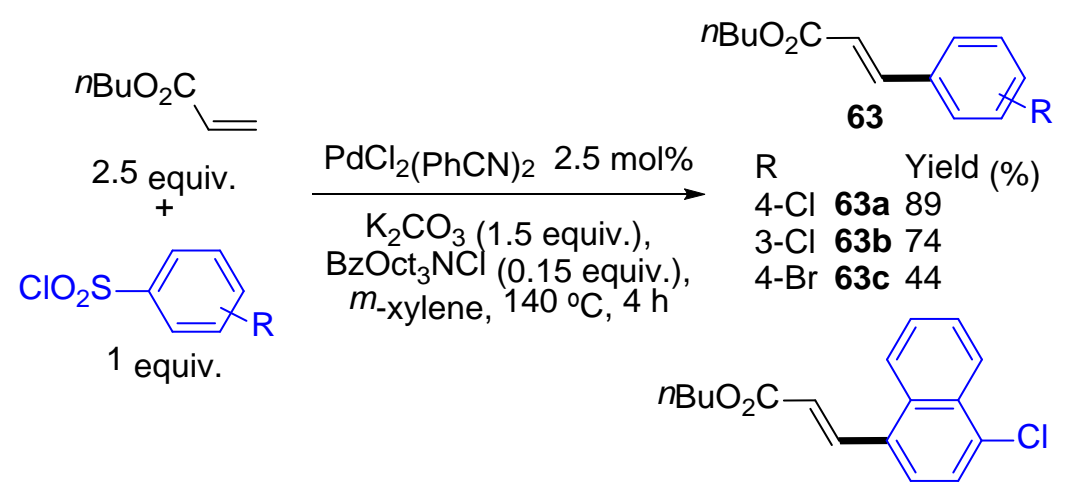

$6481 \%$

Scheme 36. Heck type reaction using halo-substituted benzenesulfonyl chlorides

In 2016, our group extended this reaction to a wide variety of (poly)halo-substituted benzenesulfonyl chlorides (Scheme 37). ${ }^{67}$ We observed that styrenes in the presence of bromo- or iodo-benzenesulfonyl chlorides and phosphine-free palladium catalyst $\mathrm{PdCl}_{2}\left(\mathrm{MeCN}_{2}\right.$ led to the expected $\beta$-arylated Heck type products 65 and 66 with complete regio- and stereo-selectivities, without cleavage of the $\mathrm{C}-\mathrm{Br}$ and $\mathrm{C}$-I bonds. Moreover, the reaction tolerated a variety of substituents at C2- or C4-positions on the halobenzenesulfonyl chloride such as methoxy, ethyl, fluoro or trifluoromethyl. A bromo-substituent on the styrene derivative was also tolerated. From 4-bromobenzenesulfonyl chloride as central unit, the consecutive desulfitative Heck reaction followed by Pd-catalyzed direct arylation allowed to prepare heteroarylated stilbene derivatives in only two steps. 


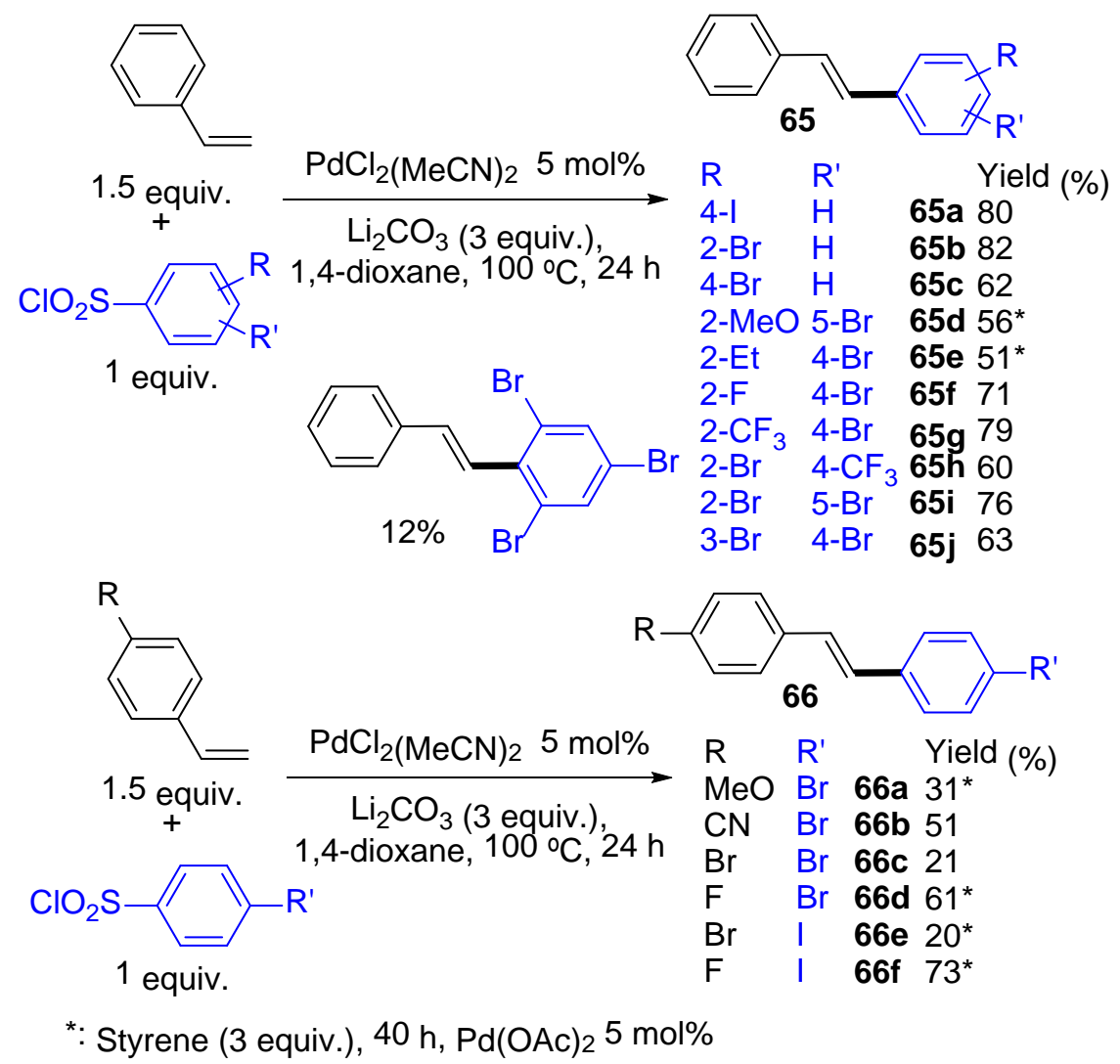

Scheme 37. Heck type reaction using halo-substituted benzenesulfonyl chlorides

Our group also investigated the reactivity of other alkenes under these reaction conditions (Scheme 38). The reaction of $n$-butylacrylate with 4-bromobenzenesulfonyl chloride afforded the corresponding cinnamate derivative $\mathbf{6 7 b}$ in $70 \%$ yield with complete regio- and stereo-selectivities in favor of the formation of the E-isomer. C2-substituents on 4-bromobenzenesulfonyl chloride, were tolerated affording the bromo-substituted cinnamates $\mathbf{6 7 d}$ and $67 \mathbf{e}$ in $83 \%$ and $85 \%$ yields. Two dibromobenzene-1-sulfonyl chlorides were also successfully coupled with $n$-butylacrylate. The reaction of $n$-butylacrylate with 4-iodobenzenesulfonyl chloride was also successful affording the Heck type product $\mathbf{6 7 a}$ in $82 \%$ yield, without C-I bond cleavage. Conversely, the reaction of 3,3-dimethylbut-1-ene with 4-bromobenzenesulfonyl chloride gave the styrene derivative $68 \mathbf{a}$ in only 36\% yield, and from dimethyl(phenyl)(vinyl)silane and 4-iodobenzenesulfonyl chloride, the vinylation product $\mathbf{6 8 b}$ was also obtained in low yield. 

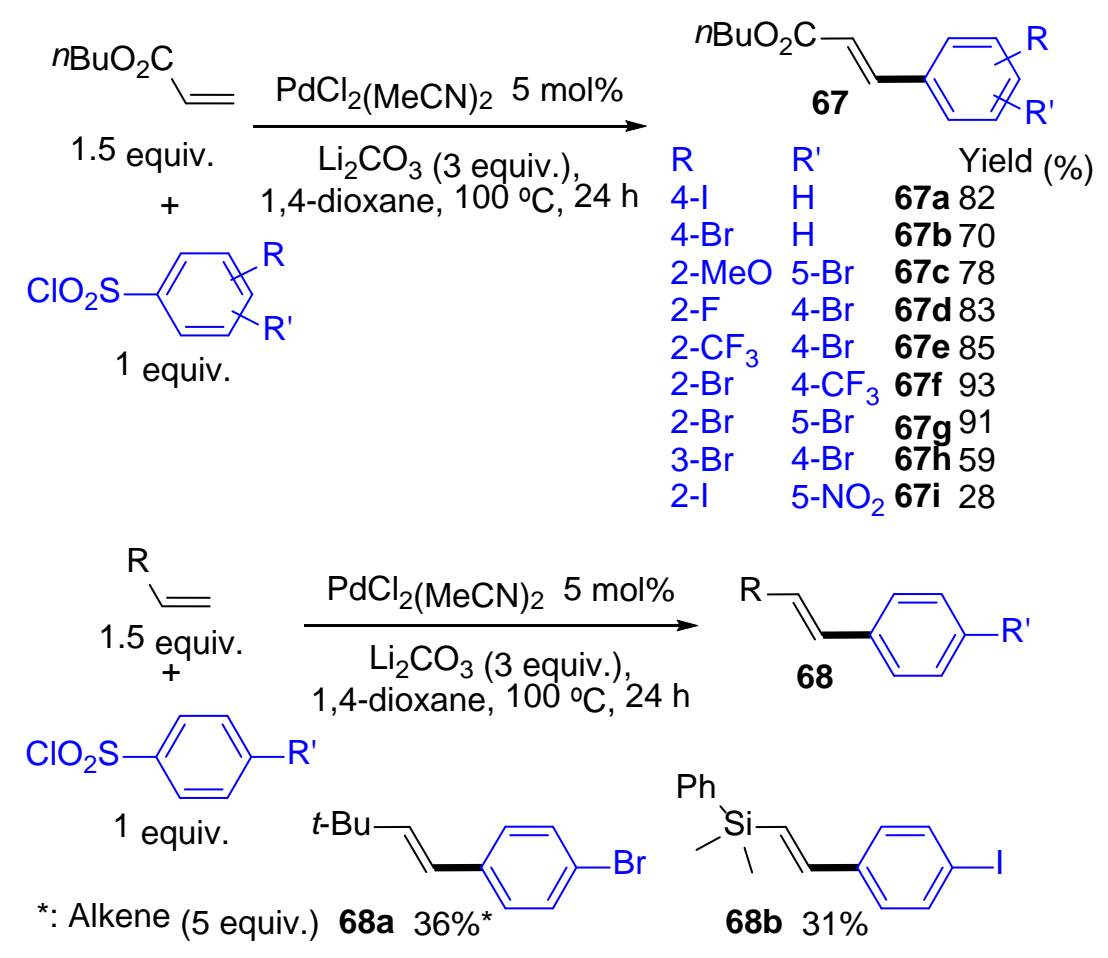

Scheme 38. Heck type reaction using halo-substituted benzenesulfonyl chlorides

In 2005, Dubbaka and Vogel described the use of a rhodium catalyst for the Heck reaction of 4bromobenzenesulfonyl chloride with styrenes (Scheme 39). ${ }^{68}$ For this procedure, no base, phosphine ligand or additive were required and the (E)-1-bromo-4-styrylbenzene $\mathbf{6 9}$ was obtained in $70 \%$ yield. Chloro-substituents were tolerated on styrene, and a 2-phenylethene-1-sulfonyl chloride could also be employed as reaction partners.

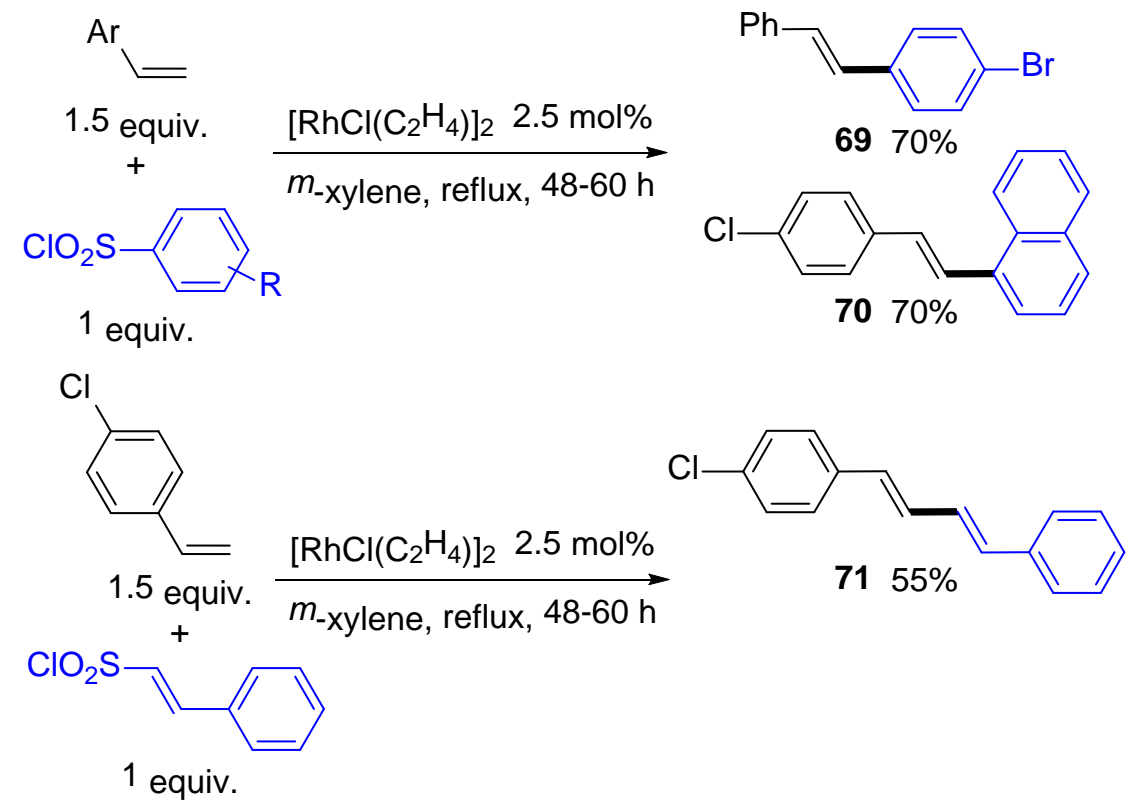


Scheme 39. Heck type reaction using halo-substituted benzenesulfonyl chlorides

Several groups extended the desulfitative Heck reaction to other aryl sources: sodium 4bromobenzenesulfinate (Schemes 40 and 41), benzenesulfonyl hydrazides (Scheme 42) and benzenesulfinic acids (Scheme 43). The major drawback of these procedures is that these three aryl sources are less easily available than benzenesulfonyl chlorides. Moreover, the presence of an oxidant is required. Therefore, they are probably less attractive than the procedures described in the schemes 36-39.

In 2011, Deng et al. described the reaction of an acrylate with sodium 4-bromobenzenesulfinate (Scheme 40, a). ${ }^{69}$ They observed that both the ligand and the solvent played an important role in the reaction. The combination of $\mathrm{PdCl}_{2} / \mathrm{DPEphos}$ (DPEphos: bis(2diphenylphosphinophenyl)ether) in anisole, using molecular oxygen as terminal oxidant gave the desired product 72 in 78\% yield. In 2013, Qi et al. employed a phosphine-free procedure for the vinylation of a wide variety of halo-substituted benzenesulfinates with $n$-butyl acrylate (Scheme 40, b). ${ }^{70}$ They performed the reaction using $5 \mathrm{~mol} \% \operatorname{Pd}(\mathrm{OAc})_{2}$ catalyst with the assistance of a stoichiometric amount of $\mathrm{Cu}(\mathrm{OAc})_{2}$ under simple aerobic conditions at $70{ }^{\circ} \mathrm{C}$. Interestingly, the reaction tolerated a 4-iodo-substituent. Moreover, the position of the bromo- or chloro-substituents on the benzenesulfinate ( $o$-, $m$ - and $p$-) exhibited a minor effect on the reaction yield. 
a)

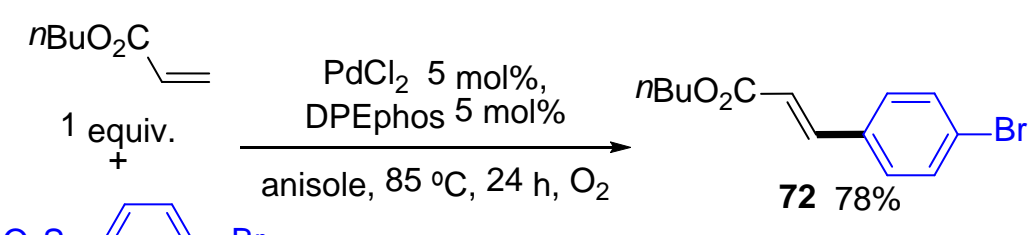<smiles>[NH3+]OS(=O)(=O)c1ccc(Br)cc1</smiles>

2 equiv.

b) $\mathrm{nBuO}_{2} \mathrm{C}$
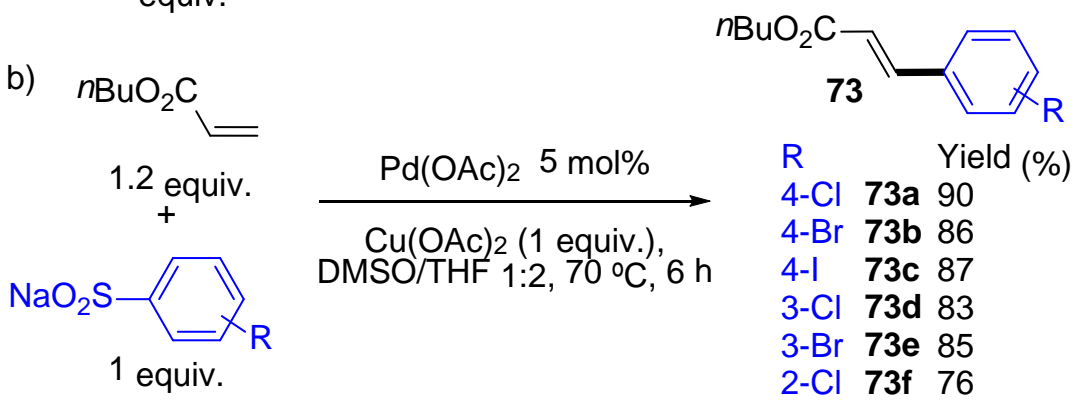

$\begin{array}{ll}\mathrm{R} & \text { Yield (\%) } \\ 4-\mathrm{Cl} & 73 \mathrm{a} 90\end{array}$

$4-\mathrm{Br} 73 \mathrm{~b} 86$

$4-$ I $\quad 73 c 87$

$3-\mathrm{Cl} 73 d 83$

$3-\mathrm{Br} 73 \mathrm{e} 85$

$2-\mathrm{Cl} 73 \mathrm{f} 76$

$2-\mathrm{Br} 73 g 78$

Scheme 40. Heck type reaction using halo-substituted sodium benzenesulfinates

The same year, Taniguchi employed $10 \mathrm{~mol} \% \mathrm{PdCl}_{2} / 2,2$ '-bis(2-oxazoline) as catalyst and a mixture of water, $\mathrm{AcOH}$ and $\mathrm{DMF}$ as the solvent with $\mathrm{NH}_{4} \mathrm{PF}_{6}$ as additive to promote this coupling reaction (Scheme 41). ${ }^{71}$ These reaction conditions afforded the 1,2-diphenylethenes 74 with an $E$ configuration in good yields using 4-chlorobenzenesulfinate with styrene or benzenesulfinate with 4-chlorostyrene.

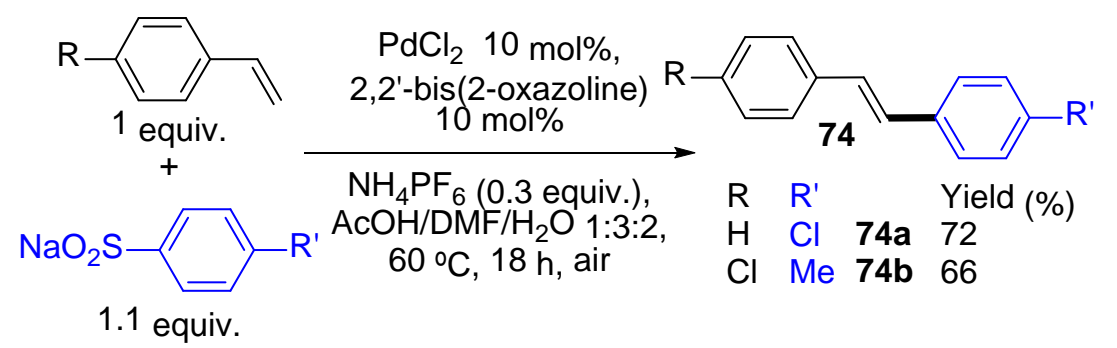

Scheme 41. Heck type reaction using halo-substituted sodium benzenesulfinates

In 2012, Tian et al. described the use of halo-substituted benzenesulfonyl hydrazides for Heck type reaction with styrene derivatives (Scheme 42, a). ${ }^{72}$ They reported that the treatment of chloro- and bromo-benzenesulfonyl hydrazides with styrene or 4-chlorostyrene using $10 \mathrm{~mol} \%$ of $\mathrm{Pd}(\mathrm{OAc})_{2}$ in DMSO/nitromethane under normal pressure of molecular oxygen as oxidant afforded the halo- 
substituted 1,2-diphenylethenes 75 in good yields with exclusive E selectivity. Recently, Yuen, So and Kwon employed $\mathrm{Pd}(\mathrm{OAc})_{2}$ associated to a pyridine derivative as ligand and air as oxidant for such couplings (Scheme 42, b). ${ }^{73}$ Again, the coupling products 76 were obtained in good yields.
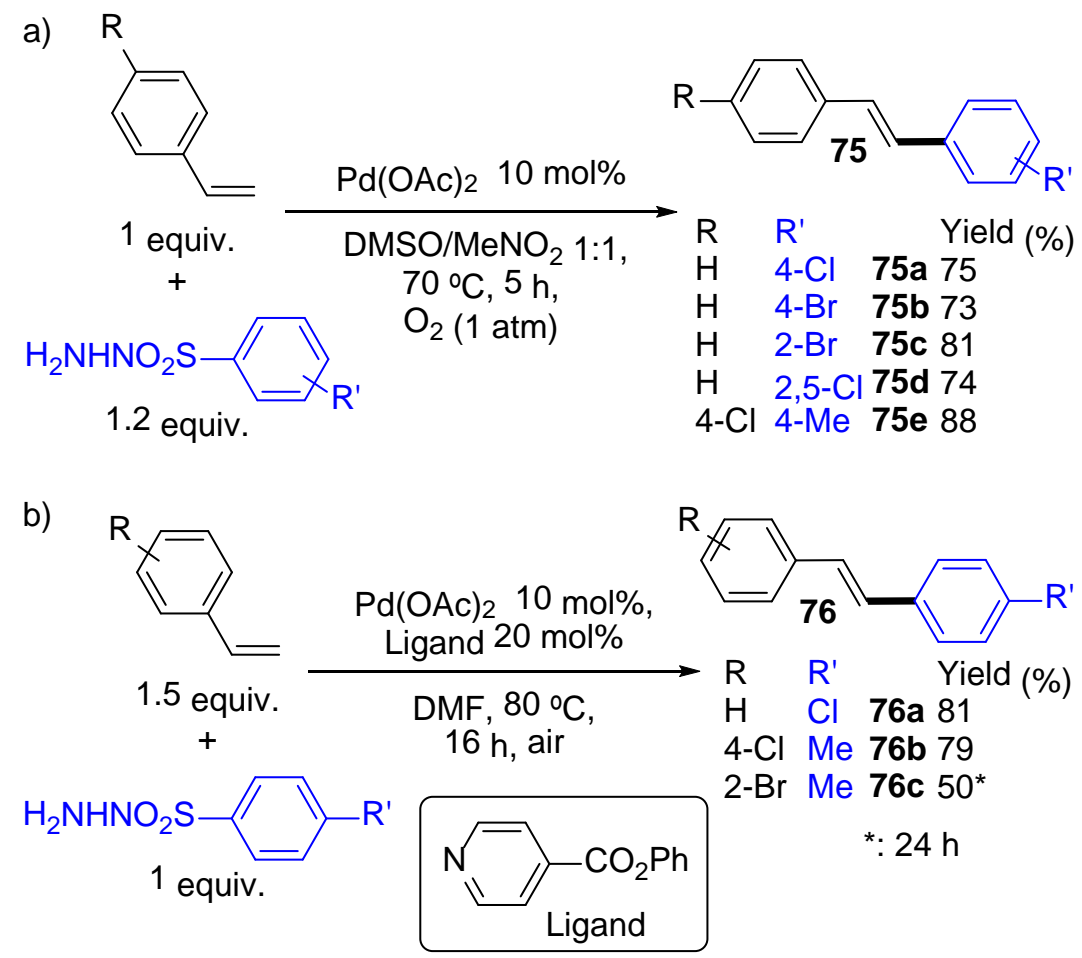

Scheme 42. Heck type reaction using halo-substituted benzenesulfonyl hydrazides

Wang and Miao investigated the Heck type reaction with benzenesulfinic acids (Scheme 43). ${ }^{74}$ They employed $\mathrm{Pd}(\mathrm{OAc})_{2}$ as catalyst and copper(II) acetate as oxidant. A set of benzenesulfinic acids including 4-chlorobenzenesulfinic acid were successfully coupled with 4-chlorostyrene affording products 77 in 67-83\% yields. Moreover, under these conditions, the coupling of 4chlorobenzenesulfinic acid with an acrylate also provided the chloro-substituted Heck type product 78 in high yield. 


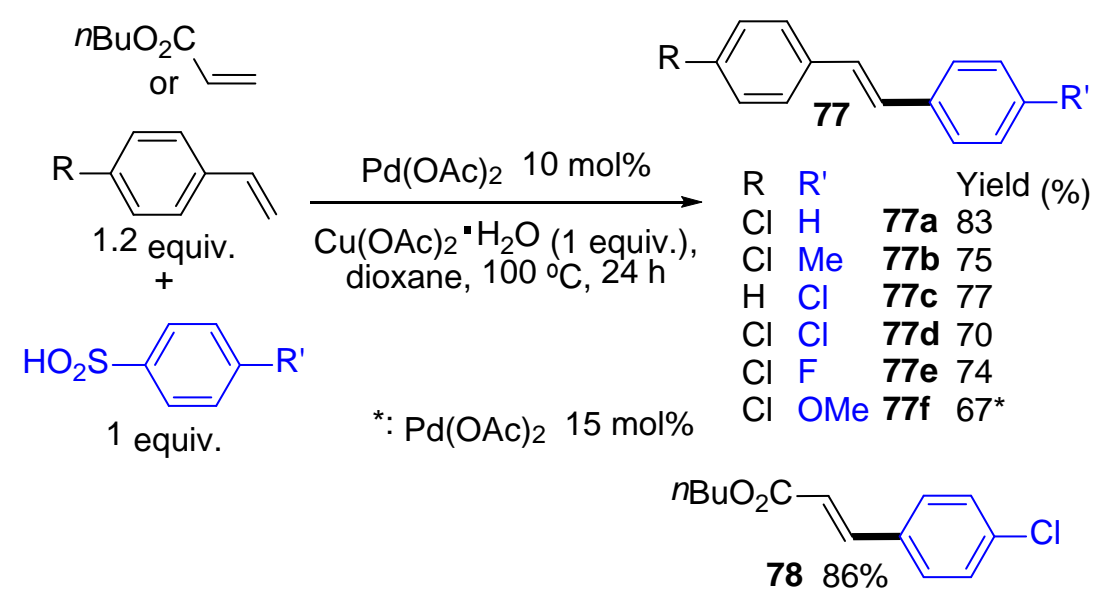

Scheme 43. Heck type reaction using halo-substituted benzenesulfinic acids

Wu, Jiang et al. reported in 2015 the Pd-catalyzed desulfitative oxidative Heck-type reaction of sodium benzenesulfinates with allylic alcohols (Scheme 44). ${ }^{75}$ They employed Pd(TFA) 2 associated to a phenanthroline ligand as catalyst and $\mathrm{Cu}(\mathrm{TFA})_{2}$ as oxidant. This method provides a straightforward access to the halo-substituted $\beta$-aryl ketones $\mathbf{7 9}$ in moderate to good yields, as they demonstrated the compatibility of this reaction with iodo- and bromo-functionalities on the benzenesulfinate.

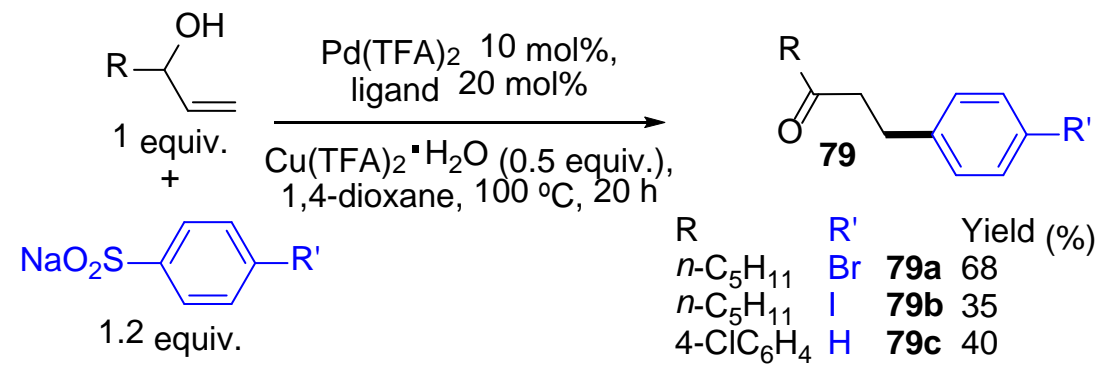

Ligand: 4,7-dimethyl-1,10-phenanthroline

Scheme 44. Heck-type reaction of sodium benzenesulfinates with allylic alcohols

The Pd-catalyzed desulfitative Heck coupling of benzenesulfonyl chlorides with glycals for the stereoselective synthesis of the 2,3-deoxy-C-aryl glycosides $\mathbf{8 0}$ was investigated by Mukherjee et al. in 2015 (Scheme 45, a). ${ }^{76}$ Their strategy was based on use of OAc as leaving group. The use of $10 \mathrm{~mol} \% \mathrm{PdCl}_{2}\left(\mathrm{PPh}_{3}\right)_{2}$ catalyst, $\mathrm{Li}_{2} \mathrm{CO}_{3}$ base in dioxane at $140{ }^{\circ} \mathrm{C}$ was found to be the optimal 
conditions. Two months later, Ma, Liu et al. described the same reaction using sodium benzenesulfinates as aryl sources (Scheme 45 , b). ${ }^{77} \mathrm{CuCl}_{2}$ was used as the oxidant and the reaction was performed under air atmosphere.

a)<smiles>CC(=O)OC[C@H]1OC=C[C@H](OC(C)=O)[C@@H]1OC(C)=O</smiles>

1 equiv.

$\mathrm{PdCl}_{2}\left(\mathrm{PPh}_{3}\right)_{2} 10 \mathrm{~mol} \%$

$+$

$\mathrm{Li}_{2} \mathrm{CO}_{3}$ (2 equiv.),

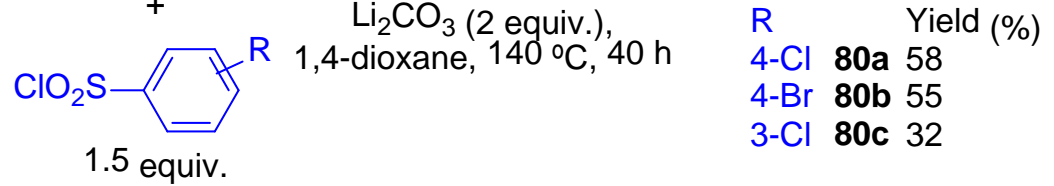

b)<smiles>CC(=O)OC[C@H]1OC=C[C@H](OC(C)=O)[C@H]1OC(C)=O</smiles>

1 equiv.

$+$ $\mathrm{CuCl}_{2}$ (1 equiv.),
$\mathrm{LiCl}\left(1\right.$ equiv.), MeCN, $75{ }^{\circ} \mathrm{C}$,
$8 \mathrm{~h}$, air (balloon)

4 equiv.
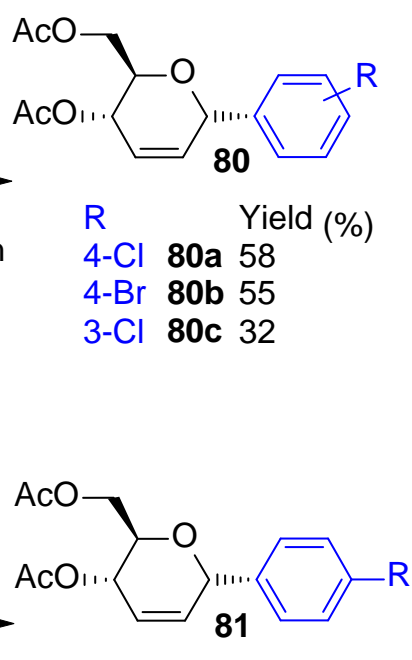

$\mathrm{R} \quad$ Yield (\%)

Cl 81a 74

$\mathrm{Br}$ 81b 58

Scheme 45. Heck coupling of benzenesulfonyl chlorides with glycals

They proposed the following mechanism for this reaction: oxidative addition of the benzenesulfonyl chloride to $\mathrm{Pd}(0)$ to give $\mathbf{B}$ followed by elimination of $\mathrm{SO}_{2}$ to form $\mathrm{Pd}(\mathrm{II})$ species $\mathbf{C}$ (Figure 4). The addition of this Pd(II) species to the double bond of the glycal triacetate would generate $\pi$ complex D. Finally, reductive elimination under basic conditions affords the $C$-aryl glycoside and regenerates $\mathbf{A}$. 


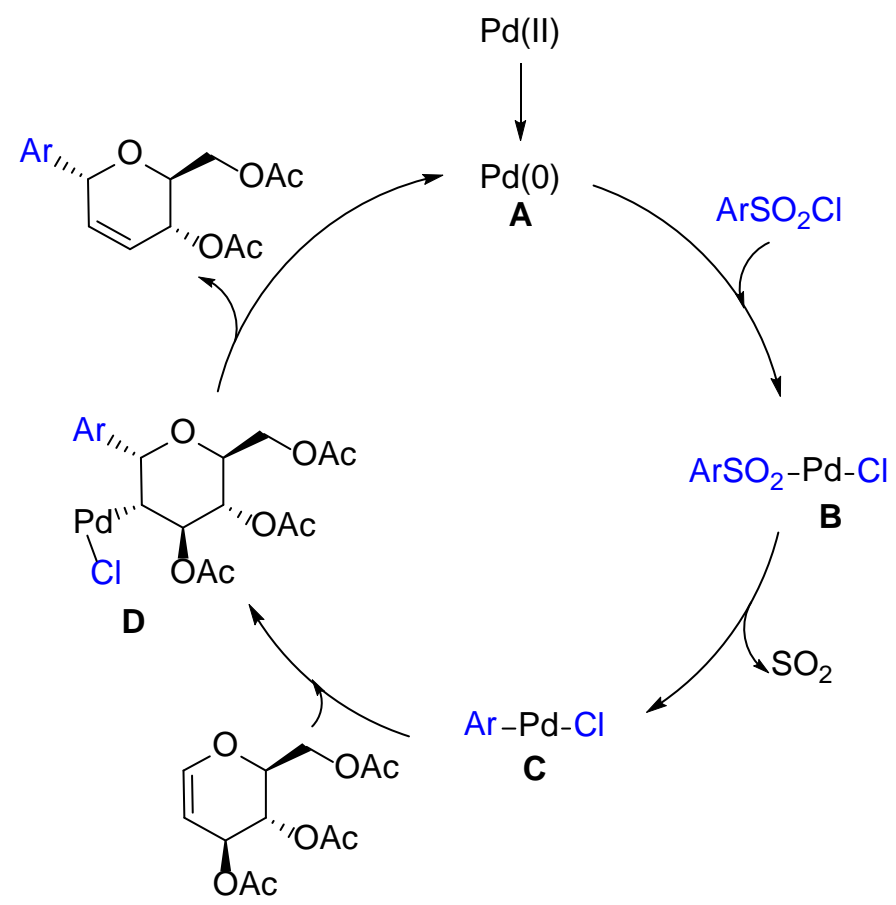

Figure 4. Proposed mechanism

\subsection{Reductive Heck reaction}

Li, Duan et al. described in 2012 the Pd(II)-catalytic desulfitative conjugate addition of 4-chloroand 4-bromo-substituted benzenesulfinic acids with $\alpha, \beta$-unsaturated carbonyl compounds (Scheme 46, a). ${ }^{78}$ These reactions were performed with $5 \mathrm{~mol} \%$ of $\mathrm{Pd}(\mathrm{OAc})_{2} / 2,2$ '-bipyridine as catalyst, in aqueous methanol in the presence of sulfuric acid at $90{ }^{\circ} \mathrm{C}$. Only the conjugate addition products 82 were formed, as they never detected the Mizoroki-Heck type coupling product. They succeeded to identify reacting intermediates including an aryl $\mathrm{Pd}(\mathrm{II})$-sulfinic species and a C=O-Pd complex, which were captured by ESI-MS/MS analysis. The same year, Deng et al. reported the conjugate addition of sodium benzenesulfinates with benzylideneacetone derivatives in 1,4-dioxane/ $\mathrm{H}_{2} \mathrm{O} / \mathrm{TFA}$ (2:2:1) by using $\mathrm{Pd}(\mathrm{OH})_{2}$ as catalyst in the presence of DABCO (Scheme $\left.46, \mathrm{~b}\right){ }^{79}$ Bromo- and chloro-substituents were tolerated on both coupling partners, affording the halo-substituted 4,4diarylbutan-2-ones $\mathbf{8 3}$ in good yields. 
a)<smiles>O=C1C=CCCC1</smiles>

1 equiv.<smiles>[R]c1ccc(S(=O)(=O)O)cc1</smiles>

1.5 equiv.

b)<smiles>CC(=O)/C=C/c1ccc(P)cc1</smiles>

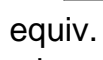<smiles>[111I-]</smiles><smiles>[R]c1ccc(S(=O)(=O)O[Na])cc1</smiles>

2 equiv.
$\mathrm{Pd}(\mathrm{OAc})_{2} 5 \mathrm{~mol} \%$ 2,2'-bipyridine $5 \mathrm{~mol} \%$ $\mathrm{H}_{2} \mathrm{SO}_{4} 50 \%$ (2 equiv.), $\mathrm{MeOH}, 90{ }^{\circ} \mathrm{C}, 15 \mathrm{~h}$, air $R$

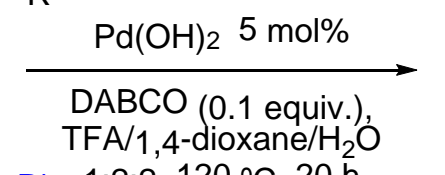
$1: 2: 2,120{ }^{\circ} \mathrm{C}, 20 \mathrm{~h}$

Scheme 46. Pd-catalyzed desulfitative conjugate additions

One year later, Nagaiah et al. developed a Pd-catalyzed desulfitative Heck-Type reaction from sodium benzenesulfinates and Baylis-Hillman adducts (Scheme 47). ${ }^{80}$ They obtained the highly functionalized $\alpha$-benzyl- $\beta$-ketoester derivatives $\mathbf{8 4}$ in good to excellent yields from chloro- and bromo-substituted benzenesulfinates. A bromo-substituent on the Baylis-Hillman adduct was also tolerated.

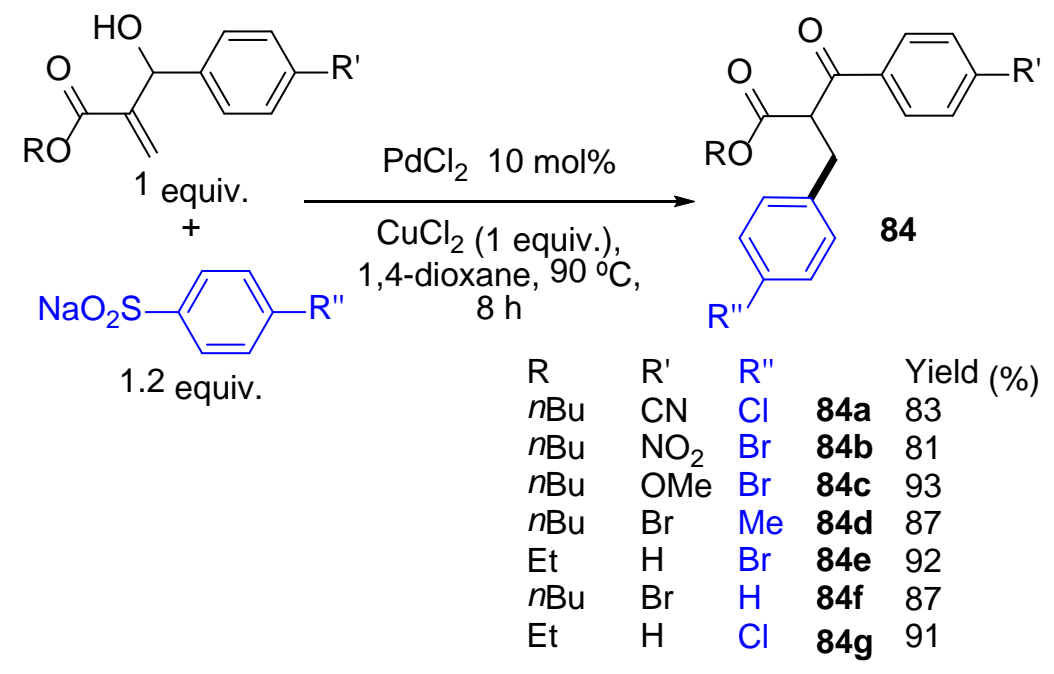

Scheme 47. Pd-catalyzed desulfitative conjugate additions 
The Pd-catalyzed reaction of halo-substituted benzenesulfonyl chlorides with enones was investigated by our group (Scheme 48). ${ }^{81}$ The reaction with benzalacetone or $\beta$-ionone was found to afford selectively the conjugate addition products $\mathbf{8 5}$ and $\mathbf{8 6}$ instead of the expected Heck type products. The reaction tolerated chloro-, bromo- and even iodo-substituents on the benzenesulfonyl chloride.

a)
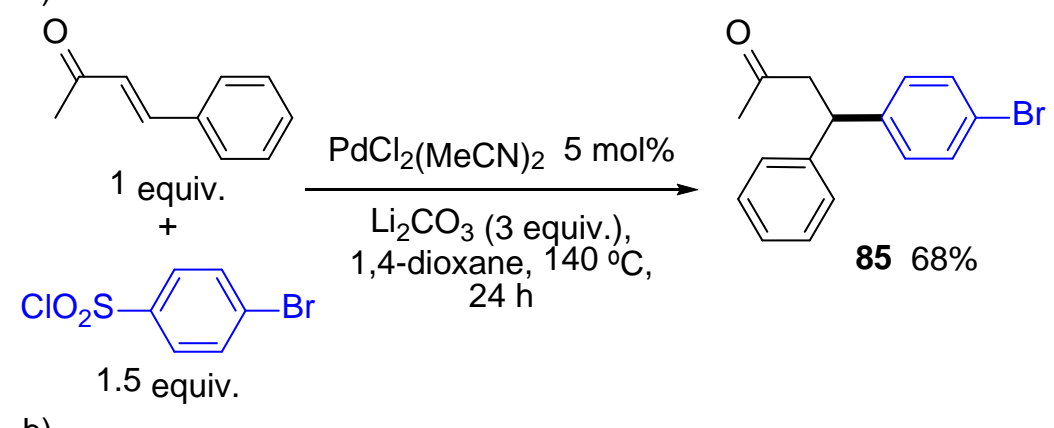

b)
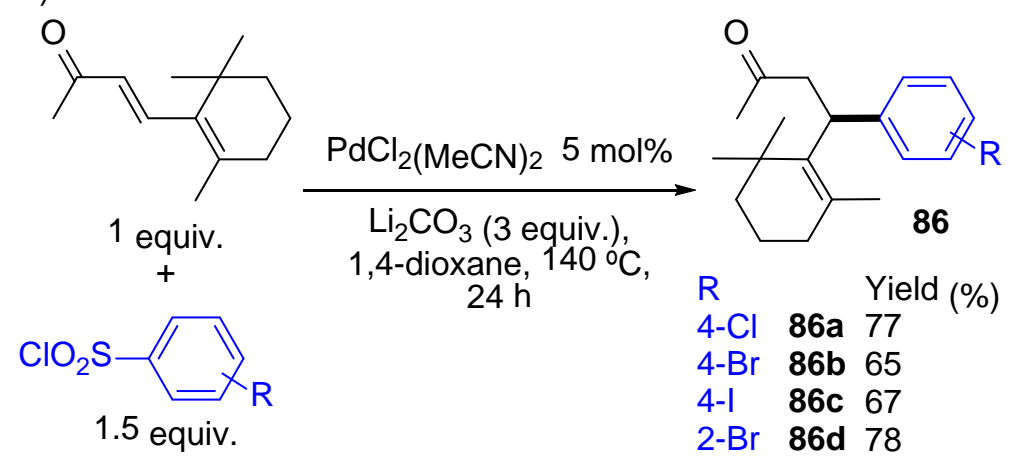

Scheme 48. Pd-catalyzed desulfitative conjugate additions with benzenesulfonyl chlorides

\subsection{Ring-opening of oxabenzonorbornadienes}

Yang et al. described in 2016 the Pd-catalyzed syn-stereocontrolled ring-opening reaction of oxabenzonorbornadienes with sodium benzenesulfinates for the preparation of cis-2-aryl-1,2dihydronaphthalen-1-ols 87 (Scheme 49, a). ${ }^{82 a}$ The reaction tolerated several functional groups including bromo- and chloro-substituents on the benzenesulfinate and bromo-substituents on the oxabenzonorbornadiene. In 2017, this group employed a platinum catalyst instead of a palladium 
catalyst to promote this reaction (Scheme $49, \mathrm{~b}) .{ }^{82 \mathrm{~b}}$ The ring-opening products $\mathbf{8 8}$ were produced in slightly lower yields than with the palladium catalyst.

a)<smiles>[R4]c1cccc2c1[C@H]1C=C[C@H]2O1</smiles><smiles>[R16]c1ccccc1S(=O)(=O)O</smiles><smiles>[R]c1cccc([C@@H]2C=Cc3ccccc3[C@H]2O)c1</smiles>

$\mathrm{R}^{\prime} \quad$ Yield (\%)

4-Cl 87a 96

4- $\mathrm{Br}$ 87b 69

$3-\mathrm{Cl}$ 87c 98

2-Cl 87d 93

b)<smiles>[R4]c1cccc2c1C1C=CC2C1(C)C</smiles><smiles>[R]c1ccc(S(=O)(=O)O[Na])cc1</smiles>

3 equiv.<smiles>[R]c1cccc(C2C=Cc3ccccc3C2O)c1</smiles>

$\mathrm{R}^{\prime} \quad$ Yield (\%)

4-Cl 88a 87

4- $\mathrm{Br}$ 88b 62

$3-\mathrm{Cl} \mathbf{8 8 c} 90$

2-Cl 88d 83

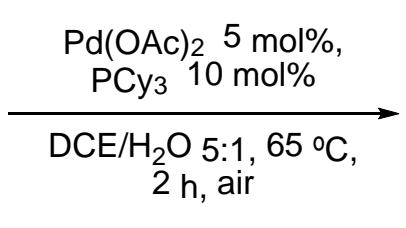<smiles>[R]c1cccc([C@H]2C=Cc3c([R])cccc3[C@@H]2O)c1</smiles>

87<smiles>[R]c1ccc([C@H]2C=Cc3cc(Br)c(Br)cc3[C@@H]2O)cc1</smiles>

$\mathrm{R}^{\prime} \quad$ Yield (\%)

$\mathrm{Cl}$ 87e 93

$\mathrm{Br} 87 f 75$<smiles>[R]c1cccc([C@@H]2C=Cc3c(OC)ccc(OC)c3[C@@H]2O)c1</smiles>

$$
\begin{array}{lll}
\mathrm{R}^{\prime} & & \text { Yield (\%) } \\
4-\mathrm{Cl} & \mathbf{8 7 g} & 88 \\
4-\mathrm{Br} & \mathbf{8 7 h} & 57 \\
3-\mathrm{Cl} & \mathbf{8 7 i} & 98 \\
2-\mathrm{Cl} & \mathbf{8 7 j} & 92
\end{array}
$$

Scheme 49. Pd- and Pt-catalyzed ring-opening of oxabenzonorbornadienes with sodium benzenesulfinates

A mechanism for this Pd-catalyzed ring-opening reaction was proposed (Figure 5). In the first step, $\operatorname{Pd}(0)$ species $\mathbf{A}$ is generated from $\mathrm{Pd}(\mathrm{OAc})_{2}$ through homo-coupling of sodium benzenesulfinates. Then, the oxidative addition of oxabenzonorbornadiene to $\mathrm{Pd}(0)$ produces ( $\pi$-allyl)-palladium(II) 
complex $\mathbf{B}$, followed by an exchange reaction with sodium benzenesulfinates to give $\mathbf{C}$. Then, desulfonylation affords (aryl)( $\pi$-allyl)Pd(II) intermediate D. Finally, reductive elimination affords the product with regeneration of the $\operatorname{Pd}(0)$ species $\mathbf{A}$.

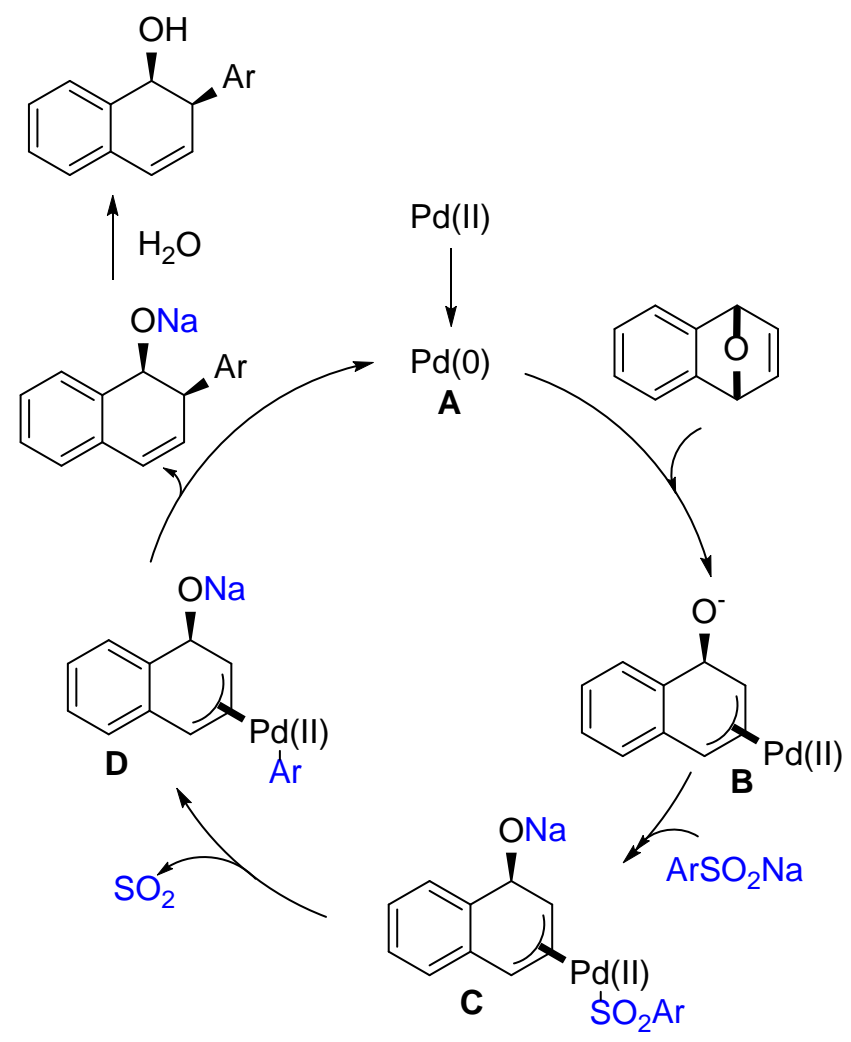

Figure 5. Proposed mechanism

\subsection{Synthesis of 4-aryl-1,2,3,4-tetrahydroquinolines}

In 2016, our group developed a Pd-catalyzed cascade reaction allowing an efficient synthesis of 4aryl-1,2,3,4-tetrahydroquinolines $\mathbf{8 9}$ from $N$-allyl- $N$-arylsulfonamides and benzenesulfonyl chlorides (Scheme 50). ${ }^{83}$ In the course of this reaction, two $\mathrm{C}\left(\mathrm{sp}^{2}\right)-\mathrm{C}\left(\mathrm{sp}^{3}\right)$ bonds were formed via the activation of $\mathrm{C}\left(\mathrm{sp}^{2}\right)-\mathrm{H}$ bonds. The reaction proceeded using $\mathrm{PdCl}_{2}$ catalyst, $\mathrm{Li}_{2} \mathrm{CO}_{3}$ base and $\mathrm{CuBr}$ as additive, and tolerated chloro- and bromo-substituents on the benzenesulfonyl chloride and bromo- and iodo-substituents on the aniline derivative. 


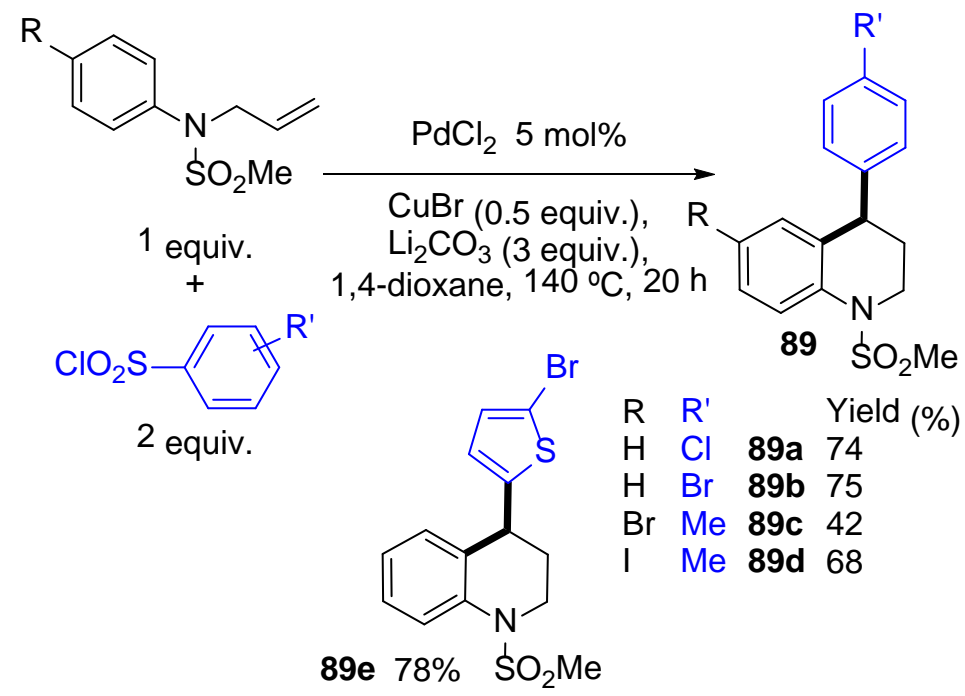

Scheme 50. Pd-catalyzed cascade reaction of $N$-allyl- $N$-arylsulfonamides with benzenesulfonyl chlorides

The mechanism was not elucidated, but on the basis of preliminary mechanistic studies and on previous reports, our group proposed a catalytic cycle (Figure 6). The first step is probably the oxidative addition of $\mathrm{ArSO}_{2} \mathrm{Cl}$ to a $\mathrm{Pd}(0)$ species and release of $\mathrm{SO}_{2}$ to afford a $\mathrm{Pd}(\mathrm{II})$ intermediate A, although a $\mathrm{Pd}(\mathrm{II}) / \mathrm{Pd}(\mathrm{IV})$ mechanism is also possible. Then, coordination of the $\mathrm{N}$-allyl- $\mathrm{N}$ phenylmethanesulfonamide followed by the insertion of the allyl $\mathrm{C}=\mathrm{C}$ bond into the Ar-Pd bond occurs gives C. Next, a C-H bond activation would afford six membered palladacycle D. After rearrangement and reductive elimination, the 1,2,3,4-tetrahydroquinoline derivative is produced with regeneration of a $\operatorname{Pd}(0)$ species. 


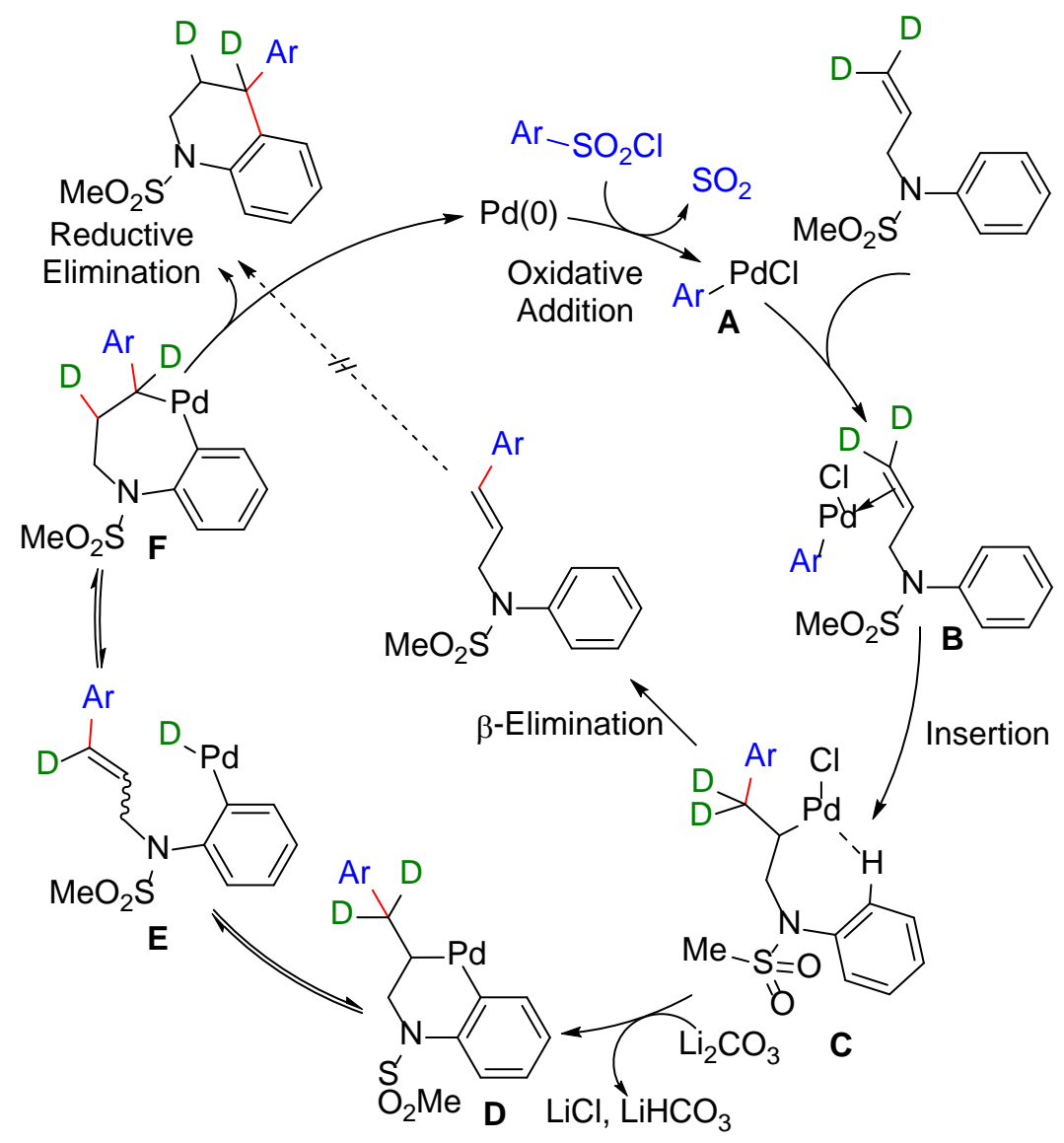

Figure 6. Proposed catalytic cycle

\subsection{Heck-type alkylation/aryl migration/desulfonylation}

Li et al. reported in 2015 a Pd(II)-catalyzed alkene oxidative difunctionalization, initiated by Heck insertion, for the synthesis of products $\mathbf{9 0}$ and $\mathbf{9 1}$ containing a quaternary stereocenter (Scheme 51). ${ }^{84}$ The reaction involved an oxidative Heck-type alkylation, an aryl migration, and a desulfonylation. A chloro-substituent on the benzenesulfonyl moiety was tolerated. 


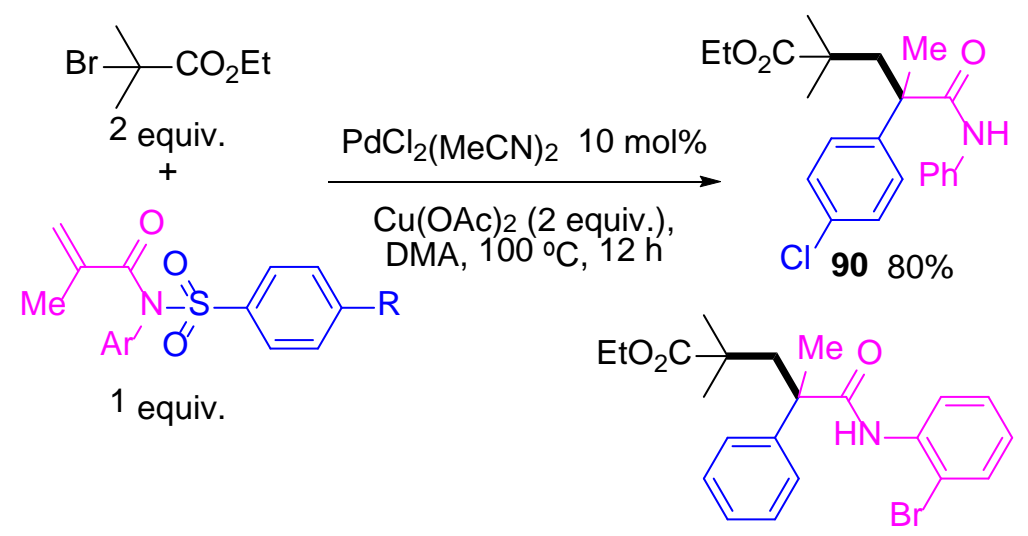

$9158 \%$

Scheme 51. Pd-catalyzed alkylation/aryl migration/desulfonylation

\section{Reaction with alkynes}

\subsection{Hydroarylation of alkynes}

The Pd-catalyzed desulfitative hydroarylation of alkynes with sodium 4-halobenzenesulfinates has been described by Deng et al. in 2013 (Scheme 52). ${ }^{85}$ In the presence of 5 mol\% Pd(OAc) 2 associated to 10 mol\% 1,8-naphthalenediamine as catalytic system under argon, diphenylacetylene was hydroarylated to afford the corresponding trisubstituted alkenes $\mathbf{9 2}$ in good stereoselectivities and yields. 4-Bromo- and 4-chloro-benzenesulfinates were successfully employed, without cleavage of these C-halo bonds. Trifluoroacetic acid played an important role in this reaction, and its replacement by acetic acid decreased the reactions yields.

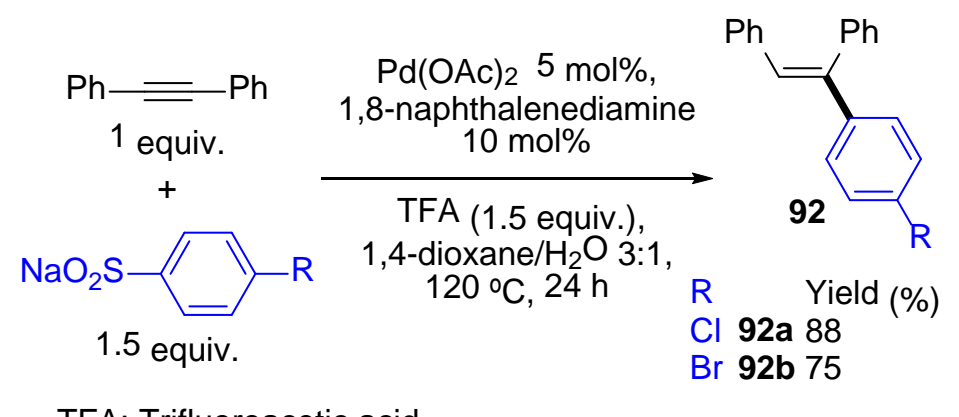

Scheme 52. Pd-catalyzed desulfitative hydroarylation of an alkyne 


\subsection{Sonogashira type cross-coupling}

The Pd-catalyzed Sonogashira type cross-coupling of sodium 4-halobenzenenesulfinates with terminal alkynes for the formation of internal alkynes 93 was reported by Jiang et al. in 2014 (Scheme 53). ${ }^{86}$ This transformation was found to proceed under ligand-free conditions, and $\mathrm{PdCl}_{2}$ was the optimal palladium source. The nature of the solvent exhibited a strong effect on this reaction and DMSO was found to be the best medium for such couplings. The reaction with 1ethynyl-4-methoxybenzene tolerated bromo- and chloro-substituents on the benzenenesulfinate.

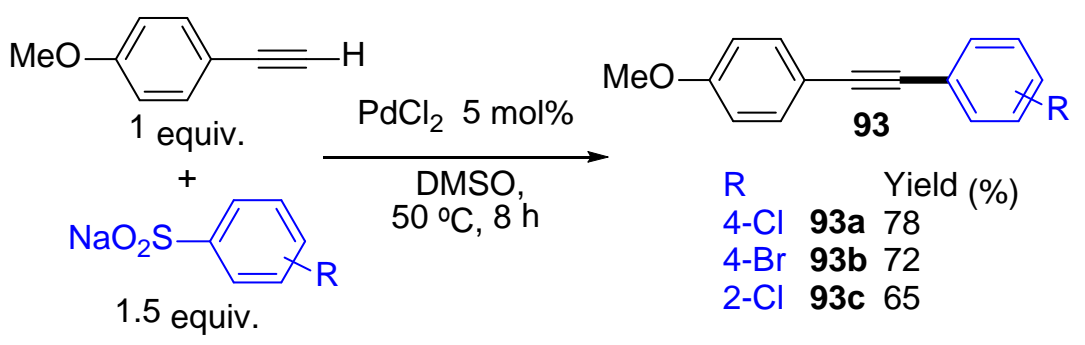

Scheme 53. Pd-catalyzed Sonogashira cross-couplings of sodium 4-halobenzenenesulfinates

Three years later, Zhou et al. extended the reaction to benzenesulfonyl hydrazides (Scheme 54). ${ }^{87}$ A wide scope of terminal alkynes was reacted with 4-bromobenzenesulfonyl hydrazide using 5 mol\% $\mathrm{Pd}(\mathrm{OAc})_{2} / \mathrm{dppb}$ as catalyst and $\mathrm{Cu}(\mathrm{OAc})_{2}$ as oxidant, affording the bromo-substituted internal alkynes 94 in good to high yields. They also employed 2- and 3-bromobenzenesulfonyl hydrazides for coupling with a phenylacetylene derivative. Moreover, from 4-iodobenzenesulfonyl hydrazide and 1-ethynyl-4-bromobenzene, the corresponding dihalo-substituted 1,2-diphenylethyne $\mathbf{9 4 k}$ was obtained in $48 \%$ yield. In all cases, only the coupling reaction involving the sulfonylhydrazide functional groups occurred. Finally, they prepared more complex molecules from some of the prepared halo-substituted 1,2-diphenylethynes through Suzuki, Sonogashira and Heck reactions. 


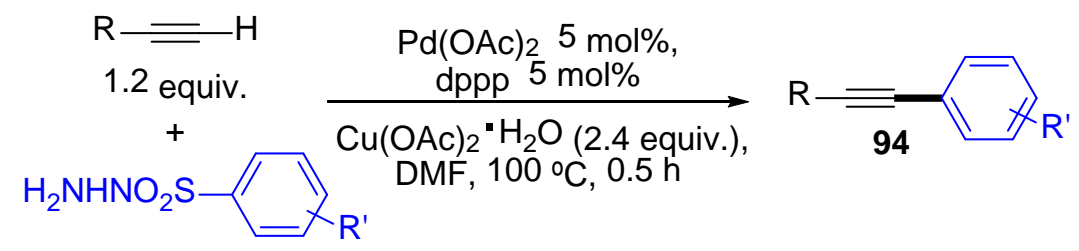

1 equiv.
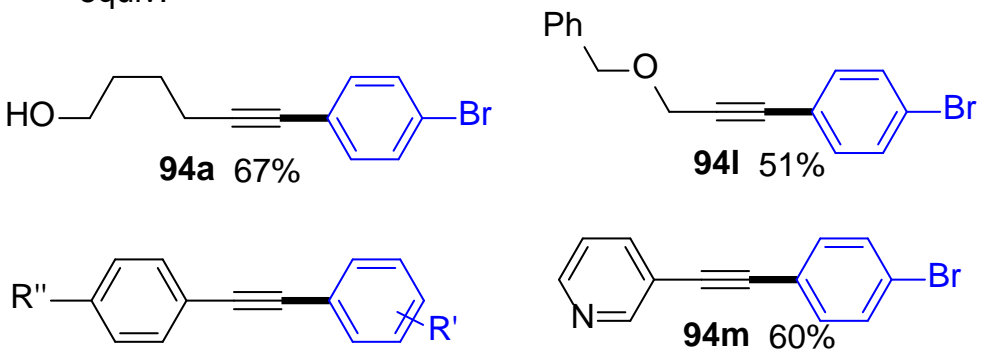

$\begin{array}{llll}\mathrm{R} " & \mathrm{R} & & \text { Yield (\%) } \\ \mathrm{CN} & 4-\mathrm{Br} & \mathbf{9 4 b} & 62 \\ \mathrm{Br} & 4-\mathrm{Br} & \mathbf{9 4 c} & 80 \\ n-\mathrm{Pr} & 3-\mathrm{Br} & \mathbf{9 4 d} & 72 \\ n-\mathrm{Pr} & 2-\mathrm{Br} & \mathbf{9 4 e} & 34 \\ \mathrm{Br} & \mathrm{H} & \mathbf{9 4 f} & 75 \\ \mathrm{Br} & 4-\mathrm{OMe} & \mathbf{9 4 g} & 57 \\ \mathrm{Br} & 4-\mathrm{F} & \mathbf{9 4 h} & 85 \\ \mathrm{Br} & 4-\mathrm{Cl} & \mathbf{9 4 i} & 81 \\ \mathrm{Br} & 4-\mathrm{NO}_{2} & \mathbf{9 4 j} & 92 \\ \mathrm{Br} & 4-\mathrm{I} & \mathbf{9 4 k} & 48\end{array}$
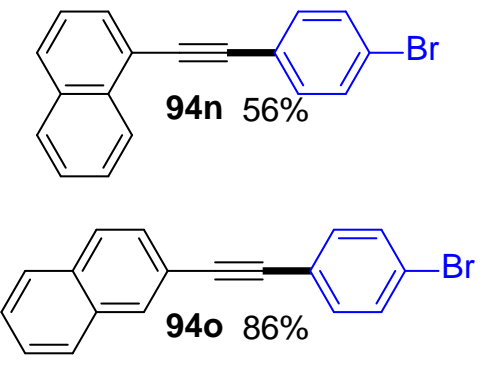

Scheme 54. Pd-catalyzed Sonogashira cross-couplings of benzenesulfonyl hydrazides

\section{Reaction with nitriles}

\subsection{Carbonylation}

In 2011, Li, Deng et al. reported the synthesis of aryl ketones via Pd-catalyzed addition of sodium benzenesulfinates to nitriles (Scheme 55, a). ${ }^{88}$ For these reactions, a combination of $\mathrm{Pd}(\mathrm{OH})_{2}$ and 1,10-phenanthroline was used as catalyst. They observed that the reaction of sodium 4bromobenzenesulfinate with 4-methylbenzonitrile in 1,4-dioxane/water (3:2) in the presence of trifluoroacetic acid in air gave the bromo-substituted benzophenone derivative 95 in $50 \%$ yield. Under the same conditions, a 4-chloro-substituted benzonitrile reacted with sodium $p$ toluenesulfinate to give the corresponding chloro-substituted benzophenone $\mathbf{9 6}$ in $73 \%$ yield. Then, Miao and Wang extended the reaction to benzenesulfinic acids (Scheme 55, b). ${ }^{89}$ The reaction of 
benzonitriles and benzenesulfinic acids was promoted by $\mathrm{Pd}(\mathrm{OAc})_{2} / 2,2$ '-bipyridine catalyst and concentrated $\mathrm{H}_{2} \mathrm{SO}_{4}$ in isobutyl alcohol to afford the halo-substituted benzophenones 97 via hydrolysis of the ketimine intermediates. The reaction tolerated bromo- and chloro-substituents on the benzonitrile moiety and chloro-substituents on the benzenesulfinic acid. Moreover, they obtained higher yields than those reported by Li and Deng (Scheme 55a).

a)
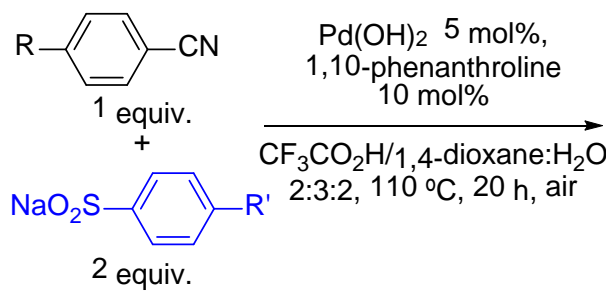

b)
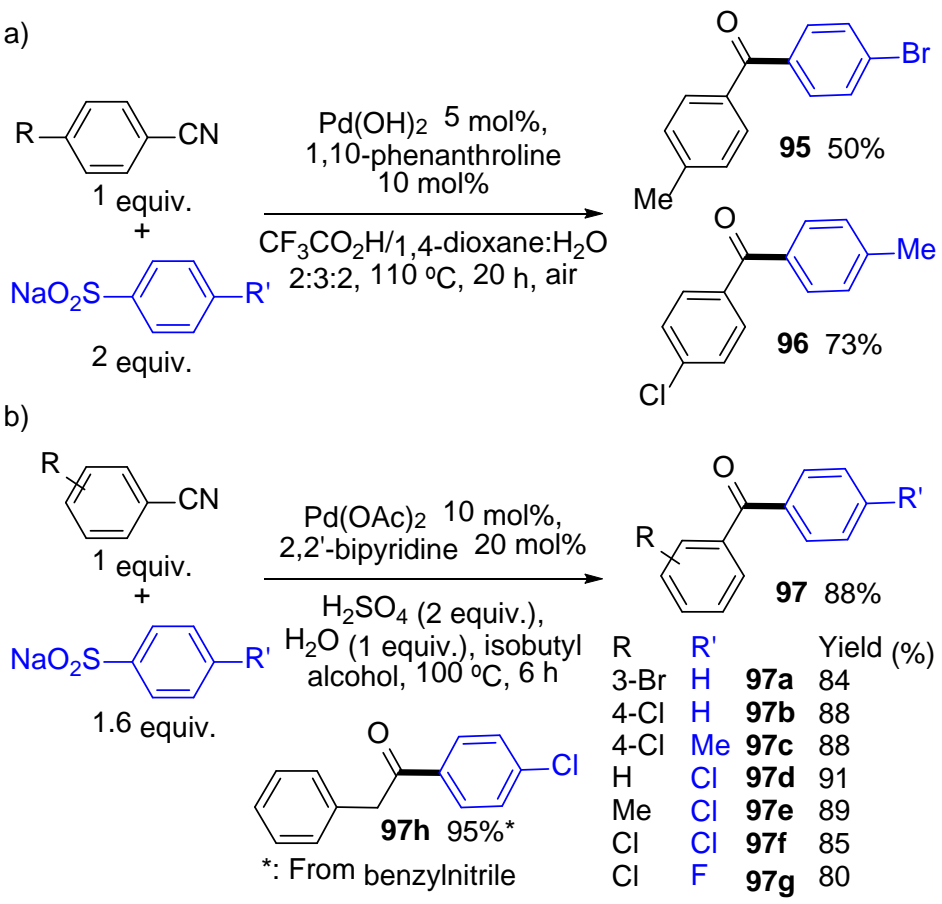

Scheme 55. Pd-catalyzed addition of sodium benzenesulfinates to nitriles

In 2011, Lahred et al. reported a Pd-catalyzed microwave-promoted procedure to synthesize aryl ketones and from benzenesulfinates and nitriles (Scheme 56). ${ }^{90,91} \mathrm{Pd}\left(\mathrm{O}_{2} \mathrm{CCF}_{3}\right)_{2}$, which was found to be more efficient than $\mathrm{Pd}\left(\mathrm{O}_{2} \mathrm{CCH}_{3}\right)_{2}$ as Pd-source, was associated to 6-methyl-2,2'-bipyridyl ligand. They evaluated the scope of the reaction by employing a set of sodium 4chlorobenzenesulfinates to react with acetonitrile under their optimized conditions. They also employed a wide variety of halo-substituted benzonitriles. 2-, 3-, And also 4-bromo-substituents on benzonitriles were tolerated affording the bromo-substituted benzophenone derivatives $\mathbf{9 8}$ and $\mathbf{9 9}$ in good yields. 


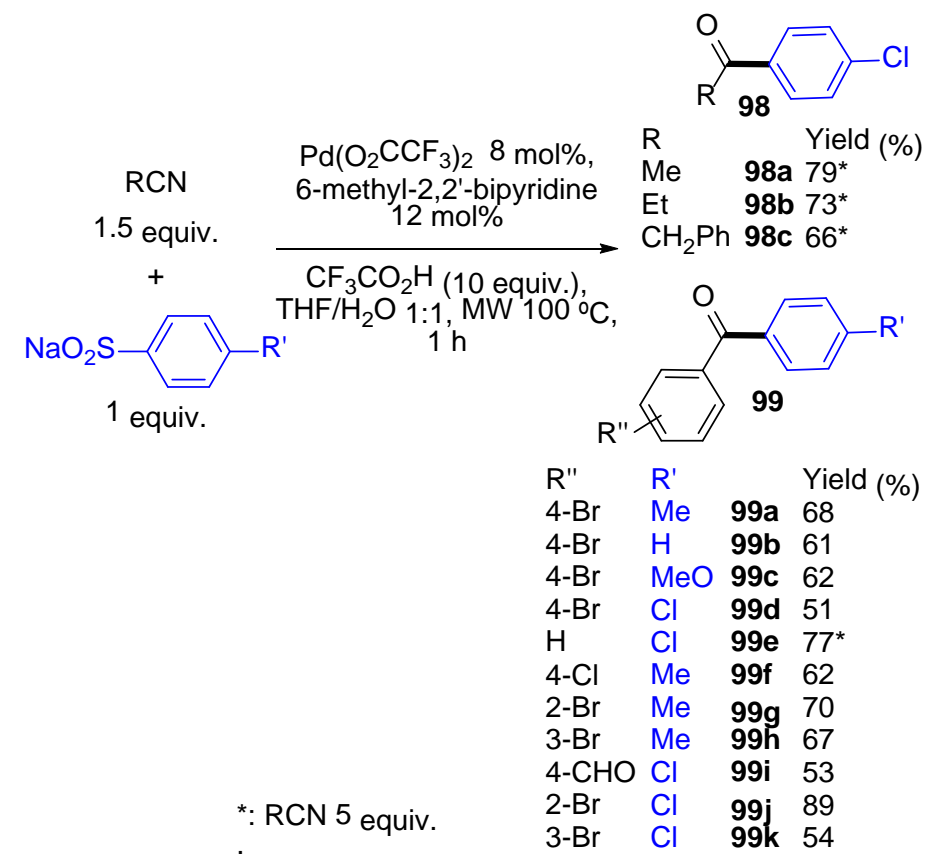

Scheme 56. Pd-catalyzed addition of sodium benzenesulfinates to nitriles

\subsection{Cyanation}

In 2012, Cheng et al. developed a Pd-catalyzed desulfitative cyanation of benzenesulfonyl chlorides, affording benzonitriles (Scheme 57). ${ }^{92}$ This reaction tolerated bromo- and chlorosubstituents on the benzensulfonyl chlorides. After screening of several catalysts, copper sources and bases, they found that the use of $\mathrm{PdCl}_{2}(\mathrm{MeCN})_{2}$ associated to $\mathrm{Cu}(\mathrm{acac})_{2}$ and $\mathrm{Na}_{2} \mathrm{CO}_{3}$ furnished the halo-substituted benzonitriles $\mathbf{1 0 0}$ in good yields.

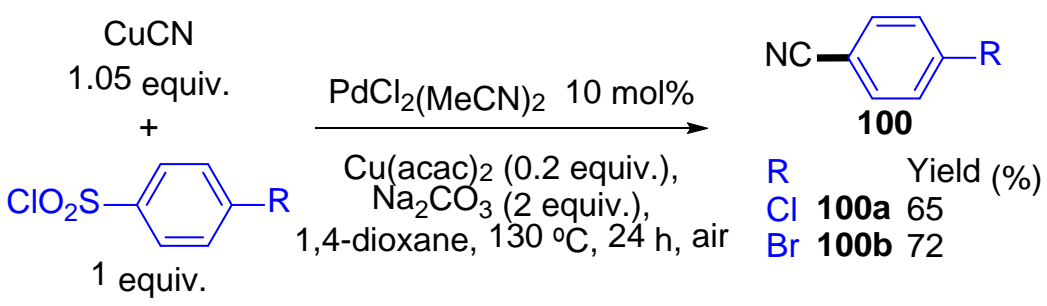

Scheme 57. Pd-catalyzed desulfitative cyanation of benzenesulfonyl chlorides

\subsection{Synthesis of 2-arylbenzofurans}


Su et al. described in 2014 the Pd-catalyzed one-pot synthesis of 2-arylbenzofurans via a tandem reaction of 2-hydroxyarylacetonitriles with sodium benzenesulfinates (Scheme 58). ${ }^{93}$ The use of $\operatorname{Pd}(\mathrm{OAc})_{2}$ and 2,2'-bipyridine as the catalytic system with $p$-nitrobenzenesulfonic acid as additive using a mixture of 2-MeTHF and water as solvent afforded the 2-arylbenzofurans $\mathbf{1 0 1}$ in moderate to excellent yields. The reaction tolerated chloro-substituents on the sodium benzenesulfinate and bromo- and chloro-substituents on the 2-hydroxyarylacetonitrile unit. This reaction might proceed via the formation of a ketimine, which undergoes hydrolysis to form the corresponding 2-(2hydroxyphenyl)-1-arylethanones under acidic conditions. Then, an intramolecular annulation under acidic conditions would deliver the 2-arylbenzofurans.

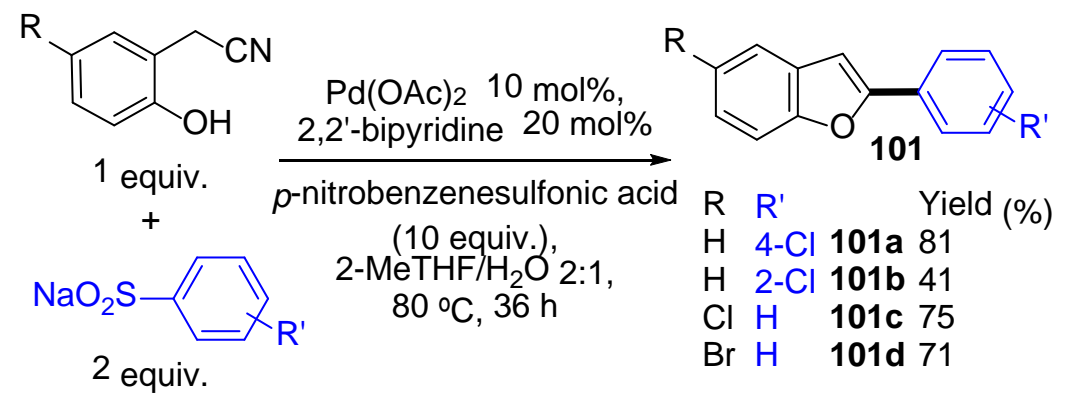

Scheme 58. Pd-catalyzed tandem reaction of 2-hydroxyarylacetonitriles with sodium benzenesulfinates

\section{Conclusion and Perspectives.}

In summary, during the last decade, the scope of the Pd-catalyzed formation of C-C bonds using halo-substituted benzenesulfonyl and benzenesulfinate derivatives such as $\mathrm{ArSO}_{2} \mathrm{Cl}, \mathrm{ArSO}_{2} \mathrm{Na}_{\text {and }}$ $\mathrm{ArSO}_{2} \mathrm{NHNH}_{2}$ has been largely extended. The use of halo-substituted $\mathrm{ArSO}_{2} \mathrm{R}$ as coupling partners presents several advantages compared to the reactions with aryl halides, as in most cases, the reaction proceeds without cleavage of the C-halo bonds, even in the presence of iodo-substituted arenes. The numerous transformations which have been recently reported using these coupling partners demonstrate that they are actually regarded as some of the most promising building blocks 
for the access to halo-substituted compounds. Moreover, in some cases, such as for the Pdcatalyzed direct arylations of thiophenes or selenophenes, C3-arylation products were obtained; whereas, with aryl halides regioselective C2-arylated heteroaromatics were generally produced. A modification in the regioselectivity was also observed for the arylation of benzofurans, as $\mathrm{ArSO}_{2} \mathrm{Cl}$ selectively afforded the C2-arylated benzofurans; whereas, reactions performed with aryl halides led to mixtures of mono- and di-arylated benzofurans. Despite the numerous recent reports on the reactivity of benzenesulfonyls and benzenesulfinates as substrates in Pd-catalyzed reactions, a number of challenges remain. As benzenesulfonyls chlorides are much more easily available than benzenesulfinates and sulfonylhydrazides, the extension of some of the reactions reported here to these aryl sources is important. In several cases, the substrate scope was very limited and/or quite high catalyst loadings were employed; therefore, more efficient catalysts permitting wider substrate scope and/or lower catalyst loadings need to be discovered in order to provide more attractive procedures. Concerning catalytic cycles and elementary steps, for most of the transformation reported using $\mathrm{ArSO}_{2} \mathrm{R}$ derivatives, a large number of interrogations are not addressed. In the presence of benzenesulfonyl chloride, the first step might be the oxidative addition of $\mathrm{ArSO}_{2} \mathrm{Cl}$ to a $\mathrm{Pd}(\mathrm{II})$ species and release of $\mathrm{SO}_{2}$ to afford a $\mathrm{Pd}(\mathrm{IV})$ intermediate, although a $\mathrm{Pd}(0) / \mathrm{Pd}(\mathrm{II})$ mechanism is also possible. Determining in more detail the reasons of the much higher reactivity of the $\mathrm{SO}_{2} \mathrm{R}$ group vs the halo-substituents of arenes for these reactions could allow further improvement in terms of reactions selectivities and yields, substrate scope and catalyst efficiency. However, undoubtedly the use of $\mathrm{ArSO}_{2} \mathrm{R}$ derivatives as substrates for metal-catalyzed coupling reactions will help both material and synthetic chemists a great deal making the access to many important halo-substituted arene derivatives simpler.

\section{References}

(1) L. Ackermann, Modern arylation methods; Wiley, 2009. 
(2) (a) J. J. Li and G. W. Gribble, Palladium in Heterocyclic Chemistry; Pergamon, Amsterdam, 2000; (b) E.-I. Negishi, Handbook of Organopalladium Chemistry for Organic Synthesis; Wiley, New York, 2002; (c) J. Le Bras and J. Muzart, Chem. Rev. 2011, 111, 1170-1214; (d) Science of Synthesis: Cross Coupling and Heck-Type Reactions, Vols. 1-3; edited by G. A. Molander, J. P. Wolfe and M. Larhed, Georg Thieme Verlag: Stuttgart, New York, 2013; (e) A. Skhiri, R. Ben Salem, J.-F. Soulé and H. Doucet ChemCatChem 2017, 9, 2895-2913.

(3) J. Hassan, M. Sévignon, C. Gozzi, E. Schulz and M. Lemaire, Chem. Rev. 2002, 102, 13591470.

(4) (a) S. R. Dubbaka and P. Vogel, Angew. Chem., Int. Ed. 2005, 44, 7674-7684; (b) Boronic Acids: Preparation and Applications in Organic Synthesis, Medicine and Materials, Ed. D.G. Hall, 2nd Edition, Wiley-VCH, Weinheim, Germany, 2011; (c) L. Wang, W. He and Z. Yu, Chem. Soc. Rev. 2013, 42, 599-621.

(5) (a) N. S. Johary and L. N. Owen, J. Chem. Soc. 1955, 1307-1311; (b) A. Barco, S. Benetti, G. P. Pollini and R. Taddia, Synthesis 1974, 877-878; (c) R. J. Cremlyn, T. Cronje and K. Goulding, Austr. J. Chem. 1979, 32, 445-452; (d) S. Fujita, Synthesis 1982, 423-424; (e) A. L. Borror, E. Chinoporos, M. P. Filosa, S. R. Herchen, C. P. Petersen, C. A. Stern and K. D. Onan, J. Org. Chem. 1988, 53, 2047-2052; (f) T. Kataoka, T. Iwama, T. Setta and A. Takagi, Synthesis 1998, 423-426; (g) G. Blotny, Tetrahedron Lett. 2003, 44, 1499-1501; (h) P. Evans, T. McCabe, B. S. Morgan and S. Reau, Org. Lett. 2005, 7, 43-46; (i) S. Madabhushi, R. Jillella, V. Sriramoju, R. Singh, Green Chem. 2014, 16, 3125-3131.

(6) (a) L. K. Liu, Y. Chi and K.-Y. Jen, J. Org. Chem. 1980, 45, 406-410; (b) B. Rao, W. Zhang, L. Hu and M. Luo, Green Chem. 2012, 14, 3436-3440; (c) J. Liu, L. Yu, S. Zhuang, Q. Gui, X. Chen, W. Wang and Z. Tan, Chem. Commun. 2015, 51, 6418-6421.

(7) (a) X. Yu, X. Li and B. Wan, Org. Biomol. Chem. 2012, 10, 7479-7482; (b) Y. Yang, L. Tang, S. Zhang, X. Guo, Z. Zha and Z. Wang, Green Chem. 2014, 16, 4106-4109.

(8) K. Yuan, J.-F. Soule and H. Doucet, ACS Catal. 2015, 5, 978-991. 
(9) S. R. Dubbaka and P. Vogel, J. Am. Chem. Soc. 2003, 125, 15292-15293.

(10) S. R. Dubbaka, P. Steunenberg and P. Vogel, Synlett 2004, 1235-1238.

(11) N. Miyaura and A. Suzuki, Chem. Commun. 1979, 866-867.

(12) S. R. Dubbaka and P. Vogel, Org. Lett. 2004, 6, 95-98.

(13) S. Zhang, X. Zeng, Z; Wei, D. Zhao, T. Kang, W. Zhang, M. Yan and M. Luo, Synlett 2006, 1891-1894.

(14) K. Cheng, H.-Z. Yu, B. Zhao, S. Hu, X.-M. Zhang and C. Qi, RSC Adv. 2014, 4, 57923-57928.

(15) S. Zhong, C. Sun, S. Dou and W. Liu, RSC Adv. 2015, 5, 27029-27033.

(16) a) Z. Wei, D. Xue, H. Zhang and J. Guan, Appl. Organomet. Chem. 2016, 30, 767-771; b) S. Chang, Y. B. Sun, X. R. Zhang, L. L. Dong, H. Y. Zhu, H. W. Lai, D. Wang, Appl. Organomet. Chem. 2018, 32, doi.org/10.1002/aoc.3970

(17) Y. Hatanaka and T. Hiyama, J. Org. Chem. 1988, 53, 918-920.

(18) K. Cheng, S. Hu, B. Zhao, X.-M. Zhang and C. Qi, J. Org. Chem. 2013, 78, 5022-5025.

(19) W. Zhang, F. Liu, K. Li and B. Zhao, Appl. Organomet. Chem. 2014, 28, 379-381.

(20) H. Miao, F. Wang, S. Zhou, G. Zhang and Y. Li, Org. Biomol. Chem. 2015, 13, 4647-4651.

(21) C. Zhou, Q. Liu, Y. Li, R. Zhang, X. Fu and C. Duan, J. Org. Chem. 2012, 77, 10468-10472.

(22) C. Zhou, Y. Li, Y. Lu, R. Zhang, K. Jin, X. Fu and C. Duan, Chin. J. Chem. 2013, 31, 12691273.

(23) D. H. Ortgies and P. Forgione, Synlett 2013, 24, 1715-1721.

(24) F. Zhao, Q. Tan, F. Xiao, S. Zhang and G.-J. Deng, Org. Lett. 2013, 15, 1520-1523.

(25) J. Shi, X.-D. Tang, Y.-C. Wu, H.-N. Li, L.-J. Song and Z.-Y. Wang, Eur. J. Org. Chem. 2015, 1193-1197.

(26) W. Chen, P. Li, T. Miao, L.-G. Meng and L. Wang, Org. Biomol. Chem. 2013, 11, 420-424.

(27) M. Miura, H. Hashimoto, K. Itoh and M. Nomura, Chem. Lett. 1990, 459-460.

(28) T. Kashiwabara and M. Tanaka, Tetrahedron Lett. 2005, 46, 7125-7128.

(29) Q. Zhao, L. Chen, H. Lang, S. Wu and L. Wang, Chin. J. Chem. 2015, 33, 535-538. 
(30) B. Rao, W. Zhang, L. Hu and M. Luo, Green Chem. 2012, 14, 3436-3440.

(31) W. Zhang J. Chem. Res. 2016, 41, 1-3.

(32) W. Zhang, B. Zhao and K. Li, J. Chem. Res. 2013, 37, 674-676.

(33) (a) D. Alberico, M. E. Scott and M. Lautens, Chem. Rev. 2007, 107, 174-238; (b) T. Satoh and M. Miura, Chem. Lett. 2007, 36, 200-205; (c) B.-J. Li, S.-D. Yang and Z.-J. Shi, Synlett 2008, 949957; (d) F. Bellina and R. Rossi, Tetrahedron 2009, 65, 10269-10310; (e) L. Ackermann, R. Vicente and A. Kapdi, Angew. Chem. Int. Ed. 2009, 48, 9792-9826; (f) X. Chen, K. M. Engle, D.-H. Wang and J.-Q. Yu Angew. Chem. Int. Ed. 2009, 48, 5094-5115; (g) G. P. Chiusoli, M. Catellani, M. Costa, E. Motti, N. Della Ca and G. Maestri, Coord. Chem. Rev. 2010, 254, 456-469; (h) H. Li, B.-J. Li and Z.-J. Shi, Catal. Sci. Technol. 2011, 1, 191-206; (i) N. Kuhl, M. N. Hopkinson, J. Wencel-Delord and F. Glorius, Angew. Chem. Int. Ed. 2012, 51, 10236-10254; (j) P. B. Arockiam, C. Bruneau and P. H. Dixneuf, Chem. Rev. 2012, 112, 5879-5918; (k) S. I. Kozhushkov, H. K. Potukuchi, and L. Ackermann, Catal. Sci. Technol. 2013, 3, 562-571; (l) J. Wencel-Delord and F. Glorius, Nat. Chem. 2013, 5, 369-375; (m) S. I. Kozhushkov and L. Ackermann, Chem. Sci. 2013, 4, 886-896; (n) R. Rossi, F. Bellina, M. Lessi and C. Manzini, Adv. Synth. Catal. 2014, 356, 17117; (o) M. He, J.-F. Soulé and H. Doucet, ChemCatChem 2014, 6, 1824-1859; (p) R. Rossi, M. Lessi, C. Manzini, G. Marianetti and F. Bellina, Tetrahedron 2016, 72, 1795-1837; (q) C. B. Bheeter, L. Chen, J.-F. Soulé and H. Doucet, Cat. Sci. Technol. 2016, 6, 2005-2049; (r) X. Shi, A. Sasmal, J.-F. Soulé and H. Doucet, Chem. Asian J. 2018, 13, 143-157.

(34) (a) T. Miao and L. Wang, Adv. Synth. Catal. 2014, 356, 429-436; (b) X. Lin, Y. You and Z. Weng, J. Fluorine Chem. 2014, 165, 76-80.

(35) E. Kianmehr and A. Tanbakouchian, Tetrahedron 2017, 73, 5337-5343.

(36) M. Wu, J. Luo, F. Xiao, S. Zhang, G.-J. Deng and H.-A. Luo, Adv. Synth. Catal. 2012, 354, 335-340.

(37) T. Miao, P. Li, G.-W. Wang and L. Wang, Chem. Asian J. 2013, 8, 3185-3190. 
(38) R. Jin, K. Yuan, E. Chatelain, J.-F. Soulé and H. Doucet, Adv. Synth. Catal. 2014, 356, 38313841.

(39) (a) I. Idris, F. Derridj, S. Djebbar, J.-F. Soulé and H. Doucet, Tetrahedron 2015, 71, 96179625; (b) B. Saoudi, A. Debache, J.-F. Soulé and H. Doucet, RSC Adv. 2015, 5, 65175-65183.

(40) A. Skhiri, A. Belhadria, K. Yuan, J.-F. Soulé, R. Ben Salem and H. Doucet, Eur. J. Org. Chem. 2015, 4428-4436.

(41) W. Hagui, K. Yuan, N. Besbes, E. Srasra, J.-F. Soulé and H. Doucet, ChemCatChem 2015, 7, 3544-3554.

(42) A. Hfaiedh, K. Yuan, H. Ben Ammar, B. Ben Hassine, J.-F. Soulé and H. Doucet, ChemSusChem 2015, 8, 1794-1804.

(43) W. Zhang, F. Liu and B. Zhao, Appl. Organomet. Chem. 2015, 29, 524-527.

(44) C. Wang, H. Jia, Z. Li, H. Zhang and B. Zhao, RSC Adv. 2016, 6, 21814-21821.

(45) R. Jin, K. Yuan, E. Chatelain, J.-F. Soulé and H. Doucet, Adv. Synth. Catal. 2014, 356, 38313841.

(46) A. Hfaiedh, H. Ben Ammar, J.-F. Soulé and H. Doucet, Org. Biomol. Chem. 2016, 14, 49474956.

(47) C. Liu, L. Ding, G. Guo, W. Liu and F.-L. Yang, Org. Biomol. Chem. 2016, 14, 2824-2827.

(48) K. Yuan and H. Doucet, Chem. Sci. 2014, 5, 392-396.

(49) F. Abdelmalek, F. Derridj, S. Djebbar, J.-F. Soulé and H. Doucet, Beilstein J. Org. Chem. 2015, 11, 2012-2020.

(50) W. Hagui, N. Besbes, E. Srasra, T. Roisnel, J.-F. Soulé and H. Doucet, Org. Lett. 2016, 18, 4182-4185.

(51) A. Beladhria, K. Yuan, H. Ben Ammar, J.-F. Soulé, R. Ben Salem and H. Doucet, Synthesis 2014, 46, 2515-2523.

(52) L. Loukotova, K. Yuan and H. Doucet, ChemCatChem 2014, 6, 1303-1309.

(53) B. Liégault, I. Petrov, S. I. Gorelsky and K. Fagnou, J. Org. Chem. 2010, 75, 1047-1060. 
(54) A. Skhiri, R. Ben Salem, J.-F. Soulé and H. Doucet, Chem. Eur. J. 2017, 23, 2788-2791.

(55) M. Zhang, S. Zhang, M. Liu and J. Cheng, Chem. Commun. 2011, 47, 11522-11524.

(56) (a) M. Wang, D. Li, W. Zhou and L. Wang, Tetrahedron 2012, 68, 1926-1930; (b) X. Tang, K. Yang, L. Zeng, Q. Liu, H. Chen, Org. Biomol. Chem. 2017, 15, 8504-8507.

(57) X. Yu, X. Li and B. Wan, Org. Biomol. Chem. 2012, 10, 7479-7482.

(58) O. Y. Yuen, C. M. So, W. T. Wong and F. Y. Kwong, Synlett 2012, 23, 2714-2718.

(59) R. Chen, S. Liu, X. Liu, L. Yang and G.-J. Deng, Org. Biomol. Chem. 2011, 9, 7675-7679.

(60) B. Liu, Q. Guo, Y. Cheng, J. Lan and J. You, Chem. Eur. J. 2011, 17, 13415-13419.

(61) B. Liu, J. Li, F. Song and J. You, Chem. Eur. J. 2012, 18, 10830-10833.

(62) S. Wang, W. Liu, J. Lin, Y. Jiang, Q. Zhang and Y. Zhong, Synlett 2014, 25, 586-590.

(63) J. Zhu, Y. Chen, F. Lin, B. Wang, Q. Huang and L. Miu, Synlett 2015, 26, 1124-1130.

(64) (a) J. G. de Vries Can. J. Chem. 2001, 79, 1086-1092; (b) M. Oestreich, The Mizoroki-Heck Reaction, Wiley, New York, 2009; (c) D. Mc Cartney and P. J. Guiry, Chem. Soc. Rev. 2011, 40, 5122-5150; (d) M. Hussain, T. Van Sung and P. Langer, Synlett 2012, 23, 2735-2745.

(65) M. Miura, H. Hashimoto, K. Itoh and M. Nomura, Tetrahedron Lett. 1989, 30, 975-976.

(66) M. Miura, H. Hashimoto, K. Itoh and M. Nomura, J. Chem. Soc. Perkin trans. 1 1990, 22072211.

(67) A. Skhiri, R. Ben Salem, J.-F. Soulé and H. Doucet, Synthesis 2016, 48, 3097-3106.

(68) S. R. Dubbaka and P. Vogel, Chem. Eur. J. 2005, 11, 2633-2641.

(69) X. Zhou, J. Luo, J. Liu, S. Peng and G.-J. Deng, Org. Lett. 2011, 13, 1432-1435.

(70) S. Hu, P. Xia, K. Cheng and C. Qi, Appl. Organomet. Chem. 2013, 27, 188-190.

(71) N. Taniguchi, Synlett 2013, 2571-2574.

(72) F.-L. Yang, X.-T. Ma and S.-K. Tian, Chem. Eur. J. 2012, 18, 1582-1585.

(73) O. Y. Yuen, C. M. So and F. Y. Kwong, RSC Adv. 2016, 6, 27584-27589.

(74) G.-W. Wang and T. Miao, Chem. Eur. J. 2011, 17, 5787-5790.

(75) J. Liao, Z. Zhang, X. Tang, W. Wu, W. Guo and H. Jiang, J. Org. Chem. 2015, 80, 8903-8909. 
(76) A. K. Kusunuru, S. K. Yousuf, M. Tatina and D. Mukherjee, Eur. J. Org. Chem. 2015, 459462.

(77) J. Ma, S. Xiang, H. Jiang and X.-W. Liu, Eur. J. Org. Chem. 2015, 949-952.

(78) H. Wang, Y. Li, R. Zhang, K. Jin, D. Zhao and C. Duan, J. Org. Chem. 2012, 77, 4849-4853.

(79) W. Chen, X. Zhou, F. Xiao, J. Luo and G.-J. Deng, Tetrahedron Lett. 2012, 53, 4347-4350.

(80) K. B. Raju, V. Mari and K. Nagaiah, Synthesis 2013, 45, 2867-2874.

(81) K. Yuan, R. Sang, J.-F. Soulé and H. Doucet Cat. Sci. Technol. 2015, 5, 2904-2912.

(82) (a) Y. Li, W. Yang, G. Cheng and D. Yang, J. Org. Chem. 2016, 81, 4744-4750; (b) R. Wu, W. Yang, W. Chen, D. Yang, Org. Chem. Front. 2017, 4, 1921-1925.

(83) K. Yuan, J.-F. Soulé, V. Dorcet and H. Doucet, ACS Catal. 2016, 6, 8121-8126.

(84) J.-H. Fan, J. Yang, R.-J. Song and J.-H. Li, Org. Lett. 2015, 17, 836-539.

(85) S. Liu, Y. Bai, X. Cao, F. Xiao and G.-J. Deng, Chem. Commun. 2013, 49, 7501-7503.

(86) Y. Xu, J. Zhao, X. Tang, W. Wu and H. Jiang, Adv. Synth. Catal. 2014, 356, 2029-2039.

(87) L.-W. Qian, M. Sun, J. Dong, Q. Xu, Y. Zhou and S.-F. Yin, J. Org. Chem. 2017, 82, 67646769.

(88) J. Liu, X. Zhou, H. Rao, F. Xiao, C.-J. Li and G.-J. Deng, Chem. Eur. J. 2011, 17, 7996-7999.

(89) T. Miao and G.-W. Wang, Chem. Commun. 2011, 47, 9501-9503.

(90) M. Behrends, J. Savmarker, P. J. R. Sjoberg and M. Lahred, ACS Catal. 2011, 1, 1455-1459.

(91) B. Skillinghaug, C. Skold, J. Rydfjord, F. Svensson, M. Behrends, J. Savmarker, P. J. R. Sjoberg and M. Lahred, J. Org. Chem. 2014, 79, 12018-12032.

(92) J. Chen, Y. Sun, B. Liu, D. Liu and J. Cheng, Chem. Commun. 2012, 48, 499-451.

(93) J. Chen, J. Li and W. Su, Org. Biomol. Chem. 2014, 12, 4078-4083.

\section{Acknowledgements}


We thank China Scholarship Council for providing financial support to H. L.; CEFIPRA for providing financial support to A. S.; and ANR for providing financial support to X. S.

\section{Bibliographical sketch}

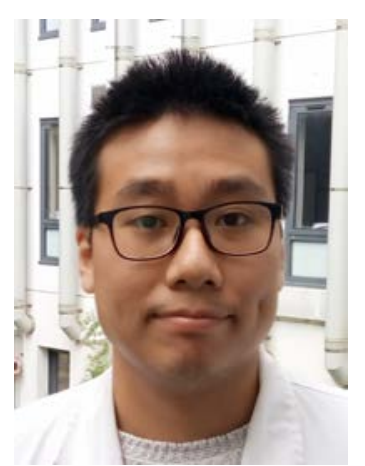

Haoran Li was born in P.R. China. He joined the international master's program "Catalysis, Molecules and Green Chemistry” in the University of Rennes 1 (France) in 2015. He performed his master's research training in Prof. C. Darcel's team in the University of Rennes 1. He currently works towards a PhD degree of ENSCR under the supervision of Dr. Henri Doucet. He received a grant from the China Scholarship Council (CSC) in 2017. His work focuses on the C-H bond functionalization using palladium catalysis.

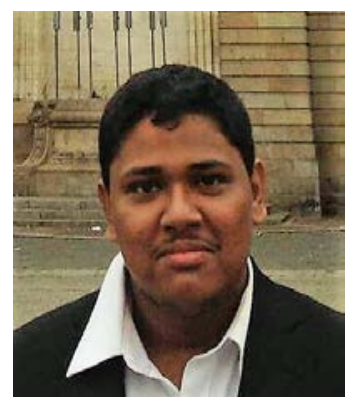

Arpan Sasmal received his B.Sc degree in Chemistry from University of Calcutta in 2014. He received his M.Sc degree in Chemistry from IIT Madras in 2016. Afterwards, he did International Master in Molecular Catalysis and Green Chemistry from University of Rennes 1 (France) in 2017. Now he is a $\mathrm{PhD}$ student at University of Rennes 1 (France) under the supervision of Prof. Henri Doucet and Dr. Jean Francois Soule. His research focuses on C-H bond activation using palladium catalysis. 


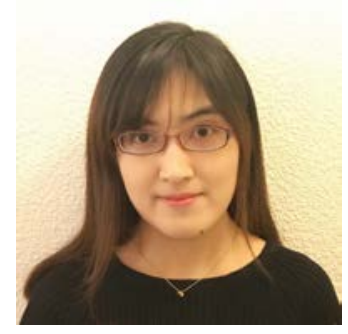

Xinzhe Shi was born in P.R. China. She joined the international master's program "Catalysis, Molecules and Green Chemistry” in the University of Rennes 1 (France) receiving grants from the Foundation Rennes 1 in 2015. She performed her master's research training in H. Doucet's team. She currently works towards a PhD degree of University of Rennes 1 under the supervision of Dr. Henri Doucet and Dr. Jean-François Soulé. Her work focuses on the C-H bond functionalization using palladium catalysis.

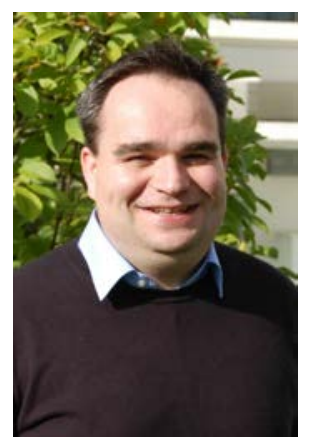

Jean-François Soulé completed his $\mathrm{PhD}$ in 2007 working on the Petasis reaction applied on the synthesis of biological interest molecules under the supervision of the Prof. Jean-Marie Beau, at the Institut de Chimie des Substances Naturelles, Gif-sur- Yvette (France). In 2010, he joined the group of the Prof. Shu Kobayashi at the University of Tokyo (Japan) as a postdoctoral fellow. In October 2013, he was appointed as “Chargé de Recherche” CNRS at the University of Rennes 1 in the group of Dr. Henri Doucet. His main interest focuses on the development of sustainable chemistry, notably, transition-metals catalyzed C-H functionalizations.

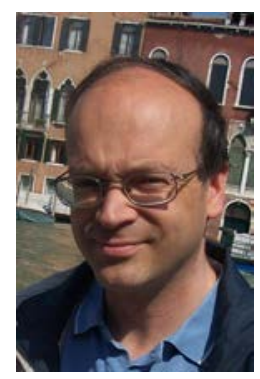


Henri Doucet received his PhD in chemistry working with Prof. P. H. Dixneuf and Dr. C. Bruneau at Rennes 1 University (France) in 1994. After post-doctoral appointments at Oxford university (UK) with Prof. J. M. Brown; and Nagoya university, (Japan) with Prof. R. Noyori, he moved to the University of Marseille (France) as CNRS researcher in the group of Prof M. Santelli. In 2006 he moved to Rennes 1 University. His research interests include organic synthesis by metal-catalyzed processes, ligands synthesis and green chemistry. 